\title{
ESTUDO SOBRE A APLICAÇÃO DE AGREGADO RECICLADO DE CONCRETO EM CONSTRUÇÃO DE PAVIMENTOS
}

\section{WALLACE FIORAVANTI DE SOUSA}

\begin{abstract}
Dissertação apresentada à Escola de Engenharia de São Carlos, da Universidade de São Paulo, como parte dos requisitos para obtenção do Título de Mestre em Ciências, Programa de Pós-graduação em Engenharia de Transportes. Área de concentração: Infraestrutura de Transportes
\end{abstract}

Orientador: Prof. Tit. Alexandre Benetti Parreira

São Carlos 

FOLHA DE JULGAMENTO

Candidato: Engenheiro WALLACE FIORAVANTI DE SOUSA

Título da dissertação: Estudo sobre a aplicação de agregado reciclado de concreto em construção de pavimentos.

Data da defesa: 21/09/2011:

\section{Comissão Julgadora:}

Prof. Titular Alexandre Benetti Parreira (Orientador)

(Escola de Engenharia de São Carlos/EESC)

Prof. Dr. Marcelo de Castro Takeda

(Universidade Federal de São Carlos/UFSCar)

Prof ${ }^{\mathrm{a}}$. Dr ${ }^{\mathrm{a}}$. Ana Paula Furlan

(Escola de Engenharia de São Carlos/EESC)

\section{Resultado:}

APROUADO

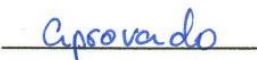

aprovado

Coordenador do Programa de Pós-Graduação em Engenharia de Transportes e Presidente da Comissão de Pós-Graduação:

Prof. Associado Paulo Cesar Lima Segantine 

A persistência é o menor caminho do êxito.

(Charles Chaplin) 

Em especial, ao meu orientador Prof. Alexandre Benetti Parreira pelos ensinamentos, excelente orientação, apoio, dedicação, conselhos e oportunidade oferecida.

Ao Prof. Glauco Túlio Pessa Fabbri pela contribuição nesta pesquisa, principalmente no desenvolvimento dos programas e equipamentos para realização dos ensaios triaxiais cíclicos.

A todos os professores do Departamento de Transportes da EESC pelos ensinamentos transmitidos.

A todos os funcionários do Departamento de Transportes da EESC pela colaboração e constante atenção, em especial à Heloísa, Beth, João, Paulo e Gigante.

Aos meus amigos de São Carlos pelo apoio, contribuições e momentos de descontração, em especial à Madalena, Rafael, Diego, Carioca, Baiano, Marcelo, Gaúcho, Gustavo, Carlinha, Francis, Mineiro, David e Luís.

Aos meus pais, Marta e Vanderlei, pela grande força, conselhos, demonstração de amor e, principalmente, pela educação que me foi dada.

Ao CNPq pela bolsa de estudos concedida.

Ao Programa de Pós-Graduação do Departamento de Transportes da EESCUSP.

À Escola de Engenharia de São Carlos, USP. 
Por fim, ao Prof. Paulo Barbosa da Universidade Federal de Viçosa, que contribuiu muito na minha formação como Engenheiro e me incentivou a ingressar no programa de mestrado da EESC - USP. 


\section{RESUMO}

SOUSA, W. F., Estudo sobre a aplicação de agregado reciclado de concreto em construção de pavimentos. 122p. Dissertação (Mestrado) - Escola de Engenharia de São Carlos, Universidade de São Paulo. 2011.

A exploração dos recursos naturais e a degradação do meio ambiente têm sido fonte de preocupação no âmbito mundial. A busca por soluções alternativas que não causem ou que diminuam os impactos ambientais tornou-se comum na sociedade. Nesse contexto, a pavimentação vem contribuindo significativamente com soluções alternativas para destinação final de diversos tipos de resíduos, principalmente os oriundos da indústria da construção civil que sempre foi uma das maiores geradoras. Os resíduos da construção e demolição (RCD) podem ser transformados em agregados reciclados de ótima qualidade e podem ser aplicados em diversos serviços de engenharia. Os agregados reciclados, segundo a NBR 15116 (ABNT, 2004), são separados em misto e de concreto (ARC). No Brasil existem poucas pesquisas com o $A R C$, no entanto, as que existem e as pesquisas internacionais relatam que uma característica marcante do $A R C$ é a cimentação própria. Portanto, o objetivo desta pesquisa é estudar o comportamento mecânico, ao longo do tempo de cura, do agregado reciclado de concreto proveniente da Usina de Reciclagem de São Carlos e de sua mistura com um solo laterítico, a fim de utilizá-los na construção de pavimentos. O estudo envolveu a análise dos resultados de resistência à compressão simples, módulo tangente, módulo de resiliência, deformação permanente e índice de suporte Califórnia (CBR) de corpos-de-prova de ARC e da sua mistura com solo laterítico, moldados em diferentes energias de compactação e ensaiados com tempos de cura variados. Ao final, concluiu-se que o agregado reciclado de concreto $(A R C)$ é uma alternativa para construção de bases de pavimentos, podendo também substituir o agregado natural da mistura solo arenoso laterítico - brita descontínua, muito utilizada nas rodovias do interior de São Paulo.

Palavras chave: Agregado Reciclado de Concreto (ARC), Resíduos de Construção e Demolição (RCD), Pavimentos, Deformação Permanente, Módulo de Resiliência e Cimentação Própria. 

SOUSA, W. F., Study on application of recycled concrete aggregate in pavement construction. 122p. Master's Thesis - Escola de Engenharia de São Carlos, Universidade de São Paulo. 2011.

Natural resources exploitation and the environmental degradation are a worldly problem nowadays. Searching for alternative solutions is something usual in most countries. Pavement systems are now contributing significantly with these alternative solutions by using the waste of construction demolition. This specific kind of waste can turn into mixed recycled aggregate or recycled concrete aggregate. There are just few researches in Brazil about the use of recycled concrete aggregate (RCA), however international researches have shown that this aggregate has a very characteristic and positive mark: self cementation. This research has got the objective of studying the mechanic behavior of the recycled concrete aggregate and its mix with lateritic soil on the construction of base pavements with different analytic basis. The study involved the analysis of the laboratorial tests results of the unconfined compressive strength, tangent modulus, resilient modulus, permanent deformation and California Bearing Ration (CBR) of RCA specimens and its mix with lateritic soil, molded in different compaction energy and tested in different curing times. In conclusion, this kind of recycled aggregate has proved to be a sustainable alternative for the natural aggregate in the construction of many roads in small cities of the State of São Paulo - Brazil.

Keywords: Recycled Concrete Aggregate (RCA), Construction and Demolition Waste (C \& D), Pavements, Permanent Deformation, Resilient Modulus and Self-cementing. 



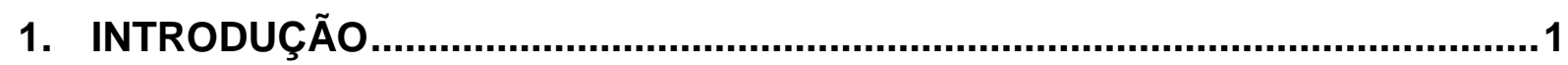

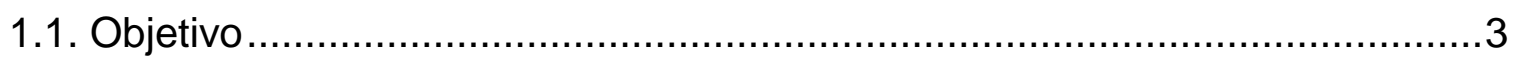

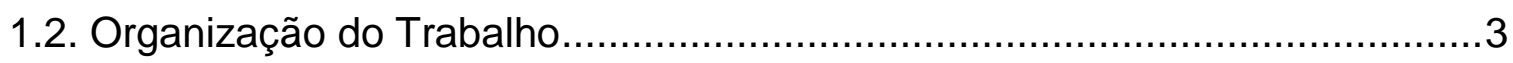

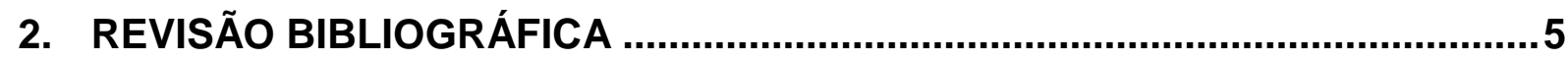

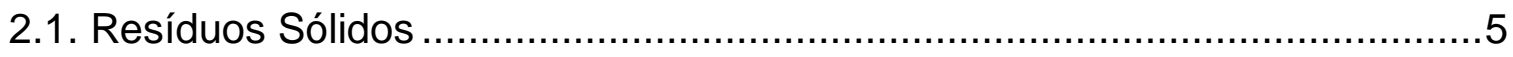

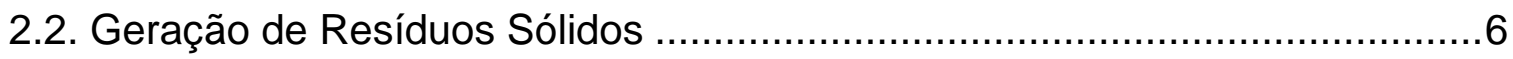

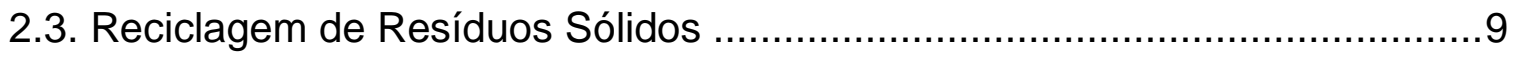

2.4. Usina de reciclagem de São Carlos ........................................................11

2.5. Utilização de Agregados Reciclados .......................................................14

2.6. Agregados Reciclados de Concreto .....................................................15

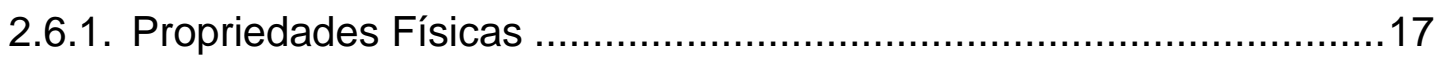

2.6.2. Índice de Suporte Califórnia (CBR) ..............................................19

2.6.3. Módulo de Resiliência ................................................................20

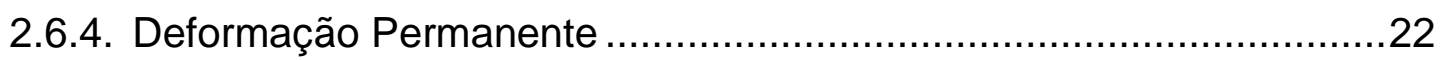

2.6.5. Cimentação Própria ……………………………………………....24

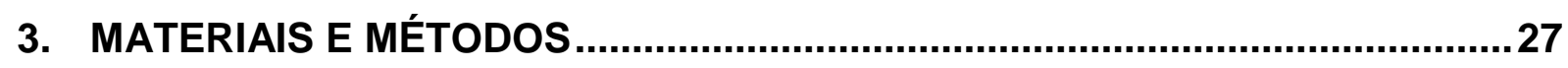

3.1. Origem e Características Físicas dos Materiais Estudados ........................27 
3.1.2. Solo 29

3.2. Misturas 31

3.2.1. Agregado Reciclado de Concreto .................................................... 31

3.2.2. Mistura Solo - Agregado Reciclado de Concreto ............................. 33

3.3. Escolha da Energia de Compactação .................................................... 35

3.4. Moldagem e Cura dos Corpos-de-Prova ……........................................ 35

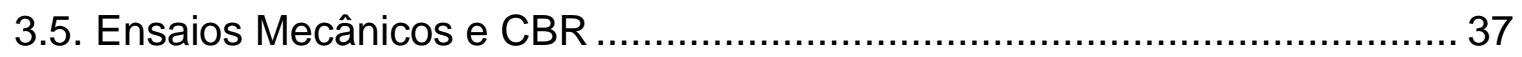

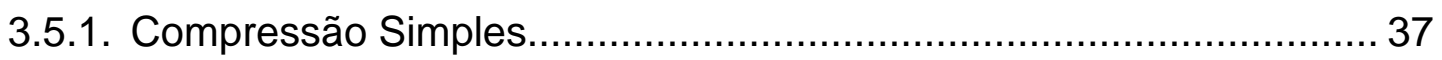

3.5.2. Ensaio Triaxial Cíclico - Módulo de Resiliência ............................... 40

3.5.3. Ensaio Triaxial Cíclico - Deformação Permanente ........................... 42

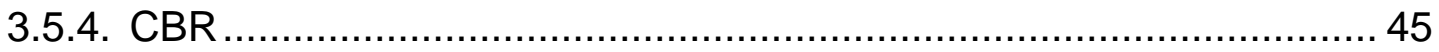

3.6. Análise dos Resultados .................................................................... 47

4. APRESENTAÇÃO E DISCUSSÃO DOS RESULTADOS ….............................48

4.1. AGREGADO RECICLADO DE CONCRETO............................................ 48

4.1.1. Resistência à compressão simples ............................................. 48

4.1.2. Resistência à compressão simples após outros ensaios .................. 52

4.1.3. Módulo tangente a $50 \%$ da tensão de ruptura.................................. 54

4.1.4. Módulo de resiliência ................................................................... 58 
4.1.5. Deformação permanente

4.1.6. Módulo de resiliência determinado ao longo do ensaio de deformação permanente

4.1.7. Índice de suporte Califórnia.

4.2. MISTURA SOLO - ARC

4.2.1. Resistência à compressão simples

4.2.2. Módulo tangente a $50 \%$ da tensão de ruptura .83

4.2.3. Módulo de resiliência .85

4.2.4. Deformação permanente .88

4.2.5. Módulo de resiliência determinado ao longo do ensaio de deformação permanente .93

4.2.6. Índice de suporte Califórnia. .95

4.3. COMPARAÇÃO ENTRE O ARC E A MISTURA SOLO - ARC .97

5. CONCLUSÕES 105

5.1. RECOMENDAÇÕES PARA TRABALHOS FUTUROS 110

6. REFERÊNCIAS BIBLIOGRÁFICAS 111

ANEXO I - CARACTERIZAÇÃO.

APÊNDICE I - RCS, $E_{50 \%}$ e $\Delta$ w .ii APÊNDICE II - COMPACTAÇÃO E CBR 5 PONTOS iv 



\section{LISTA DE SIGLAS E ABREVIATURAS}

AASHTO - American Association of State Highway and Transportation Officials ABNT - Associação Brasileira de Normas Técnicas

ARC - Agregado(s) Reciclado(s) de Concreto

c' - Coeficiente de deformabilidade da classificação MCT

CBR - California Bearing Ratio

CONAMA - Conselho Nacional de Meio Ambiente

DNER - Departamento Nacional de Estradas de Rodagem

DNIT - Departamento Nacional de Infra-Estruturas de Transportes

e' - Índice da classificação MCT

$\mathrm{E}_{50 \%}$ - Módulo Tangente a $50 \%$ da tensão de ruptura

EC - European Commission

EESC - Escola de Engenharia de São Carlos

EPA - Environment Protection Agency

FHWA - Federal Highway Administration U.S. Department of Transportation

HRB - Highway Research Board

ISC - Índice de Suporte Califórnia

LA' - Solo arenoso de comportamento laterítico

LA - Solo arenoso de comportamento não laterítico

LG' - Solo argilo de comportamento laterítico

MR - Módulo de Resiliência

$\mathrm{MPa}$ - Mega Pascal

NBR - Norma Brasileira Registrada

$\mathrm{N}$ - Número de aplicações de carga

PMSP - Prefeitura Municipal de São Paulo

RCD - Resíduos de Construção e Demolição

RCS - Resistência à Compressão Simples

$\mathrm{R}^{2}$ - Coeficiente de Determinação

TRB - Transportation Research Board

USP - Universidade de São Paulo

$\varepsilon_{\mathrm{p}}$ - Deformação Permanente

$\varepsilon_{r}$ - Deformação Resiliente

$\theta$ - Tensão volumétrica ou Primeiro invariante de tensões

pd - Massa específica seca

pd,máx - Massa específica seca máxima

$\omega$ - Teor de umidade

wót. - Teor de umidade Ótima

$\tau_{\text {oct }}$ - Tensão octaédrica

$\sigma_{1}$ - Tensão principal maior

б3 - Tensão principal menor

$\sigma_{c}$ - Tensão confinante

$\sigma_{d}$ - Tensão desvio 



\section{SUMÁRIO DE FIGURAS}

FIGURA 2.1. - Contribuição de cada setor e atividade da construção civil na geração de resíduos nos Estados Unidos (EPA, 2003)

FIGURA 2.2. - Usina de reciclagem de resíduos da construção civil da PROHAB na cidade de São Carlos - SP

FIGURA 2.3. - Módulos de resiliência obtidos para diferentes estados de tensão em corpos-de-prova ensaiados com diferentes tempos de cura (Arm, 2001) ..... 25

FIGURA 2.4. - Variação da RCS do agregado reciclado de concreto ao longo do tempo de cura (Grubba, 2009)

FIGURA 3.1. - As três frações do agregado reciclado de concreto, pedrisco, areia e brita 1 (Grubba, 2009)

FIGURA 3.2. - Distribuições granulométricas das três frações do ARC (Grubba, 2009)

FIGURA 3.3. - Local de coleta do solo

FIGURA 3.4. - Curva granulométrica do solo (Kakuda, 2010).

FIGURA 3.5. - Distribuição granulométrica da mistura de ARC e os limites da faixa $C$ do DNER (Grubba, 2009)

FIGURA 3.6. - Curva granulométrica da mistura solo - ARC e de seus materiais constituintes

FIGURA 3.7. - Prensa empregada na moldagem dos corpos-de-prova. 36

FIGURA 3.8. - Cilindros utilizados na moldagem dos corpos-de-prova 36

FIGURA 3.9. - Desmoldagem dos corpos-de-prova....................................... 37

FIGURA 3.10. - Selagem dos corpos-de-prova ........................................... 37

FIGURA 3.11. - Prensa utilizada no ensaio de Compressão Simples. 38

FIGURA 3.12. - Esquema para determinação do módulo tangente a 50\% da tensão de ruptura (Grubba, 2009)

FIGURA 3.13. - Equipamento triaxial

FIGURA 3.14. - Tela principal do programa na fase de controle e aquisição dos dados durante o ensaio triaxial.

FIGURA 3.15. - Tela principal do programa de aquisição de dados e controle do ensaio de deformação permanente

FIGURA 3.16. - Compactação do corpo-de-prova (Grubba, 2009) 46

FIGURA 3.17. - Imersão por 4 dias 
FIGURA 3.18. - Penetração do pistão padronizado na prensa automática

FIGURA 4.1. - Resultados de RCS dos corpos-de-prova de ARC ensaiados em diferentes tempos de cura

FIGURA 4.2. - Resultados das médias de RCS dos corpos-de-prova de ARC, desta pesquisa e da pesquisa de Grubba (2009), ensaiados em diferentes tempos de cura.

FIGURA 4.3. - Resultados de RCS dos corpos-de-prova de ARC, especialmente moldados para o ensaio de compressão simples e dos corpos-de-prova de ARC usados anteriormente nos ensaios triaxiais cíclicos, ensaiados em diferentes tempos de cura 53

FIGURA 4.4. - Resultados de E50\% dos corpos-de-prova de ARC ensaiados em diferentes tempos de cura

FIGURA 4.5. - Resultados das médias de E50\% dos corpos-de-prova de ARC, desta pesquisa e da pesquisa de Grubba (2009), ensaiados em diferentes tempos de cura......

FIGURA 4.6. - Estrutura de pavimento utilizada para determinação do módulo de resiliência no centro da camada de base.

FIGURA 4.7. - Valores de módulo de resiliência do ARC, desta pesquisa e da pesquisa de Grubba (2009), determinados no centro da camada de base da estrutura proposta.

FIGURA 4.8. - Curvas de deformação permanente em função do número de aplicações de carga para corpos-de-prova de ARC ensaiados com diversos tempos de cura

FIGURA 4.9. - Deformação permanente inicial do ARC em função do tempo de cura

FIGURA 4.10. - Deformação permanente final do ARC em função do tempo de cura

FIGURA 4.11. - Deformação permanente em função do número de aplicações de carga, para três pares de tensões (E1, E2 e E3), de corpos-de-prova de ARC ensaiados aos 28 dias de cura

FIGURA 4.12. - Módulo de resiliência com o número de aplicações de carga para corpos-de-prova de ARC ensaiados em diversos tempos de cura

FIGURA 4.13. - Módulo de resiliência com o número de aplicações de carga para corpos-de-prova de ARC ensaiados com 28 dias de cura para três estados de tensão (E1, E2 e E3).

FIGURA 4.14. - Resultados de CBR dos corpos-de-prova de ARC ensaiados com diversos tempos de cura.

FIGURA 4.15. - Resultados de RCS dos corpos-de-prova da mistura solo - ARC ensaiados em diferentes tempos de cura 
FIGURA 4.16. - Resultados de E50\% dos corpos-de-prova da mistura solo - ARC ensaiados em diferentes tempos de cura.

FIGURA 4.17. - Valores de módulo de resiliência da mistura solo - ARC determinados no centro da camada de base da estrutura proposta para diferentes tempos de cura.

FIGURA 4.18. - Curvas de deformação permanente em função do número de aplicações de carga para corpos-de-prova da mistura solo - ARC ensaiados em diferentes tempos de cura

FIGURA 4.19. - Deformação permanente inicial da mistura solo - ARC em função do tempo de cura

FIGURA 4.20. - Deformação permanente final da mistura solo - ARC em função do tempo de cura

FIGURA 4.21. - Módulo de resiliência em função do número de aplicações de carga para corpos-de-prova da mistura solo - ARC ensaiados em diferentes tempos de cura

FIGURA 4.22. - Resultados de CBR dos corpos-de-prova da mistura solo - ARC ensaiados em diferentes tempos de cura.

FIGURA 4.23. - Médias dos resultados de RCS do ARC e da mistura solo - ARC para tempos de cura até 28 dias

FIGURA 4.24. - Médias dos resultados de E50\% do ARC e da mistura solo - ARC para tempos de cura até 28 dias

FIGURA 4.25. - Valores de MR do ARC e da mistura solo - ARC calculados a partir do pavimento proposto

FIGURA 4.26. - Deformações permanentes finais do ARC e da mistura solo - ARC para tempos de cura até 28 dias

FIGURA 4.27. - Médias dos resultados de CBR do ARC e da mistura solo - ARC obtidos para tempos de cura até 28 dias

FIGURA 1 - Curvas de compactação do ARC para as energias intermediária e modificada (Grubba, 2009).

FIGURA 1 - Curva de compactação da mistura solo - ARC .................................

FIGURA 2 - CBR 5 pontos da mistura solo - ARC ........................................ vi 



\section{SUMÁRIO DE TABELAS}

TABELA 2.1. - Geração de RCD em alguns países da União Européia (EC, 2000) ...7

TABELA 2.2. - Abrasão Los Angeles de ARC (apud GRUBBA, 2009). 18

TABELA 2.3. - Resultados de CBR do agregado reciclado de concreto de diversas pesquisas (apud Motta, 2005)

TABELA 3.1. - Resultados da caracterização, classificação e compactação (Kakuda, 2010) 30

TABELA 3.2. - Classificação do solo e resultados dos ensaios da metodologia MCT (Kakuda, 2010)

TABELA 3.3. - Distribuição granulométrica da mistura de ARC

TABELA 3.4. - Parâmetros obtidos da distribuição granulométrica do ARC e limites recomendados pela norma NBR 15115

TABELA 3.5. - Recomendações de Nogami e Villibor (1995) e parâmetros da mistura solo - ARC.

TABELA 3.6. - Programa experimental do ensaio de Compressão Simples

TABELA 3.7. - Tensões empregadas no ensaio triaxial cíclico (AASHTO T 307 99)

TABELA 3.8. - Estados de tensão utilizados para realização dos ensaios triaxiais cíclicos para determinação da deformação permanente em função das aplicações de carga

TABELA 4.1. - Resultados de RCS dos corpos-de-prova de ARC ensaiados com diversos tempos de cura e percentual e gradiente de ganho de resistência.

TABELA 4.2. - Resultados das médias de RCS, percentual de ganho de resistência e diferença entre os ganhos dos corpos-de-prova de ARC, desta pesquisa e da pesquisa de Grubba (2009), ensaiados em diferentes tempos de cura

TABELA 4.3. - Resultados de RCS dos corpos-de-prova de ARC, especialmente moldados para o ensaio de compressão simples e dos corpos-de-prova de ARC usados anteriormente nos ensaios triaxiais cíclicos, ensaiados em diferentes tempos de cura

TABELA 4.4. - Resultados de $E_{50 \%}$ dos corpos-de-prova de ARC ensaiados com diversos tempos de cura, percentual e gradiente de ganho de rigidez

TABELA 4.5. - Resultados das médias de $\mathrm{E}_{50 \%}$, percentual de ganho de rigidez e diferença entre os ganhos dos corpos-de-prova de ARC, desta pesquisa e da pesquisa de Grubba (2009), ensaiados em diferentes tempos de cura 
TABELA 4.6. - Constantes de calibração e $R^{2}$ dos modelos de módulo de resiliência dos corpos-de-prova de ARC ensaiados em diversos tempos de cura

TABELA 4.7. - Valores de módulo de resiliência do ARC, desta pesquisa e da pesquisa de Grubba (2009), determinados no centro da camada de base da estrutura proposta.

TABELA 4.8. - Estados de tensão utilizados para realização dos ensaios triaxiais cíclicos para determinação da deformação permanente em função das aplicações de carga 66

TABELA 4.9. - Constantes de calibração e $R^{2}$ do modelo de Monismith et al. (1975) aplicado as curvas de deformação permanente em função do número de aplicações de carga para corpos-de-prova de ARC ensaiados com diversos tempos de cura .. 67

TABELA 4.10. - Deformações permanentes iniciais e finais, para diferentes tempos de cura e suas respectivas reduções em relação aos resultados sem cura.

TABELA 4.11. - Constantes de calibração e $R^{2}$ do modelo de Monismith et al. (1975) aplicados aos resultados dos ensaios de deformação permanente em função do número de aplicações de carga, para três pares de tensões (E1, E2 e E3), de corpos-de-prova de ARC ensaiados aos 28 dias de cura.

TABELA 4.12. - Deformação permanente inicial e final do ARC para os três pares de tensões estudados (E1, E2 e E3)

TABELA 4.13. - Magnitudes e variações do módulo de resiliência inicial e final para corpos-de-prova de ARC ensaiados em diversos tempos de cura

TABELA 4.14. - Magnitudes e variações do módulo de resiliência inicial e final para corpos-de-prova de ARC ensaiados com 28 dias de cura para três estados de tensão (E1, E2 e E3).

TABELA 4.15. - Resultados de CBR dos corpos-de-prova de ARC ensaiados com diversos tempos de cura.

TABELA 4.16. - Resultados de RCS dos corpos-de-prova da mistura solo - ARC ensaiados com diversos tempos de cura e percentual e gradiente de resistência ... 82

TABELA 4.17. - Resultados de $E_{50 \%}$ dos corpos-de-prova da mistura solo - ARC ensaiados com diversos tempos de cura, percentual e gradiente de ganho de rigidez

TABELA 4.18. - Constantes de calibração e $\mathrm{R}^{2}$ dos modelos de módulo de resiliência dos corpos-de-prova da mistura solo - ARC ensaiados em diferentes tempos de cura

TABELA 4.19. - Valores de módulo de resiliência da mistura solo - ARC determinados no centro da camada de base da estrutura proposta para diferentes tempos de cura. 
TABELA 4.20. - Constantes de calibração e $R^{2}$ da deformação permanente em função do número de aplicações de carga para corpos-de-prova da mistura solo ARC ensaiados em diferentes tempos de cura

TABELA 4.21. - Deformações permanentes iniciais e finais da mistura solo - ARC para diferentes tempos de cura e suas respectivas reduções em relação aos resultados sem cura

TABELA 4.22. - Magnitude e variações do módulo de resiliência inicial e final para corpos-de-prova de ARC ensaiados em diferentes tempos de cura

TABELA 4.23. - Resultados de CBR dos corpos-de-prova da mistura solo - ARC ensaiados em diferentes tempos de cura.

TABELA 4.24. - Constantes de calibração e $R^{2}$ do modelo composto do $A R C$ e da mistura solo - ARC

TABELA 1 - Características físicas do ARC (Grubba, 2009)

TABELA 1 - RCS, $E_{50 \%}$ e variação do teor de umidade do ARC .............................. ii

TABELA 2 - RCS e variação do teor de umidade do ARC após ensaios triaxiais cíclicos para determinação do módulo de resiliência iii

TABELA 3 - RCS e variação do teor de umidade do ARC após ensaios triaxiais cíclicos para determinação da deformação permanente e do módulo de resiliência . iii TABELA 4 - RCS, $E_{50 \%}$ e variação do teor de umidade da mistura solo - ARC iv 



\section{INTRODUÇÃO}

Atualmente, a sociedade mobiliza-se na busca por soluções alternativas que não causem impactos ambientais, procurando minimizar a exploração dos recursos naturais e reduzir a degradação do meio ambiente e outras alterações ambientais. Nesse contexto, a pavimentação vem contribuindo significativamente com soluções para destinação final de diversos tipos de resíduos, antes considerados problema ambiental e agora utilizados na construção de pavimentos.

A indústria da construção civil sempre foi uma das maiores geradoras de resíduos, os quais por muito tempo foram descartados desordenadamente em terrenos baldios, encostas de cursos de água, margens de vias, lixões, aterros e outros, causando proliferação de vetores, enchentes, obstrução de vias e poluição visual e ambiental. Logo, para resolver esses problemas é indispensável um grande investimento econômico, que não seria necessário se houvessem políticas públicas de incentivo à reciclagem desses resíduos.

Nesse novo patamar da preocupação ambiental e econômica, em 2002 foi publicado pelo Conselho Nacional do Meio Ambiente - CONAMA, a resolução $n^{\circ}$ 307, que estabelece diretrizes, critérios e procedimentos para a gestão dos resíduos da construção civil. Esta resolução atribui aos geradores dos resíduos terem como objetivo prioritário a não geração dos mesmos e, secundariamente, a redução, a reutilização, a reciclagem e a destinação final. 
Por muitos anos, desde a Segunda Guerra Mundial, a reciclagem de concreto tem sido praticada em larga escala na Europa e no Japão. Na Austrália, devido à escassez de espaços para construção de aterros sanitários e elevadas taxas cobradas para depósitos de resíduos nos aterros, existe um grande esforço para utilização de produtos reciclados, como o agregado reciclado para construção de pavimentos.

Segundo Lauritizen (1994), estimativas apontaram uma geração mundial de resíduos compreendida entre 2 e 3 bilhões de toneladas por ano. Só nos Estados Unidos, estimou-se uma produção de 136 milhões de toneladas por ano (EPA, 1998), na União Européia, 180 milhões de toneladas (EC, 2000) e no Brasil, 68,5 milhões (ANGULO, 2005).

De acordo com diversas pesquisas, os resíduos da construção civil podem ser transformados em agregados reciclados de ótima qualidade e podem ser aplicados em diversos serviços de engenharia, como na produção de concreto e argamassa, em serviços de drenagem, na fabricação de pré-moldados, lastro para assentamento de dutos, na construção de pavimentos, e outros. Em muitos casos o agregado reciclado é a melhor alternativa econômica, não deixando a desejar em seu desempenho mecânico (Motta, 2005).

Na pavimentação, segundo Motta (2005), o maior atrativo para emprego desses materiais é o fator econômico, uma vez que esses materiais têm sido vendidos, geralmente, a preços inferiores aos dos convencionalmente utilizados em pavimentação. 
A norma NBR 15116 (ABNT, 2004) separa o agregado reciclado da construção civil em agregados reciclados misto e de concreto (ARC), onde os de concreto possuem em sua fração graúda no mínimo 90\%, em massa, de fragmentos à base de cimento Portland e rochas, enquanto os mistos possuem menos de $90 \%$.

Grubba (2009) estudou a utilização de agregados reciclados de concreto em pavimentação e concluiu que sua aplicação é uma alternativa interessante ao emprego de agregados naturais. Contudo, em sua pesquisa, não foi contemplada a fundo a cimentação própria, característica marcante dos agregados reciclados de concreto, nem sua deformação permanente, parâmetro importante para avaliação do comportamento mecânico dos materiais.

\subsection{OBJETIVO}

Esta pesquisa tem como objetivo estudar o comportamento mecânico, ao longo do tempo de cura, do agregado reciclado de concreto proveniente da Usina de Reciclagem de São Carlos e de sua mistura com um solo laterítico, a fim de utilizálos na construção de pavimentos.

\subsection{ORGANIZAÇÃO DO TRABALHO}

Esse texto está dividido em cinco capítulos. O primeiro capítulo apresenta uma breve justificativa sobre a relevância do tema, o objetivo do trabalho e como esse foi organizado. O segundo capítulo aborda os principais assuntos pesquisados que dão suporte ao trabalho, tais como: geração e reciclagem dos RCD, aplicações dos agregados reciclados de concretos, empregos dos agregados reciclados de concreto em camadas de bases e sub-bases de pavimentos e avaliação do comportamento 
mecânico do ARC. No terceiro capítulo, são descritos os materiais escolhidos, os procedimentos laboratoriais e as técnicas de análise de resultados empregados para a realização desta pesquisa. No quarto capítulo, são apresentados e analisados os resultados laboratoriais. No quinto capítulo, são apresentadas as conclusões de todo o estudo. O sexto capítulo apresenta as referências bibliográficas utilizadas nesta pesquisa. 


\section{REVISÃO BIBLIOGRÁFICA}

\subsection{RESÍDUOS SÓLIDOS}

Resíduos sólidos são resíduos nos estados sólido e semi-sólido, que resultam de atividades de origem industrial, doméstica, hospitalar, comercial, agrícola, de serviços e de varrição (ABNT NBR 10004, 2004).

Existem várias classificações para os resíduos sólidos. A NBR 10004 (ABNT, 2004) classifica o resíduo em função do processo ou atividade que thes deu origem e de seus constituintes e características e a comparação destes constituintes com resíduos e substâncias cujo impacto à saúde e ao meio ambiente é conhecido. Ao final, os resíduos são enquadrados em dois grupos: resíduos classe I - perigosos e classe II - não perigosos, sendo este ainda dividido em classe II A - não inertes e classe II B - inertes. Na maioria dos casos os resíduos de construção civil são enquadrados no grupo de resíduos da classe II B, ou seja, não perigosos e inertes.

A resolução do Conselho Nacional do Meio Ambiente № 307 (CONAMA, 2002) define como resíduo da construção civil o resíduo proveniente de construções, reformas, reparos e demolições de obras de construção civil, e os resultantes da preparação e da escavação de terrenos, tais como tijolos, blocos cerâmicos, concreto em geral, solos, rochas, metais, resinas, colas, tintas, madeiras e compensados, forros, argamassa, gesso, telhas, pavimento asfáltico, vidros, 
plásticos, tubulações, fiação elétrica etc., comumente chamados de entulhos de obras, caliça ou metralha.

Os resíduos ainda são classificados, pela resolução № 307 do CONAMA, em quatro classes, $A, B, C$ e D, com base no seu potencial de reciclagem e reuso. Os resíduos da classe A são aqueles reutilizáveis ou recicláveis como agregado, classe B, os recicláveis para outras destinações, classe $C$, os resíduos para os quais não foram desenvolvidas tecnologias ou aplicações economicamente viáveis que permitam a sua reciclagem e recuperação, tais como os produtos oriundos do gesso e os resíduos da classe $D$, os perigosos oriundos dos processos de construção.

Os resíduos da classe A ou agregados reciclados são definidos pela NBR 15114 (ABNT, 2004) como sendo materiais granulares provenientes do beneficiamento de resíduos de construção que apresentam características técnicas para a aplicação em obras de edificação, de infraestrutura, de aterros sanitários ou outras obras de engenharia. Estes, ainda, são classificados de acordo com a norma NBR 15116 (ABNT, 2004) em agregados reciclados misto e de concreto (ARC), onde os de concreto possuem sua fração graúda de no mínimo $90 \%$, em massa, de fragmentos à base de cimento Portland e rochas, enquanto os mistos possuem menos de $90 \%$.

\subsection{GERAÇÃO DE RESÍDUOS SÓLIDOS}

O setor da construção civil é um dos maiores geradores de resíduos sólidos no mundo. Segundo Lauritizen (1994), estimativas apontam uma geração mundial de resíduos compreendida entre 2 e 3 bilhões de toneladas por ano. 
No relatório "Management of Construction and Demolition Waste" publicado em 2000 pela Comissão Européia (EC, 2000), calculou-se, para alguns países da União Européia, uma produção de resíduos da construção e demolição de 180 milhões de toneladas por ano. A Tabela 2.1 mostra a geração anual de RCD e a geração anual per capita desses países.

TABELA 2.1. - Geração de RCD em alguns países da União Européia (EC, 2000).

\begin{tabular}{ccc}
\hline País & $\begin{array}{c}\text { Geração de } \\
\text { RCD (milhões } \\
\text { de ton./ano) }\end{array}$ & $\begin{array}{c}\text { Geração de } \\
\text { RCD per capita } \\
\text { (kg/ano) }\end{array}$ \\
\hline Alemanha & 59 & 3658 \\
Reino Unido & 30 & 1137 \\
França & 24 & 403 \\
Itália & 20 & 348 \\
Espanha & 13 & 331 \\
Holanda & 11 & 1291 \\
Bélgica & 7 & 3408 \\
Áustria & 5 & 3272 \\
Portugal & 3 & 302 \\
Dinamarca & 3 & 2030 \\
Grécia & 2 & 191 \\
Suécia & 2 & 666 \\
Finlândia & 1 & 1841 \\
Irlanda & 1 & 518 \\
\hline
\end{tabular}

Podemos observar na Tabela 2.1 que os países com maior geração de RCD per capita, tais como Alemanha, Bélgica e Áustria foram, entre os citados, os que mais sofreram com a Segunda Guerra Mundial, ou seja, este alto índice está relacionado com a reconstrução desses países.

Nos Estados Unidos, em 1996, foram gerados cerca de 136 milhões de toneladas de resíduos ou um total per capita de $463 \mathrm{~kg} / \mathrm{ano}$, não incluídos os materiais provenientes de pavimentos e pontes (EPA, 1998). Em 2003, a geração de 
resíduos aumentou para 154 milhões de toneladas ou um total per capita de 530 kg/ano, os quais 39\% são de origem residencial e 61\% não residencial (EPA, 2003). A Figura 2.1 apresenta a contribuição de cada setor e atividade da construção civil na geração de resíduos.

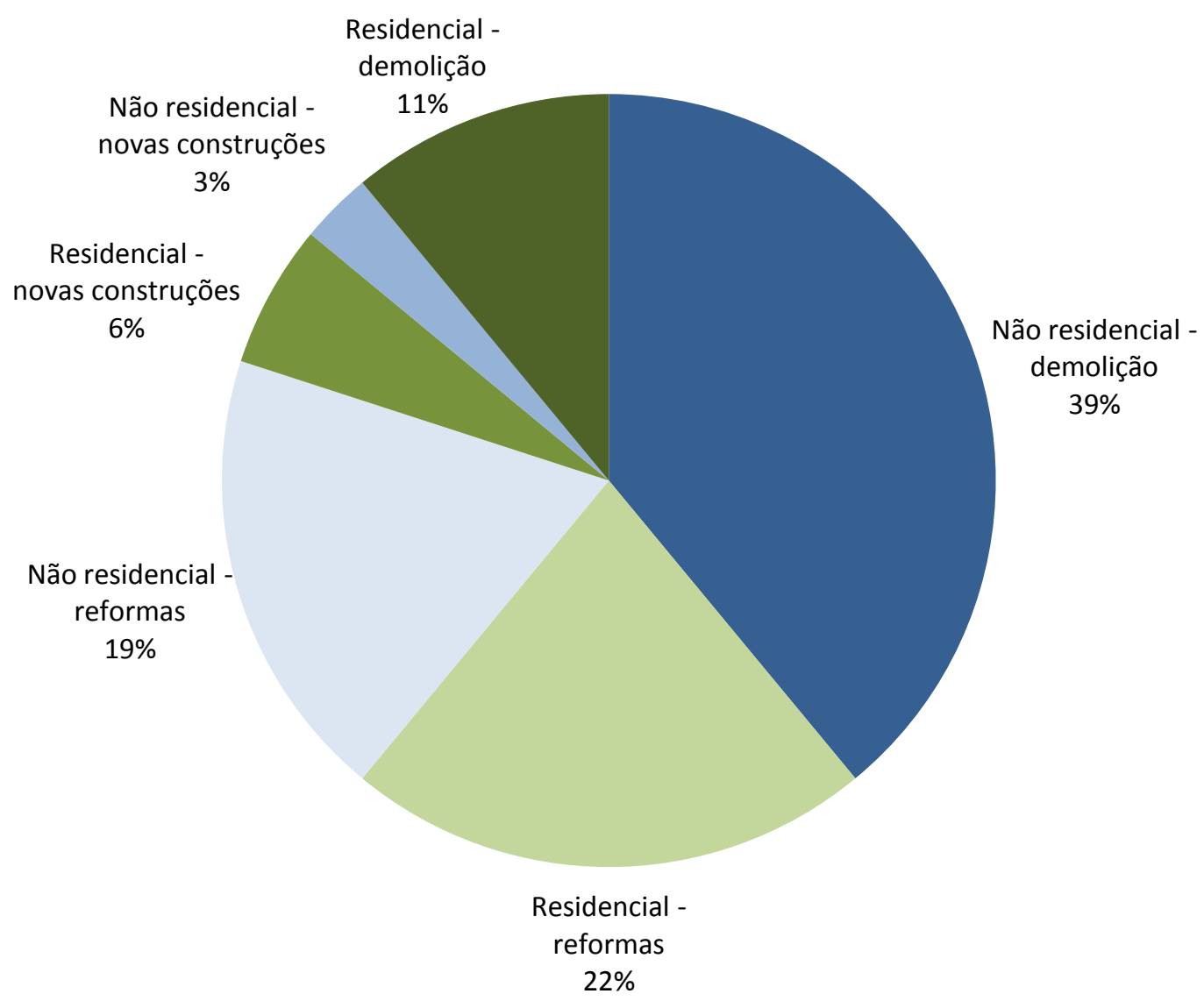

FIGURA 2.1. - Contribuição de cada setor e atividade da construção civil na geração de resíduos nos Estados Unidos (EPA, 2003)

Em Hong Kong, na China, no ano de 1991, foram gerados aproximadamente 8 milhões de toneladas (POON, 1997), enquanto em 2004 estimou-se uma produção de mais de 20 milhões de toneladas (POON; CHAN, 2006). Este aumento significativo se deve, provavelmente, ao grande crescimento do setor da construção civil, alavancado pelo crescimento da economia chinesa. 
No Brasil, não existem dados oficiais da geração de resíduos provenientes da construção civil. Entretanto, Angulo (2005) estimou uma produção anual aproximada de 68,5 milhões de toneladas de resíduos provenientes da construção civil, o que representa cerca da metade dos resíduos sólidos urbanos. Na cidade de São Paulo, segundo o relatório divulgado pela SINDUSCON-SP (2005), são gerados 5,3 milhões de toneladas anualmente, o que representa cerca de $8 \%$ do total produzido no Brasil.

Vale ressaltar que uma parte significativa dos dados relacionados às quantidades geradas é resultado direto da definição de resíduos de construção e demolição em cada local, além da possibilidade de variação em função de sua estrutura industrial, de suas características tecnológicas de construção, de seu nível de desenvolvimento, etc (ANGULO et al., 2002).

\subsection{RECICLAGEM DE RESÍDUOS SÓLIDOS}

Os resíduos de construção e demolição podem ser reciclados na forma de agregados por meio de um beneficiamento, constituído de operações de triagem, britagem, peneiramento e armazenamento (GRUBBA, 2009).

Como citado anteriormente, após a Segunda Guerra Mundial, a geração de resíduos da construção civil aumentou nos países que tiveram que ser reconstruídos. A demanda por materiais de construção era muito grande, sendo necessária a utilização de materiais alternativos, foi então que se iniciou a reciclagem de resíduos da construção civil. 
No Brasil, mais precisamente no município de São Paulo, em 1991, foi implantada a primeira usina recicladora do Brasil (CARNEIRO et al., 2001). Ao longo dos anos, algumas usinas de reciclagem foram sendo implantadas nos municípios brasileiros, chegando em 2004 a um total de 14 usinas distribuídas em 12 cidades (NUNES, 2004).

Em 2006, segundo Moreira et al. (2006), existiam 16 unidades de reciclagem de resíduos sólidos da construção civil no Brasil, localizadas nos munípios de Belo Horizonte, São Paulo, Ribeirão Preto, São José dos Campos, Londrina, Piracicaba, Guarulhos,Ribeirão Pires, São José do Rio Preto, Macaé, Brasília, Rio de Janeiro, São Gonçalo, Vinhedo e Uberlândia. Salienta-se que a Usina de Reciclagem de São Carlos, inaugurada em dezembro de 2006, não foi citada por Moreira et. al (2006).

Em um país com cerca de 180 milhões de habitantes e 5565 municípios, o número de usinas recicladoras de resíduos da construção civil é mínimo. Para efeito de comparação, em 1998 nos Estados Unidos, já existiam aproximadamente 3500 unidades de reciclagem (EPA, 1998).

Apesar da instalação das usinas terem sido iniciadas nos anos 90, só em 2002 foi publicada, pelo Conselho Nacional do Meio Ambiente, a resolução CONAMA n 307 onde se determina que os geradores devam ter como objetivo prioritário a não geração de resíduos e, secundariamente, a redução, a reutilização, a reciclagem e a destinação final.

A resolução considera que a disposição dos resíduos em locais inadequados contribui para a degradação da qualidade ambiental, que há viabilidade técnica e 
econômica para a produção e o uso de materiais provenientes de resíduos deverá proporcionar benefícios de ordem social, econômica e ambiental.

Em 2004, a Associação Brasileira de Normas Técnicas (ABNT) lançou 4 especificações que tratam desde o recebimento desses materiais até a sua reutilização, são elas:

- NBR 15112 - Resíduos de construção civil e resíduos volumosos Áreas de transbordo e triagem - Diretrizes para projeto, implantação e operação;

- NBR 15113 - Resíduos sólidos da construção civil e resíduos inertes Aterros - Diretrizes para projeto, implantação e operação;

- NBR 15114 - Resíduos sólidos da construção civil e resíduos inertes Área de reciclagem - Diretrizes para projeto, implantação e operação;

- NBR 15115 - Agregados reciclados de resíduos sólidos da construção civil - Execução de camadas de pavimentação - Procedimentos;

- NBR 15116 - Agregados reciclados de resíduos sólidos da construção civil - Utilização em pavimentação e preparo de concreto sem função estrutural - Requisitos.

\subsection{USINA DE RECICLAGEM DE SÃO CARLOS}

O agregado reciclado estudado nesta pesquisa foi coletado na usina de reciclagem de resíduos da construção civil da PROHAB na cidade de São Carlos - SP, apresentada na Figura 2.2, esta usina tem capacidade nominal de produção de 160 
toneladas por dia, uma quantidade próxima à da geração do município, que varia de 250 a 450 ton/dia.

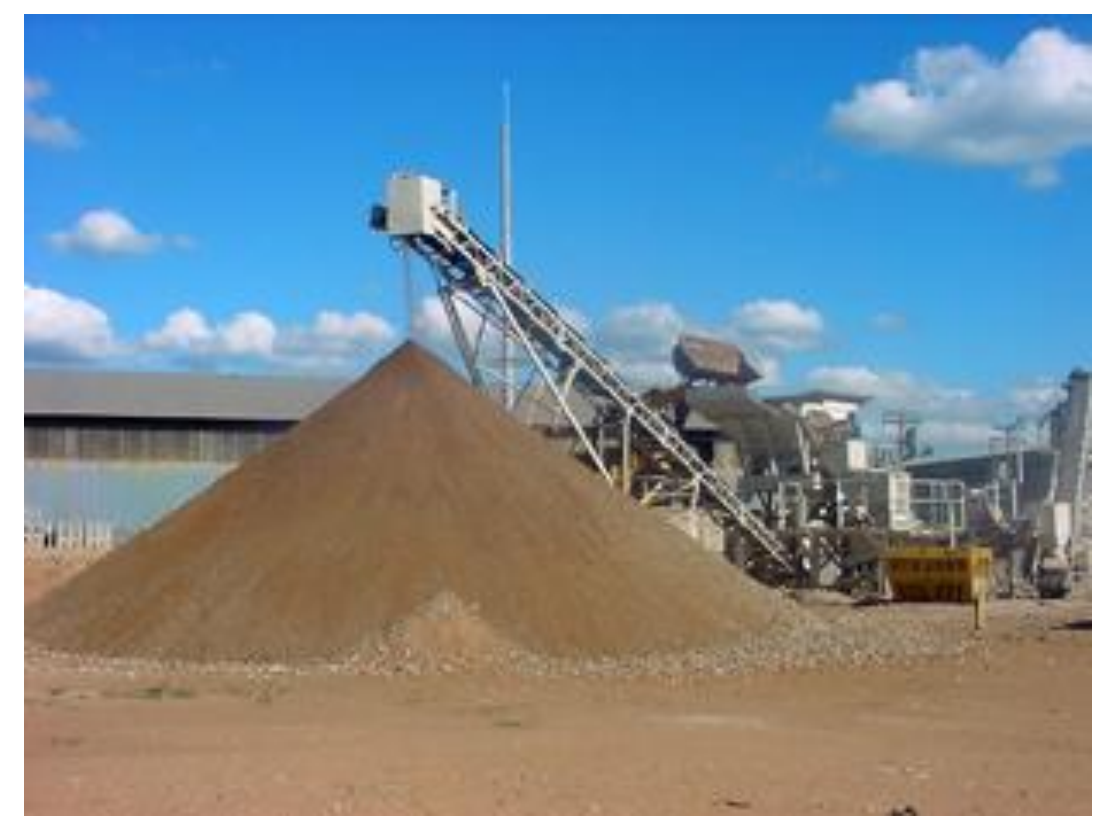

FIGURA 2.2. - Usina de reciclagem de resíduos da construção civil da PROHAB na cidade de São Carlos - SP

Dentre os resíduos reciclados na usina, estão: fragmentos de componentes cerâmicos ou de concreto, armado ou não, sem fôrmas; argamassas de cal, de cimento ou mistas; e fragmentos de pedra britada e de areia natural, sem presença significativa de terra ou outros materiais proibidos.

Muitos dos resíduos da construção civil não são reciclados pela usina, tais como: gesso; materiais com cimento amianto; madeira; matéria orgânica; papel; plástico; isopor; metais; tintas; vidros; asfalto; e outros.

Os resíduos são transbordados na usina através de uma parceria com empresas coletoras de resíduos na cidade de São Carlos. O processo de operação de reciclagem de usina de São Carlos é composto como descrito a seguir: 
- Recepção, análise visual dos resíduos recebidos e disposição em áreas para triagem;

- Retirada de contaminantes e triagem, isto é, agrupamento segundo sua constituição predominante em duas classes de resíduos, misto e de concreto;

- Alimentação do núcleo de reciclagem e processamento dos resíduos (pré-classificação, britagem, peneiração, rebritagem e transporte);

- Retirada de contaminantes após a britagem;

- Formação de pilhas de agregado reciclado na forma de "bica corrida" ou peneirado;

- Estocagem e expedição.

A Usina de Reciclagem de São Carlos produz agregados reciclados em 5 granulometrias distintas provenientes de resíduos mistos e de concreto, denominadas:

- Bica corrida - resíduo misto, com granulometria variável;

- Areia grossa - resíduo de concreto, com diâmetro até 2,4 mm;

- Pedrisco - resíduo de concreto, com diâmetro até 9,5 mm;

- Pedra no 1 - resíduo de concreto, com diâmetro até 19 mm;

- Pedregulho - resíduo misto, com diâmetro até $25 \mathrm{~mm}$. 
Em São Carlos, as principais aplicações do agregado reciclado são na fabricação de blocos de concreto e bloquetes para pavimentação com pisos intertravados, os quais utilizam o pedrisco na sua fabricação.

\subsection{UTILIZAÇÃO DE AGREGADOS RECICLADOS}

Os agregados reciclados podem ser aplicados em diversos serviços de engenharia tais como a produção de concreto e argamassa, serviços de drenagem, a fabricação de pré-moldados, lastro para assentamento de dutos, a construção de pavimentos, entre outros. Em muitos casos o agregado reciclado é a melhor alternativa econômica, não deixando a desejar em seu desempenho mecânico. Segundo Motta (2005), na pavimentação, o maior atrativo para emprego desses materiais é o fator econômico, uma vez que esses materiais têm sido vendidos, geralmente, a preços inferiores aos dos convencionalmente utilizados em pavimentação.

De acordo com Blankenagel e Guthrie (2006), nos Estados Unidos, o custo do agregado reciclado de resíduo sólido da construção civil é em torno de $30 \%$ inferior ao do agregado ou material pétreo britado, o que tem levado muitos órgãos e construtoras a substituir o agregado natural pelo reciclado.

Em São Paulo, no ano de 2003, a Prefeitura Municipal de São Paulo (PMSP) publicou a especificação de serviço PMSP/SP ETS - 001/2003 que define os critérios para a execução de camadas de reforço de subleito, sub-base ou base de pavimentos com agregados reciclados da construção civil. Em 2006 foi decretado que as contratações de obras e serviços de pavimentação de vias públicas deveriam contemplar de modo preferencial o emprego de agregados reciclados. No meio de 
2007, passou a ser obrigatório o uso de materiais reciclados onde há viabilidade técnica (PMSP, 2008).

\subsection{AGREGADOS RECICLADOS DE CONCRETO}

Segundo Carneiro et al. (2001), na cidade de Salvador, os resíduos da construção e demolição apresentam em sua composição $53 \%$ de concretos e argamassas, os quais podem ser transformados em agregados reciclados de alto potencial de utilização.

No Brasil quase não existem pesquisas referentes à aplicação do agregado reciclado de concreto em pavimentação. Grubba (2009) estudou as propriedades físicas e o comportamento mecânico do agregado reciclado de concreto proveniente da Usina de Reciclagem de Resíduos da Construção Civil de São Carlos - SP. Ao final de sua pesquisa, constatou-se que o agregado reciclado de concreto é uma alternativa interessante ao emprego de agregados naturais nas camadas de base e sub-base de pavimentos e ainda observou ganhos de resistência mecânica oriundos da cura desse material.

Nos Estados Unidos, em 1998, estimou-se uma utilização de $85 \%$ de todos os resíduos de concreto reciclados em bases de pavimentos rodoviários (WILBURN; GOONAN, 1998). No relatório “Transportation Applications of Recycled Concrete Aggregate" publicado pelo "Federal Highway Administration U.S. Departament of Transportation" (FHWA, 2004), 38 dos 50 estados americanos utilizam o agregado reciclado de concreto $(A R C)$ em camadas de base e sub-bases de pavimentos. Este relatório justifica essa aceitação do $A R C$, devido principalmente, à escassez de 
agregados naturais, e também, por ser ambientalmente correto e economicamente atrativo.

Segundo Saeed, Hammons e Reed (2007) dentre os diversos parâmetros físicos e mecânicos utilizados pela engenharia de transportes para caracterizar os materiais, o agregado reciclado de concreto quando comparado com o agregado natural comumente utilizado em bases de pavimentos, apresenta: menor massa específica; maior textura superficial; maior absorção de água; maior teor de umidade ótimo; menor resistência à abrasão; maior índice de suporte Califórnia; maior módulo de resiliência; e menor deformação permanente.

A vida útil de um pavimento, tanto quanto sua qualidade, dependem de diversos fatores, tais como as características físicas e mecânicas dos materiais, as cargas solicitantes, o clima e outros. Portanto na concepção de um pavimento todos esses fatores devem ser considerados.

O método mais consagrado para dimensionamento de pavimentos é o desenvolvido pela AASHO e apresentado por Turnbull, Foster e Ahlvin em 1962, o qual avalia o desempenho dos materiais do subleito e das camadas granulares pelo Índice de Suporte Califórnia (ISC), e o das bases cimentadas, pela resistência à compressão simples (RCS).

A utilização de métodos empíricos para dimensionamento de pavimentos tem sido discutida por muitos anos pela engenharia de pavimentação. Estes métodos são desenvolvidos baseados em experiências com variados tipos de pavimentos, utilizando diferentes materiais e em condições adversas, portanto sua utilização limita-se às condições e materiais utilizados no seu desenvolvimento. Para garantir o 
sucesso de um pavimento é necessário utilizar métodos de dimensionamento que contemplem o comportamento mecânico de seus materiais constituintes e não apenas métodos baseados em experiências (Lekarp; Isacsson; Dawson, 2000).

Os dois principais defeitos dos pavimentos asfálticos são trincas por fadiga do revestimento e deformação permanente. O primeiro defeito é ocasionado pela tensão desvio aplicada repetidamente na capa do pavimento, a qual varia em função do carregamento aplicado e do comportamento resiliente dos materiais constituintes e o segundo defeito é causado pela soma das deformações permanentes de cada camada do pavimento e do subleito.

O método mecanístico para dimensionamento de pavimentos flexíveis e semiflexíveis exige que os modelos constitutivos (relação 'tensão x deformação') dos materiais sejam conhecidos, permitindo a previsão do comportamento dos pavimentos, através dos cálculos de tensões, deformações e deslocamentos.

Portanto, quando estudamos a aplicabilidade de um material em pavimentos, devemos analisar suas características físicas e mecânicas, a fim de fornecer dados para os mais variados tipos de dimensionamento de pavimentos.

\subsubsection{Propriedades Físicas}

Segundo Poon e Chan (2006) o agregado reciclado de concreto apresenta uma maior absorção do que os agregados naturais devido à presença de argamassa aderida a seus grãos. Valores típicos de absorção dos ARC variam entre 2\% e 6\% para agregados reciclados graúdos e de $4 \%$ a $8 \%$ para agregados miúdos (SAEED; HAMOONS; REED, 2007). Estes mesmos autores, afirmaram que a massa 
específica dos agregados reciclados de concreto é menor que a dos agregados naturais.

De acordo com a FHWA (1997), a abrasão Los Angeles dos agregados reciclados de concreto varia entre 20 e 45\%. Grubba (2009) apresentou em seu trabalho vários valores de abrasão Los Angeles de agregados reciclados de concreto, provenientes de diferentes lugares e autores, estes valores estão apresentados na Tabela 2.2.

TABELA 2.2. - Abrasão Los Angeles de ARC (apud GRUBBA, 2009).

\begin{tabular}{ccc}
\hline Procedência & Fonte & Abrasão Los Angeles (\%) \\
\hline Austrália & Nataatmadja et al. (2001) & 21 a 30 \\
Taiwan & Huang et al. (2002) & 29 \\
EUA & Kuo et al. (2002) & 42 a 48 \\
EUA & Blankenagel et al. (2006) & 31 \\
Brasil & Fernandes (2004) & 52 \\
Brasil & Oliveira (2007) & 33 a 38 \\
\hline
\end{tabular}

$\mathrm{Na}$ bibliografia não é apresentada nenhuma recomendação de faixas granulométricas adequadas para o emprego deste material em pavimentação. A norma NBR 15115 “Agregados Reciclados de Resíduos Sólidos da Construção Civil - Execução de Camadas de Pavimentação - Procedimentos" recomenda alguns parâmetros que devem ser controlados, tais como: a porcentagem passante na peneira de 0,42mm deve estar entre 10 e 40\%; a dimensão característica máxima dos grãos de 63,5mm; e o coeficiente de uniformidade (Cu) no mínimo 10.

A dimensão característica máxima dos grãos é definida como a abertura da peneira em que fica retida uma porcentagem acumulada, em massa, menor ou igual a $5 \%$. 
A porcentagem de material passante na peneira $0,42 \mathrm{~mm}$ é especificada para fornecer à mistura uma quantidade mínima de material fino. Já o coeficiente de uniformidade $(\mathrm{Cu})$, que é a relação entre os diâmetros correspondentes a $60 \%$ e 10\% passantes na curva granulométrica, é definido para assegurar uma distribuição contínua. Estes parâmetros são especificados para garantir à mistura uma maior coesão e compactação.

\subsection{2. Índice de Suporte Califórnia (CBR)}

No relatório de 1997 da FHWA, "Guidelines for waste and by-product materials in pavement construction", é mencionado que os valores típicos de índice de Suporte Califórnia para os agregados reciclados de concreto variam de $94 \%$ a $148 \%$. Em 2005, no relatório "The development of a performance specification for granular base and subbase material", também publicado pela FHWA, apresenta valor de CBR de 205\%, para o ARC compactado na energia modificada.

Segundo Grubba (2009), o agregado reciclado de concreto proveniente da usina de reciclagem de São Carlos apresentou valor de CBR, na energia Proctor modificada, igual a 182\%, bem acima do exigido pela norma 15115 que especifica os limites $20 \%$ e $60 \%$ para as camadas de sub-base e base, respectivamente. De acordo com Saeed, Hammons e Reed (2007), os valores de CBR variam de 94\% a $184 \%$

Pesquisadores estrangeiros e brasileiros determinaram o índice de suporte Califórnia (CBR) do agregado reciclado de concreto em diferentes energias de compactação. A Tabela 2.3 apresenta os resultados encontrados por estes pesquisadores. 
TABELA 2.3. - Resultados de CBR do agregado reciclado de concreto de diversas pesquisas (apud Motta, 2005)

\begin{tabular}{ccc}
\hline CBR (\%) & $\begin{array}{c}\text { Energia Proctor de } \\
\text { compactação }\end{array}$ & Fontes \\
\hline 111 & não especificado & Bodi et al. (1995) \\
68 & normal & UTS (1999) \\
115 & modificada & UTS (1999) \\
88 & normal & Lim et al. (2001) \\
$120^{1}$ & não especificado & Reid (2000) \\
$245^{1}$ & não especificado & Reid (2000) \\
62 & intermediária & Ribeiro et al. (2002) \\
\hline $1-$ Valores de campo obtidos por meio de FWD (Falling Weigh Deflectometer)
\end{tabular}

Pode-se observar na Tabela 2.3 e nas citações apresentadas anteriormente, que os valores de CBR são muito variáveis, o que é explicado quando se considera a energia de compactação, o teor de umidade, a granulometria e a origem do agregado reciclado de concreto.

Muitas pesquisas, como as de Ribeiro et al. (2002), Saeed, Hammons e Reed (2007) e Grubba (2009), verificaram para o agregado reciclado de concreto valores de expansão praticamente nulos.

\subsubsection{Módulo de Resiliência}

Módulo de resiliência (MR) é o módulo de elasticidade determinado sob condições de carregamento cíclico e é definido como a relação entre a tensão desvio ( $\sigma d=\sigma 1$ б3), aplicada no ensaio triaxial cíclico, e a deformação resiliente axial, assim apresentada na Equação 2.1.

$$
M R=\sigma_{d} / \varepsilon_{r}
$$

Equação 2.1.

Onde:

$\sigma_{\mathrm{d}}$ : tensão desvio; 
$\varepsilon_{\mathrm{r}}:$ deformação resiliente.

O módulo de resiliência de solos e britas é determinado através do ensaio triaxial cíclico. Neste ensaio o corpo-de-prova é submetido a cargas repetidas, que procuram simular as condições de carregamentos impostas pelo tráfego na estrutura do pavimento.

Segundo Lekarp, Isacsson e Dawson (2000), o comportamento resiliente de materiais granulares é influenciado por diversos fatores, dentre eles os que mais influenciam seus valores, em ordem de importância, são: as tensões aplicadas; a densidade do material; a graduação, porcentagem de finos e tamanho máximo dos grãos; o grau de saturação e teor de umidade; o histórico de tensões e aplicações de carga; o tipo e a forma do agregado; e por último a duração, frequência e seqüência de carregamentos.

Grubba (2009), em concordância com Lekarp et al. (2000), relata em sua pesquisa que o comportamento resiliente dos agregados reciclados de concreto é influenciado por diversos fatores, tais como graduação, composição, grau de compactação e resistência à compressão simples do concreto de origem.

Molenaar e Van Niekerk (2002) mostraram que o módulo de resiliência dos agregados reciclados de concreto varia expressivamente com o grau de compactação e com a porcentagem de concreto apresentada nos materiais, enquanto a graduação influenciou pouco.

Fernandes (2004), em sua pesquisa sobre as características mecânicas dos agregados reciclados, constatou que os agregados reciclados de concreto 
apresentam módulo de resiliência maior que os mistos. Observou também, que a origem do agregado, a energia de compactação e a granulometria influenciam pouco o MR.

Nataatmadja e Tan (2001) analisaram agregados reciclados provenientes de concretos com resistência à compressão simples de 15, 18, 49 e $75 \mathrm{MPa}$, e concluíram que quanto maior a resistência à compressão simples do concreto de origem do agregado reciclado, maior é o módulo de resiliência deste material.

Pesquisadores, tais como Bennert et al. (2000) e Grubba (2009), encontraram valores de módulo de resiliência para o agregado reciclado de concreto superiores aos da brita graduada, em todos os níveis de tensão analisados.

\subsubsection{Deformação Permanente}

Segundo Medina (1997), embora o defeito mais freqüente nos pavimentos flexíveis brasileiros seja o trincamento do revestimento asfáltico, as deformações permanentes, irreversíveis, estão presentes seja nas trilhas de rodas dos caminhões nas estradas, seja em estacionamentos de revestimento asfáltico, constituindo um fator importante no projeto de pavimentos flexíveis.

Embora seja simples realizar a medição de deformação permanente, sua previsão é extremamente complexa, devido às variações climáticas e à estimativa das cargas aplicadas ao pavimento durante sua vida útil (Lekarp et al., 2000).

Nos países de clima temperado, tais como Estados Unidos e Inglaterra, a deformação permanente dos pavimentos tem sido amplamente estudada, por ser 0 principal defeito dos pavimentos. 
As deformações permanentes são diretamente proporcionais à tensão desvio e inversamente proporcionais à tensão confinante. Entre os fatores que influenciam na deformação permanente de materiais granulares, Lekarp et al. (2000) citam: o nível de tensões aplicado, a reorientação das tensões principais, o número de ciclos de carga, o teor de umidade ou o grau de saturação, a história de tensões, a massa específica aparente seca, a granulometria, o teor de finos e o tipo de agregado como alguns destes fatores.

Como existem vários fatores que influenciam a deformação permanente, ao longo dos anos foram ajustados inúmeros modelos matemáticos para representá-la. Uma das equações mais utilizadas é o modelo proposto por Monismith, dada por:

$$
\varepsilon_{p}=K_{1} \cdot N^{K_{2}}
$$

Onde:

$\mathrm{K}_{1}$ e $\mathrm{K}_{2}$ são coeficientes determinados experimentalmente;

N é o número de ciclos de aplicações de cargas.

Estudos realizados por Bennert et al. (2000) mostraram que o agregado reciclado de concreto apresenta uma deformação permanente de $0,38 \%$ para 100000 ciclos de carregamentos, sendo a tensão desvio de $310,26 \mathrm{kPa}$ e a tensão confinante, constante durante o ensaio, de 103,42 kPa. Neste mesmo estudo, avaliou-se o comportamento mecânico de um agregado natural com graduação densa, comumente utilizado no estado de Nova Jérsei nos Estados Unidos, o qual apresentou deformação permanente de 0,67\%. 


\subsubsection{Cimentação Própria}

Diversas pesquisas relatam a melhoria no desempenho mecânico dos agregados reciclados de concreto com o tempo, devido principalmente ao efeito da cimentação própria.

Arm (2001) analisou o comportamento mecânico de um agregado reciclado de concreto e um agregado natural, com tempos de cura que variaram de um dia a dois anos. Ao final da pesquisa, constatou-se que o módulo de resiliência do agregado reciclado de concreto aumenta acentuadamente nos primeiros meses, chegando a aumentar mais de $30 \%$ após dois anos, comparando com o medido após 1 dia, como pode ser observado na Figura 2.3. Tendo isto ocorrido para todos os níveis de tensão estudados, no entanto o agregado natural não apresentou nenhum ganho de rigidez. Ainda nesta pesquisa, verificou-se que o módulo de resiliência do agregado reciclado de concreto varia pouco com o nível de tensão aplicado, diferentemente do agregado natural. 


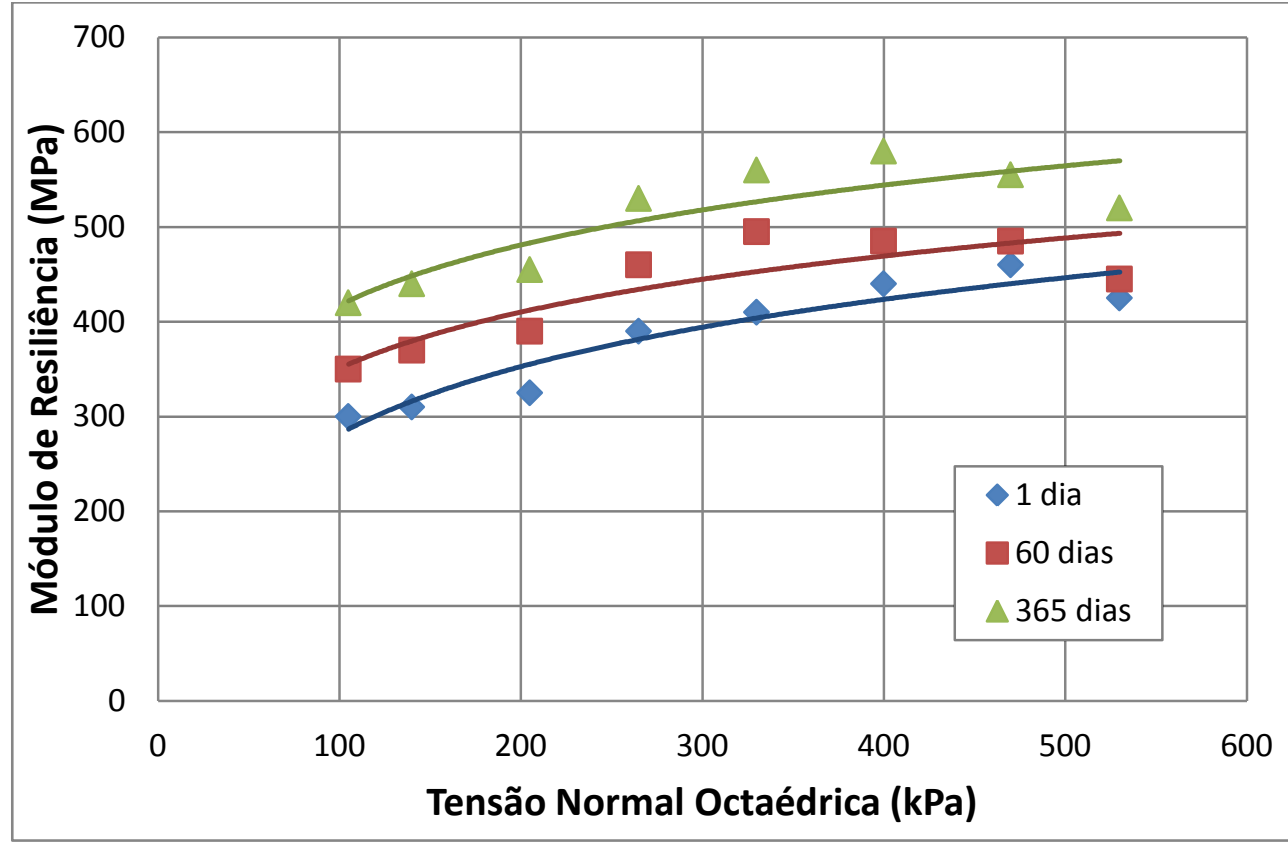

FIGURA 2.3. - Módulos de resiliência obtidos para diferentes estados de tensão em corpos-de-prova ensaiados com diferentes tempos de cura (adaptado de Arm, 2001)

Blankenagel (2005) verificou, através dos estudos com agregados reciclados de concreto que a resistência à compressão simples aumentou cerca de $70 \%$ após sete dias de cura.

Grubba (2009) estudou a influência da energia de compactação e o tempo de cura na resistência à compressão simples de corpos-de-prova de agregado reciclado de concreto. Constatou-se para a energia Proctor modificada que a resistência aos 7 dias de cura praticamente dobra e aos 90 dias quase triplica, quando comparada com a resistência imediata ( 0 dia). Os resultados são ainda mais expressivos quando se faz a mesma comparação para a energia Proctor intermediária, observase que a resistência aos 7 dias aproximadamente dobra, aos 28 dias, triplica e aos 90 dias, quintuplica. A Figura 2.4 apresenta esta evolução. 


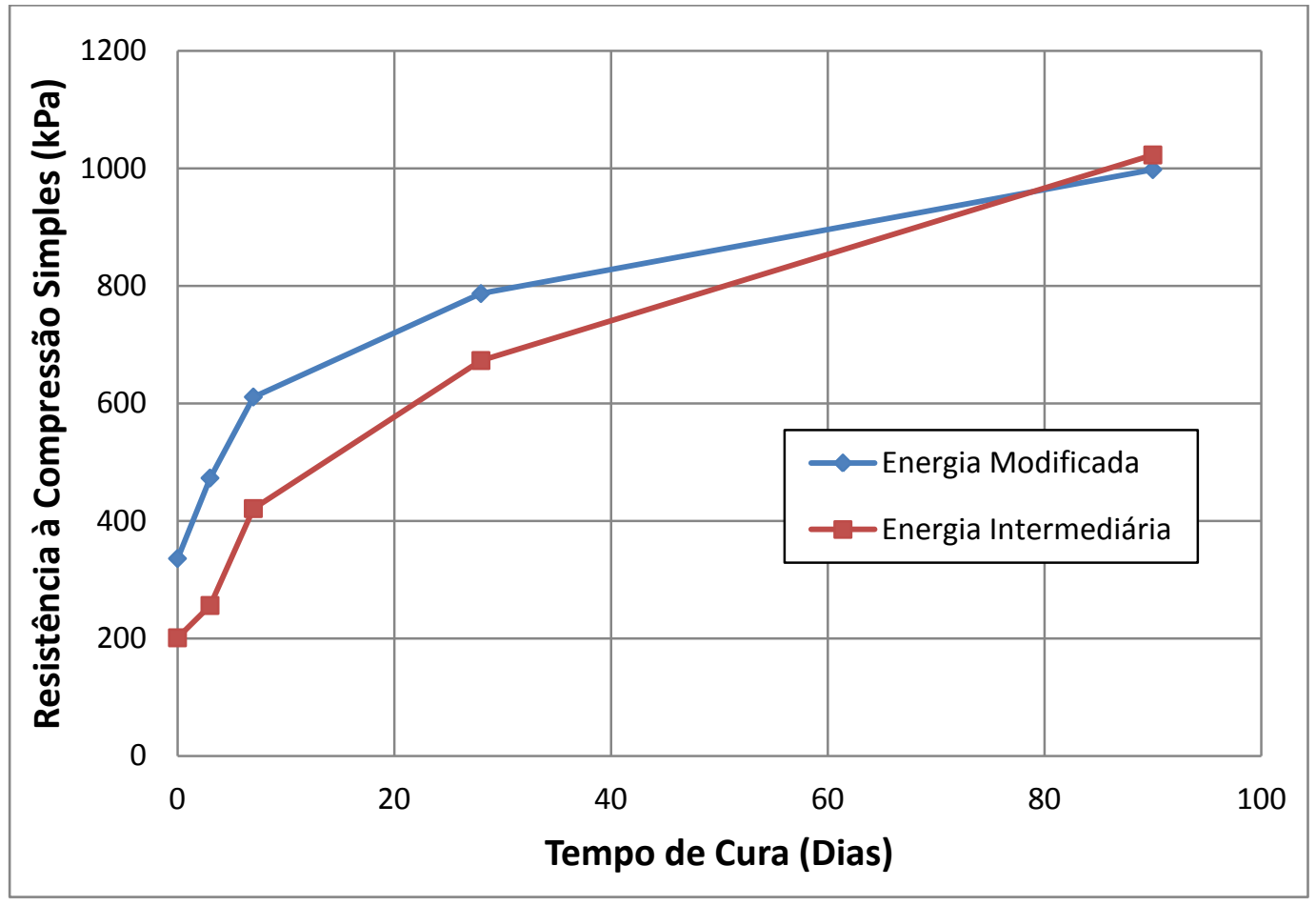

FIGURA 2.4. - Variação da RCS do agregado reciclado de concreto ao longo do tempo de cura (Grubba, 2009) 


\section{MATERIAIS E MÉTODOS}

A investigação experimental foi conduzida de forma a possibilitar o estudo do comportamento mecânico do agregado reciclado de concreto (ARC) e de uma mistura deste material com solo. O programa experimental conduzido contempla a caracterização física dos materiais estudados e ensaios mecânicos de corpos-deprova moldados segundo duas energias de compactação e ensaiados variando-se o tempo de cura.

\subsection{ORIGEM E CARACTERÍSTICAS FÍSICAS DOS MATERIAIS ESTUDADOS}

\subsubsection{Agregado Reciclado de Concreto}

O agregado reciclado de concreto foi coletado na Usina de Reciclagem de Resíduos da Construção Civil de São Carlos - SP no final de 2008 por Grubba (2009). A coleta foi feita de acordo com a norma DNER PRO 120/97 "Coleta de Amostra de Agregados". Devido à variabilidade da composição dos agregados reciclados com o tempo, coletou-se o material durante um único dia, garantindo-se que o agregado fosse oriundo do mesmo lote de resíduos.

O agregado foi fornecido pela Usina de Reciclagem em três granulometrias distintas, aqui denominadas por "brita 1", "pedrisco" e "areia". A Figura 3.1 apresenta as três frações do agregado, ainda no local de produção, antes de serem coletados. E na Figura 3.2 são apresentadas as curvas granulométricas das três frações do agregado obtidas por Grubba (2009) segundo a norma NBR 7181 "Solo - Análise Granulométrica". 


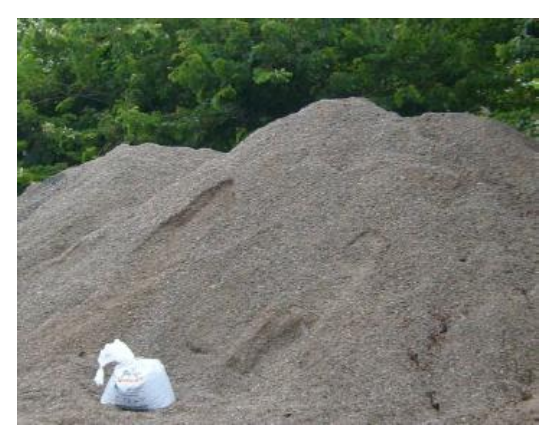

Pedrisco

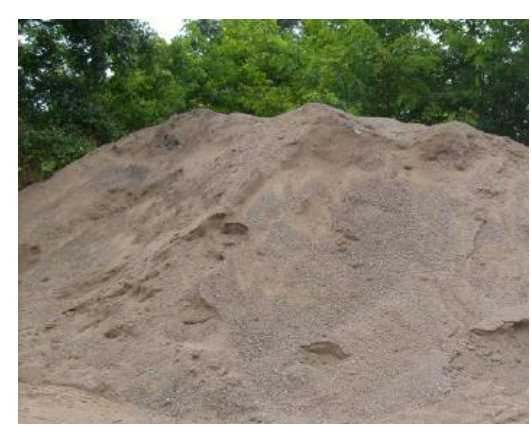

Areia

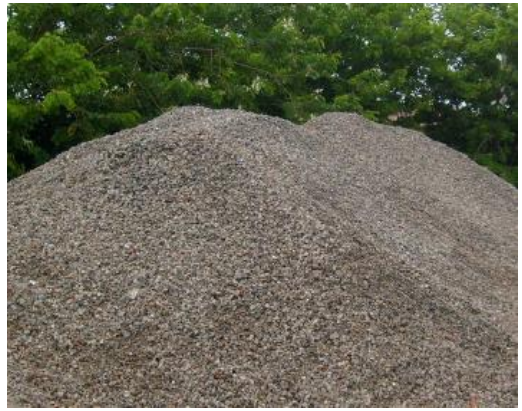

Brita 1

FIGURA 3.1. - As três frações do agregado reciclado de concreto, pedrisco, areia e brita 1 (Grubba, 2009)

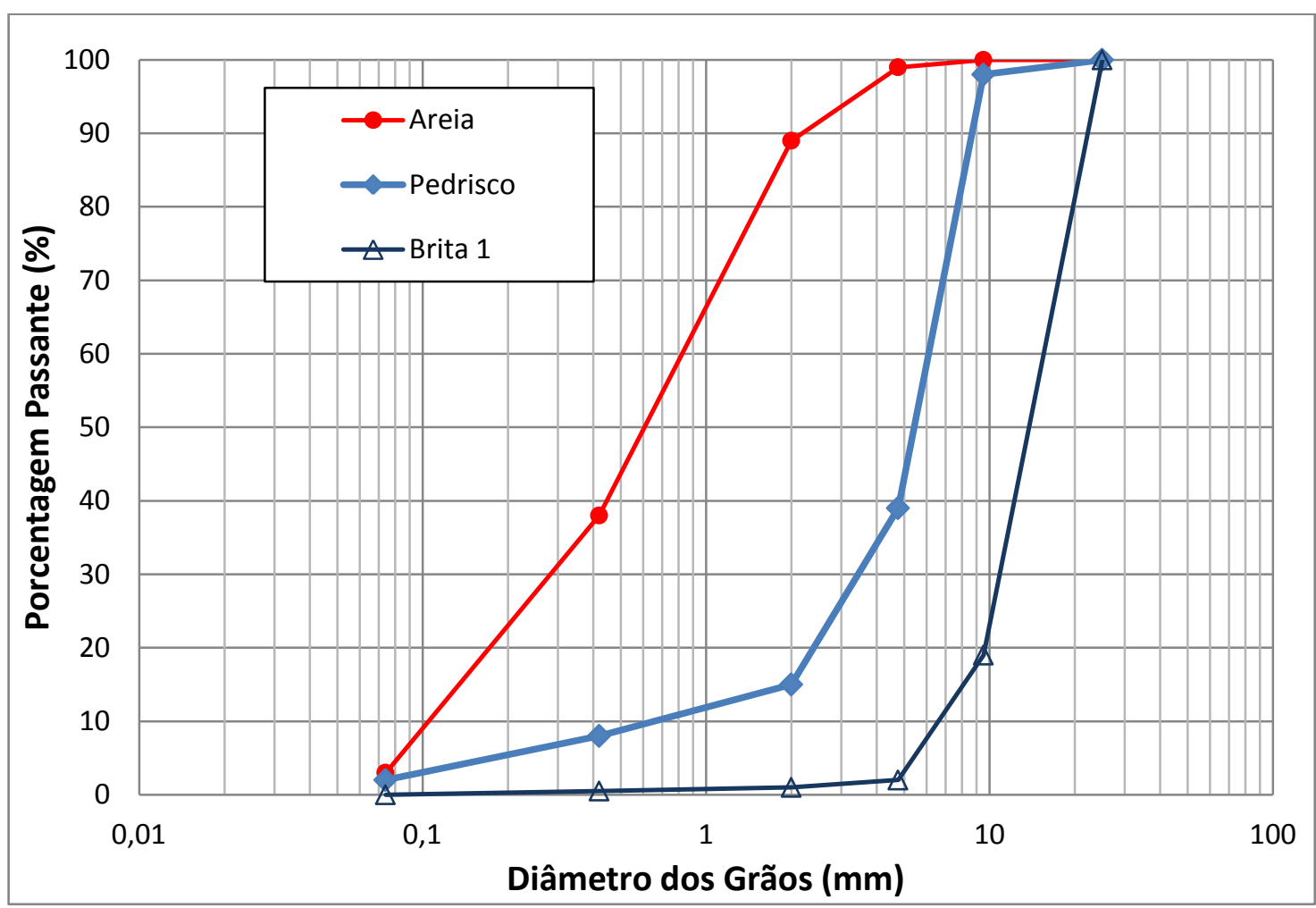

FIGURA 3.2. - Distribuições granulométricas das três frações do ARC (Grubba, 2009)

Na coleta, o material foi colocado em sacos plásticos em uma quantidade de aproximadamente $40 \mathrm{~kg}$ cada, transportados para o Laboratório de Estradas do Departamento de Transportes da EESC/USP e armazenados sobre paletes de madeira. 


\subsubsection{Solo}

O solo utilizado na mistura solo - agregado reciclado de concreto foi coletado no km $152+500 m$ da Rodovia Professor Luis Augusto de Oliveira (SP-215) no Estado de São Paulo, sentido São Carlos - Ribeirão Bonito, lado esquerdo. Na Figura 3.3 está apresentado o local de coleta do solo.

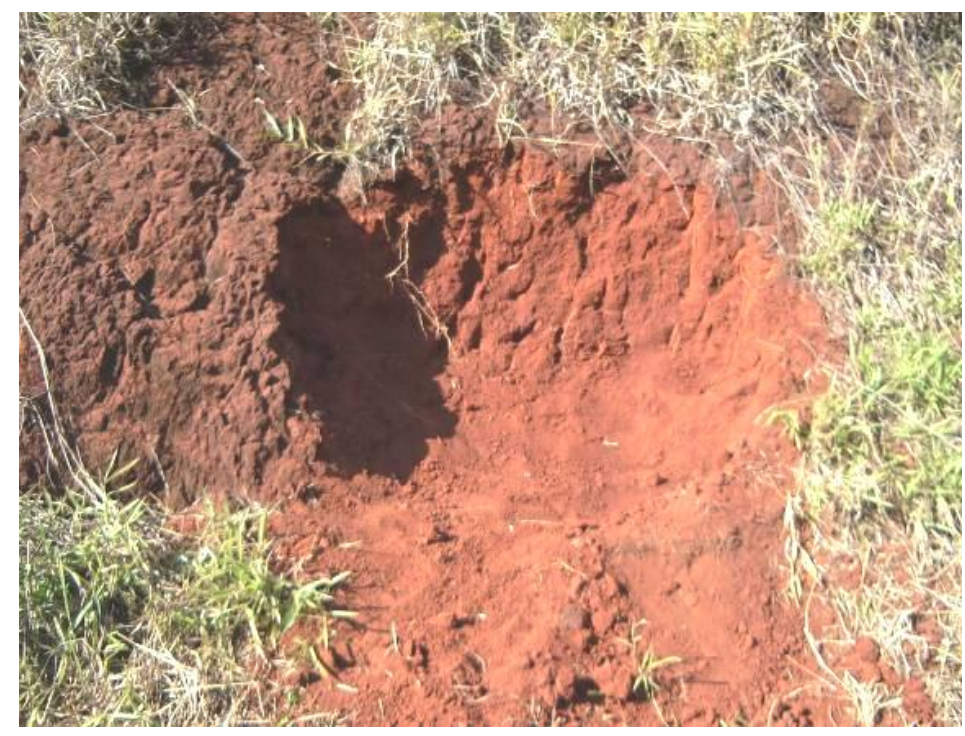

FIGURA 3.3. - Local de coleta do solo

Para caracterizar o material, Kakuda (2010) realizou os ensaios de Limites de Liquidez (ABNT NBR 6459) e Plasticidade (ABNT NBR 7180), Análise Granulométrica (ABNT NBR 7181), Massa Específica Aparente (ABNT NBR 6508) e Compactação (ABNT NBR 7182). Em seguida, o solo foi classificado segundo os procedimentos da S.U.C.S e HRB. Os resultados dos ensaios e das classificações estão apresentados na Tabela 3.1 e a Figura 3.4 ilustra a curva granulométrica do solo. 
TABELA 3.1. - Resultados da caracterização, classificação e compactação (Kakuda, 2010)

\begin{tabular}{|c|c|}
\hline Características e Propriedades & Resultados \\
\hline$\rho s\left(g / \mathrm{cm}^{3}\right)$ & 2,633 \\
\hline Limite de Liquidez (\%) & 34 \\
\hline Índice de Plasticidade (\%) & 13 \\
\hline \% Passante \#200 & 34 \\
\hline Areia (\%) & 66 \\
\hline Silte (\%) & 13 \\
\hline Argila (\%) & 22 \\
\hline Classificação HRB & $A-2-6$ \\
\hline Classificação S.U.C.S. & SC \\
\hline Wótm. (\%)* & 13,2 \\
\hline pdmáx. $\left(\mathrm{g} / \mathrm{cm}^{3}\right)^{*}$ & 1,901 \\
\hline Grau de Saturação (\%)* & 90,1 \\
\hline
\end{tabular}

*Parâmetros obtidos na energia normal de compactação

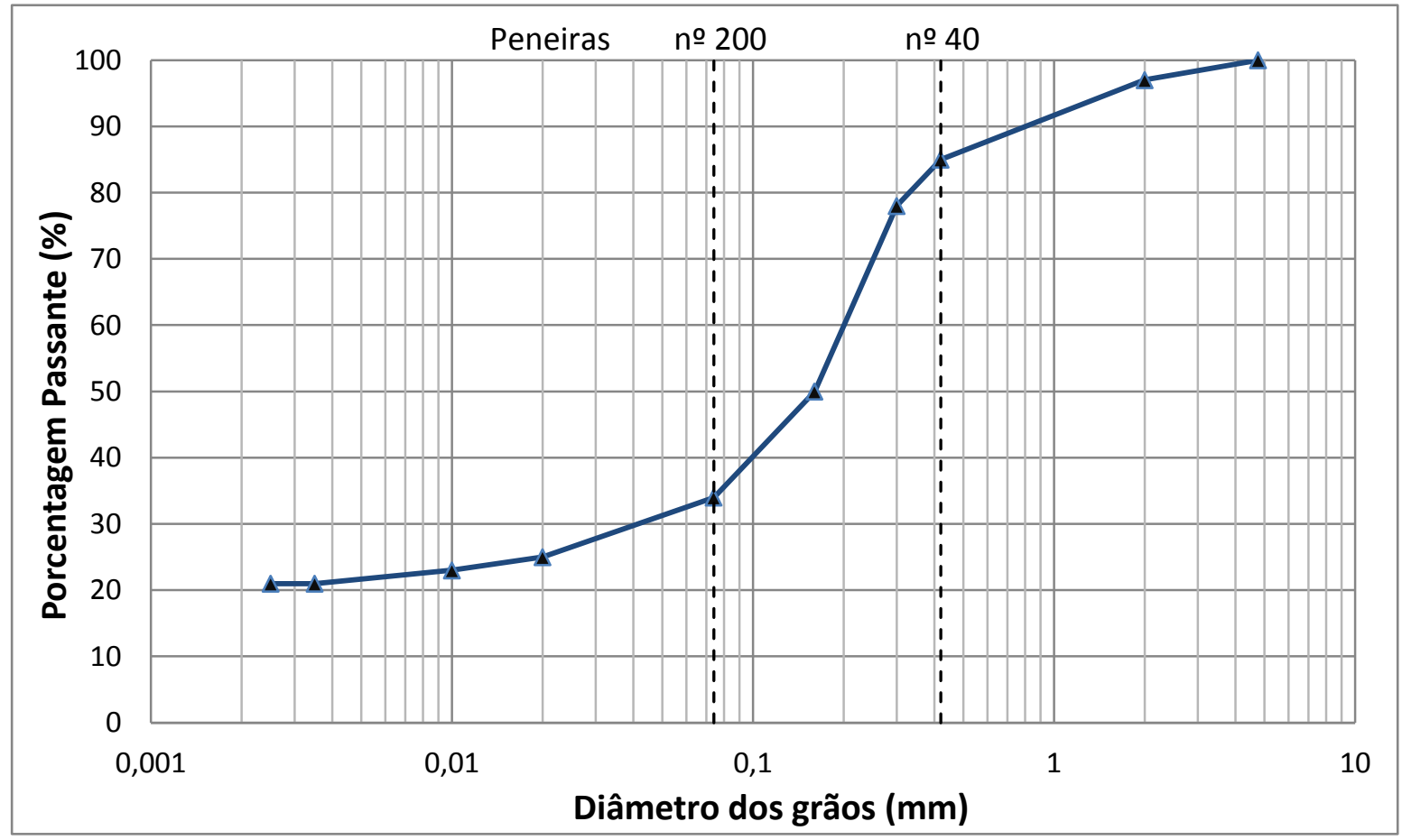

FIGURA 3.4. - Curva granulométrica do solo (adaptado de Kakuda, 2010)

Quanto à classificação do solo, foram ainda realizados os ensaios da Metodologia MCT, segundo os procedimentos descritos nas normas DNER ME 256/94, DNER CLA 259/96, DNER ME 258/94 e DNER ME 228/94. Os resultados destes ensaios estão apresentados na Tabela 3.2. 
TABELA 3.2. - Classificação do solo e resultados dos ensaios da metodologia MCT (Kakuda, 2010)

\begin{tabular}{cc}
\hline Características e Propriedades & Resultados \\
\hline Perda por Imersão (\%) & 122 \\
Coeficiente c' & 0,80 \\
Índice e' & 1,10 \\
Classificação & LA' $^{\prime}$ \\
\hline
\end{tabular}

\subsection{MISTURAS}

\subsubsection{Agregado Reciclado de Concreto}

Conforme apresentado no Capítulo 2, Revisão Bibliográfica, item 2.6.1, não existem recomendações quanto a faixas granulométricas a serem observadas para a composição de misturas de agregados reciclados. Optou-se então por utilizar como alvo uma mistura cuja granulometria se inserisse nos limites da faixa $\mathrm{C}$ da norma DNER ES 303/97, como proposto por Grubba (2009).

Segundo este critério, a composição final escolhida por Grubba (2009) após uma série de tentativas foi $30 \%$ de brita $1,30 \%$ de pedrisco e $40 \%$ de areia, quantidades consideradas em massa. A Tabela 3.3 apresenta a distribuição granulométrica do agregado reciclado resultante e os limites da faixa $\mathrm{C}$ e a Figura 3.5 ilustra a curva granulométrica do ARC e os limites da faixa C. Analisando-se a Tabela 3.3 e a Figura 3.5, observa-se que o ARC tem uma curva granulométrica situada na faixa $\mathrm{C}$, a menos da parcela mais fina, peneira $0,074 \mathrm{~mm}$, onde a quantidade, $2 \%$, é menor que o limite inferior de $5 \%$. 
TABELA 3.3. - Distribuição granulométrica da mistura de ARC

\begin{tabular}{cccc}
\hline Peneiras (mm) & \multicolumn{3}{c}{ Porcentagem Passante (\%) } \\
& $\begin{array}{c}\text { Agregado } \\
\text { Reciclado }\end{array}$ & $\begin{array}{c}\text { Limites Faixa C } \\
\text { Inferior }\end{array}$ & Superior \\
\hline 25,00 & 100 & 100 & 100 \\
9,53 & 75 & 50 & 85 \\
4,76 & 52 & 35 & 65 \\
2,00 & 41 & 25 & 50 \\
0,42 & 18 & 15 & 31 \\
0,074 & 2 & 5 & 15 \\
\hline
\end{tabular}

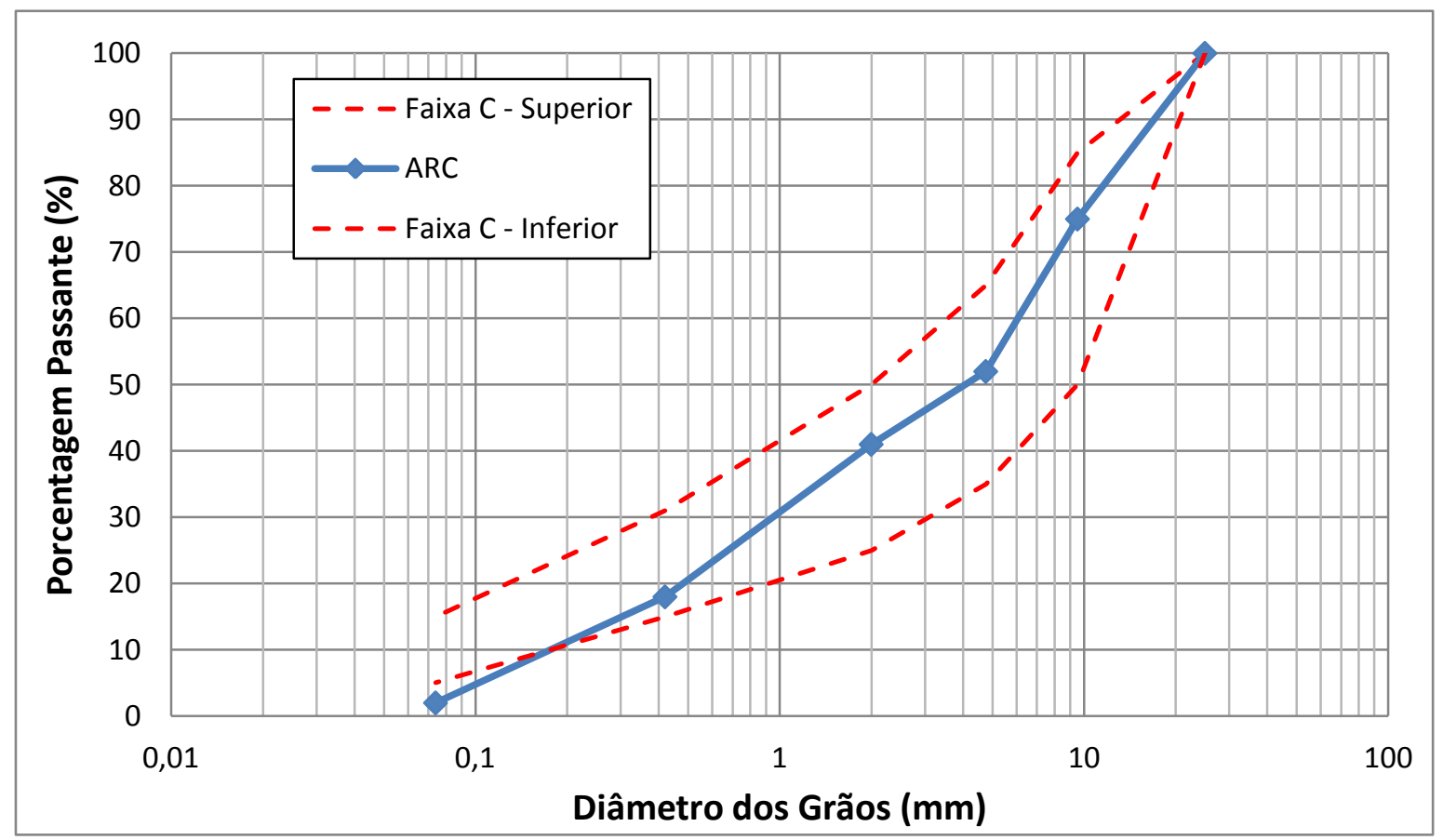

FIGURA 3.5. - Distribuição granulométrica da mistura de ARC e os limites da faixa C do DNER (Grubba, 2009)

A Tabela 3.4 apresenta os valores limites recomendados pela norma NBR 15115 - "Agregados Reciclados de Resíduos Sólidos da Construção Civil Execução de Camadas de Pavimentação - Procedimentos" e os correspondentes valores calculados a partir da curva granulométrica obtida conforme descrito anteriormente. Analisando-se a Tabela 3.4, observa-se que o ARC estudado atende às recomendações da norma. 
TABELA 3.4. - Parâmetros obtidos da distribuição granulométrica do ARC e limites recomendados pela norma NBR 15115

\begin{tabular}{ccc}
\hline Parâmetro & Limites NBR 15115 & ARC estudado \\
\hline Dimensão máxima característica $(\mathrm{mm})$ & 63,5 & 25 \\
Porcentagem passante na peneira 0,42 $\mathrm{mm}(\%)$ & $10-40$ & 18 \\
Coeficiente de uniformidade & $\geq 10$ & 33 \\
\hline
\end{tabular}

\subsubsection{Mistura Solo - Agregado Reciclado de Concreto}

Para a composição da mistura 'solo - agregado reciclado de concreto' (solo - ARC), foram escolhidas as quantidades em massa de $70 \%$ de agregado reciclado na fração brita 1 e $30 \%$ de solo. A Figura 3.6 apresenta a curva granulométrica da mistura solo - ARC e dos materiais que a compõe.

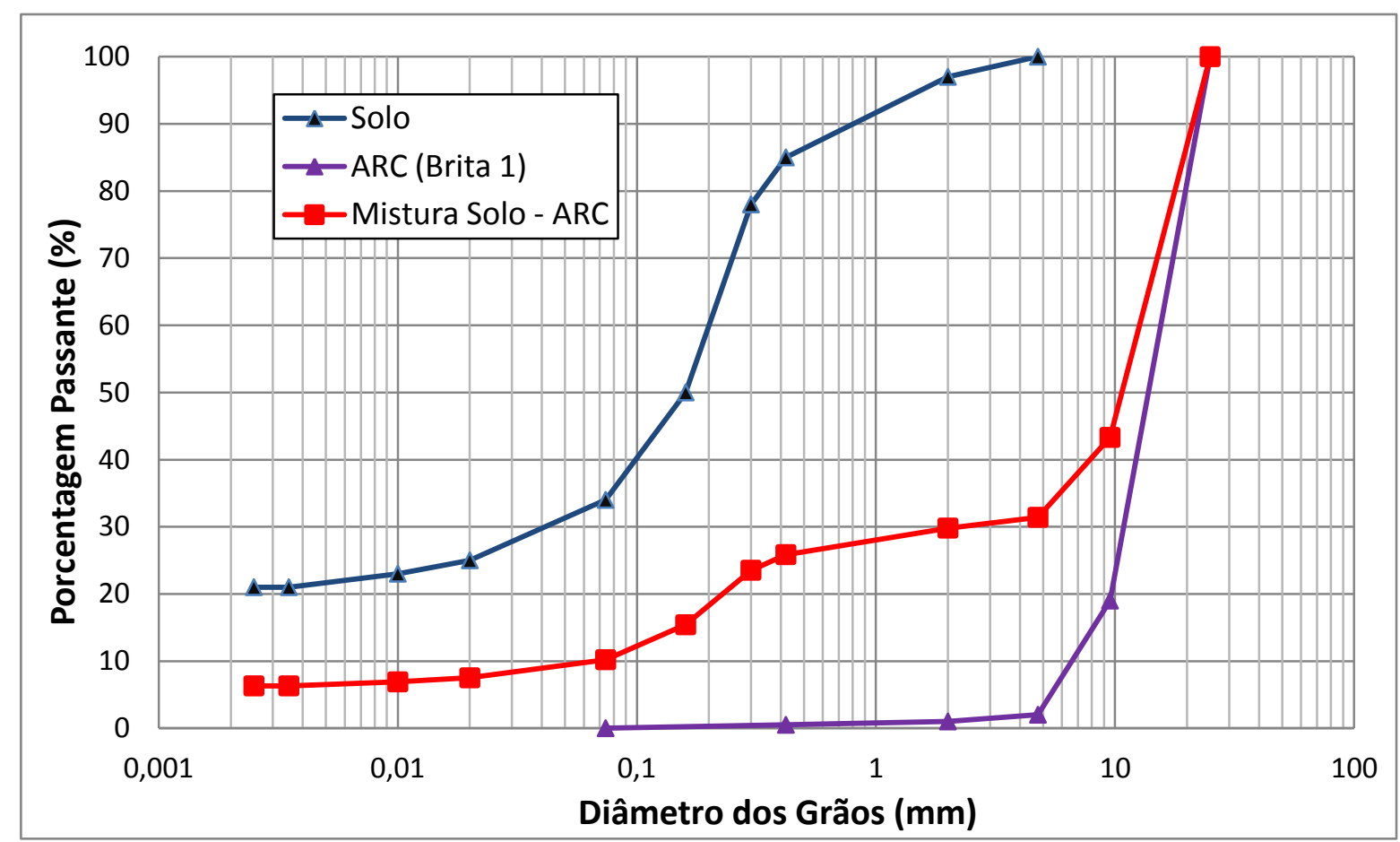

FIGURA 3.6. - Curva granulométrica da mistura solo - ARC e de seus materiais constituintes

Como não existem recomendações no tocante à composição de misturas solo - ARC, esta mistura foi analisada segundo as recomendações de Nogami e Villibor 
(1995) para bases de solo arenoso laterítico - brita descontínua, conforme apresentado na Tabela 3.5.

TABELA 3.5. - Recomendações de Nogami e Villibor (1995) e parâmetros da mistura solo - ARC

\begin{tabular}{clcc}
\hline & \multicolumn{2}{c}{ Recomendações de Nogami e Villibor (1995) } & $\begin{array}{c}\text { Mistura Solo - } \\
\text { ARC }\end{array}$ \\
\hline Solo & Classificação MCT & LA, LA' ou LG' & LA' $^{\prime}$ \\
\hline \multirow{4}{*}{ Agregado } & Granulometria & descontínua & descontínua \\
& Passa na \# 25mm & $100 \%$ & $100 \%$ \\
& Tipo da composição & bica corrida ou Brita 1 e pedrisco & Brita 1 \\
& Abrasão Los Angeles & $\leq 30 \%$ & $34 \%$ \\
\hline \multirow{2}{*}{ Mistura } & \% agregado (em massa) & $\geq 50 \%$ & $70 \%$ \\
& Granulometria & descontínua & descontínua \\
& CBR & $80 \%-$ Intermediária & $228 \%$ \\
& Expansão & $\leq 0,2 \%$ & $0 \%$ \\
\hline
\end{tabular}

Analisando-se a Tabela 3.5, observa-se que o solo utilizado, LA', atendeu a recomendação. No tocante ao agregado, os requisitos relacionados à granulometria foram atendidos, sendo que a perda na abrasão Los Angeles excede em 4\% ao recomendado. Quanto à mistura, todos os requisitos foram atendidos, destacandose porém, que os valores de CBR e de expansão obtidos para este material sem cura, respectivamente, $228 \%$ e $0 \%$, conforme apresentado no Apêndice 1, correspondem a uma mistura compactada na energia modificada do ensaio Proctor, ao invés do recomendado por Nogami e Villibor (1995), que especifica a energia intermediária. No entanto, nesta mesma bibliografia, onde é recomendado os parâmetros para construção de bases de solo laterítico - brita descontínua, é citado inúmeros exemplos de trechos de rodovias bem sucedidas construídas com estes materiais compactados na energia Proctor modificada, diferentemente da energia Proctor intermediária a qual foi recomendada. 


\subsection{ESCOLHA DA ENERGIA DE COMPACTAÇÃO}

Como citado anteriormente, no Capítulo 2, Revisão Bibliográfica, item 2.6.5, segundo estudos realizados por Grubba (2009), existe uma melhoria no comportamento mecânico do agregado reciclado de concreto ao longo do tempo de cura devido ao efeito da cimentação, e este efeito é maior nas misturas compactadas na energia intermediária, sendo que após 90 dias de cura, corpos-deprova moldados nesta energia apresentam resistência à compressão simples superior à resistência de corpos-de-prova moldados na energia modificada. Esta constatação motivou a escolha da energia intermediária para a compactação do ARC neste estudo.

Complementarmente, foi também estudada a mistura solo - ARC. Neste caso, como é comum utilizar-se a energia modificada para a compactação de misturas solo - agregado, a exemplo de obras realizadas no Estado de São Paulo, tais como: Contorno do Sul - Ribeirão Preto, Ribeirão Preto - Dumont, Ribeirão Preto Batatais, Ribeirão Preto - Sertãozinho, ligação SP-255 a SP-257, Sales de Oliveira Batatais, etc., citadas por Nogami e Villibor (1995), escolheu-se a energia modificada para a compactação da mistura.

\subsection{MOLDAGEM E CURA DOS CORPOS-DE-PROVA}

As dimensões dos corpos-de-prova utilizados nos ensaios mecânicos, $10 \mathrm{~cm}$ de diâmetro e $20 \mathrm{~cm}$ de altura foram escolhidas observando-se a norma DNER 131/94, que preconiza que a altura deve ser no mínimo duas vezes o diâmetro, e o diâmetro maior ou igual a quatro vezes o diâmetro dos grãos, sendo que para esta última 
condição ser atendida foi necessário limitar-se o diâmetro máximo dos agregados utilizados em $25 \mathrm{~mm}$.

Os corpos-de-prova foram moldados estaticamente, em cinco camadas, no teor de umidade ótimo $\left(W_{0}\right)$ e massa específica seca máxima $\left(\rho_{d m a x}\right)$, determinados nos ensaios de compactação e apresentados no Anexo I e Apêndice II, respectivamente para o ARC e para a mistura solo - ARC. A prensa hidráulica e os cilindros utilizados na moldagem dos corpos-de-prova estão apresentados nas Figuras 3.7 e 3.8, respectivamente.

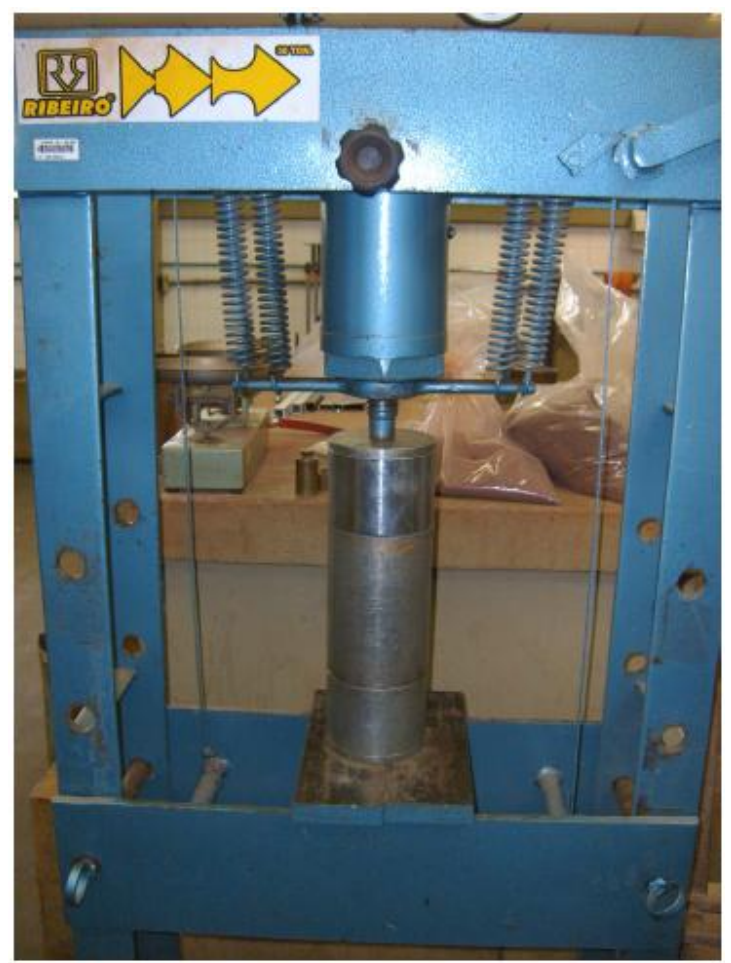

FIGURA 3.7. - Prensa empregada na moldagem dos corpos-de-prova

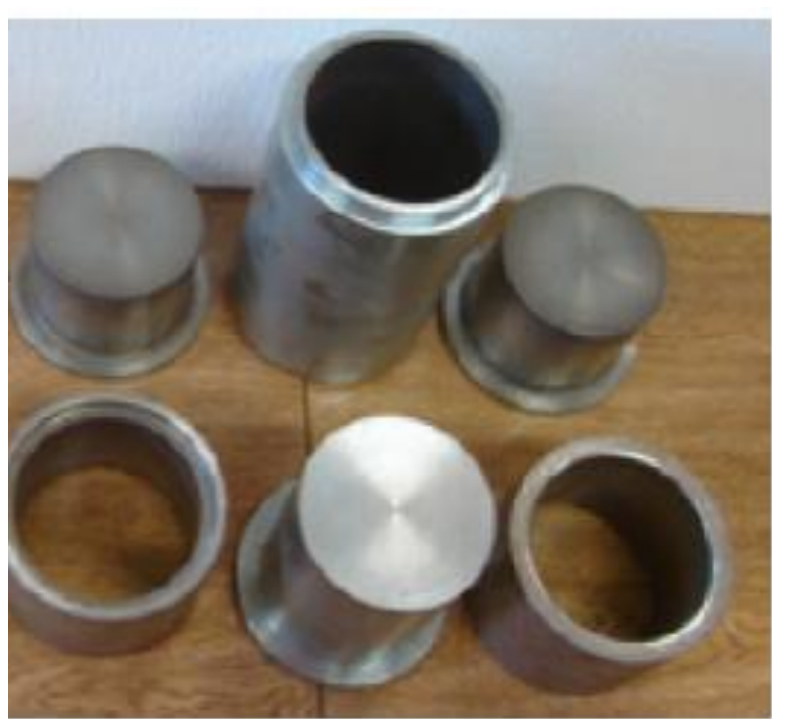

FIGURA 3.8. - Cilindros utilizados na moldagem dos corpos-de-prova

Para a desmoldagem dos corpos-de-prova, utilizou-se um macaco hidráulico conforme ilustra a Figura 3.9. Em seguida, os corpos-de-prova eram embalados com 
filme plástico, vide Figura 3.10, e armazenados em câmara úmida para a cura até o momento do ensaio.

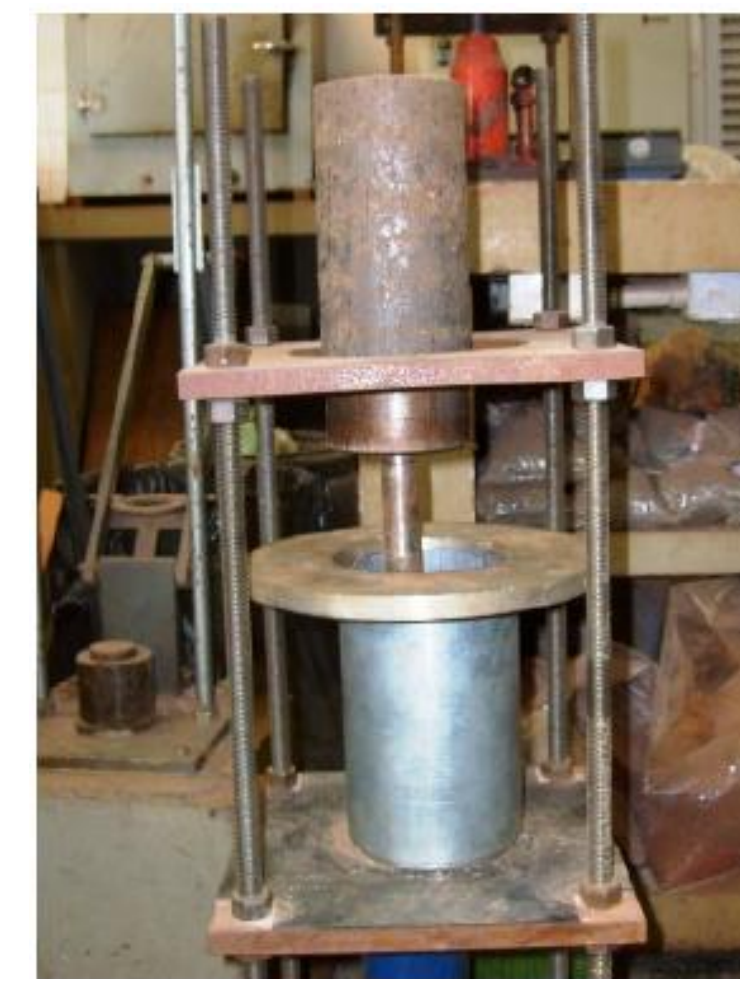

FIGURA 3.9. - Desmoldagem dos corpos-de-prova

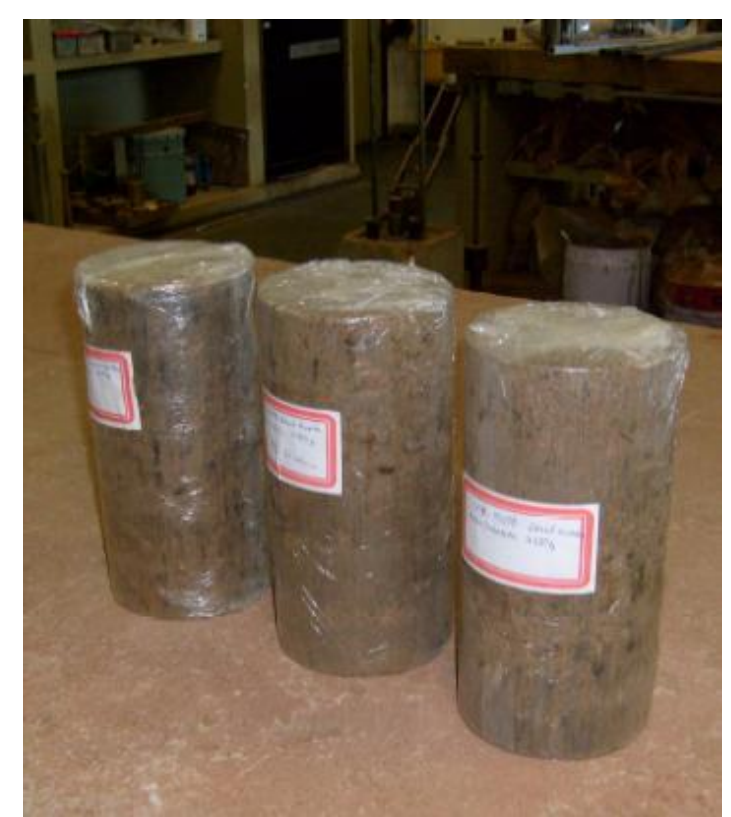

FIGURA 3.10. - Selagem dos corposde-prova

\subsection{ENSAIOS MECÂNICOS E CBR}

Para a análise do comportamento mecânico dos materiais estudados, foram realizados ensaios de compressão simples e triaxiais cíclicos. Complementarmente, foram também realizados ensaios CBR (California Bearing Ratio). Os ensaios foram realizados segundo tempos de cura variados.

\subsubsection{Compressão Simples}

Os ensaios de compressão simples foram realizados adotando-se as recomendações da norma DNER-ME 201/94 (1994) para misturas solo - cimento. Destaca-se que a velocidade de aplicação do carregamento é de $1,27 \mathrm{~mm} / \mathrm{min}$., 
coincidente com a velocidade utilizada no ensaio CBR. O ensaio foi realizado numa prensa convencional de deformação controlada, conforme ilustra a Figura 3.11, dotada de transdutores para a medida da força axial aplicada e respectivos deslocamentos, os quais foram monitorados com um sistema automático de aquisição de dados.

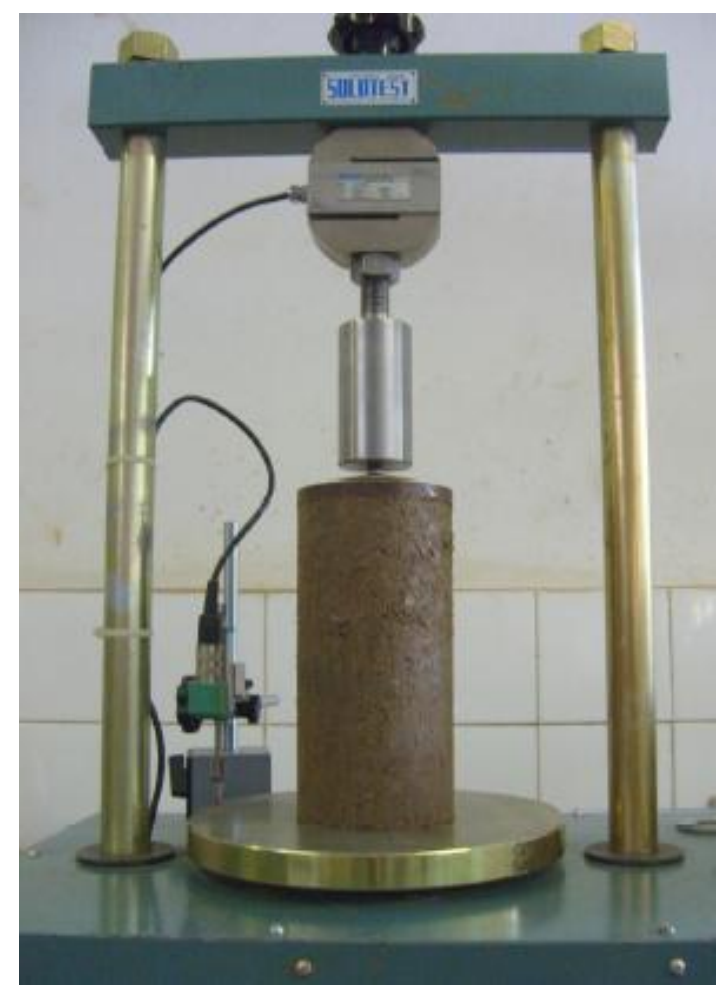

FIGURA 3.11. - Prensa utilizada no ensaio de Compressão Simples

A partir dos resultados dos ensaios de compressão simples, determinaram-se a tensão na ruptura e módulo tangente a $50 \%$ desta mesma tensão, conforme ilustra a Figura 3.12. 


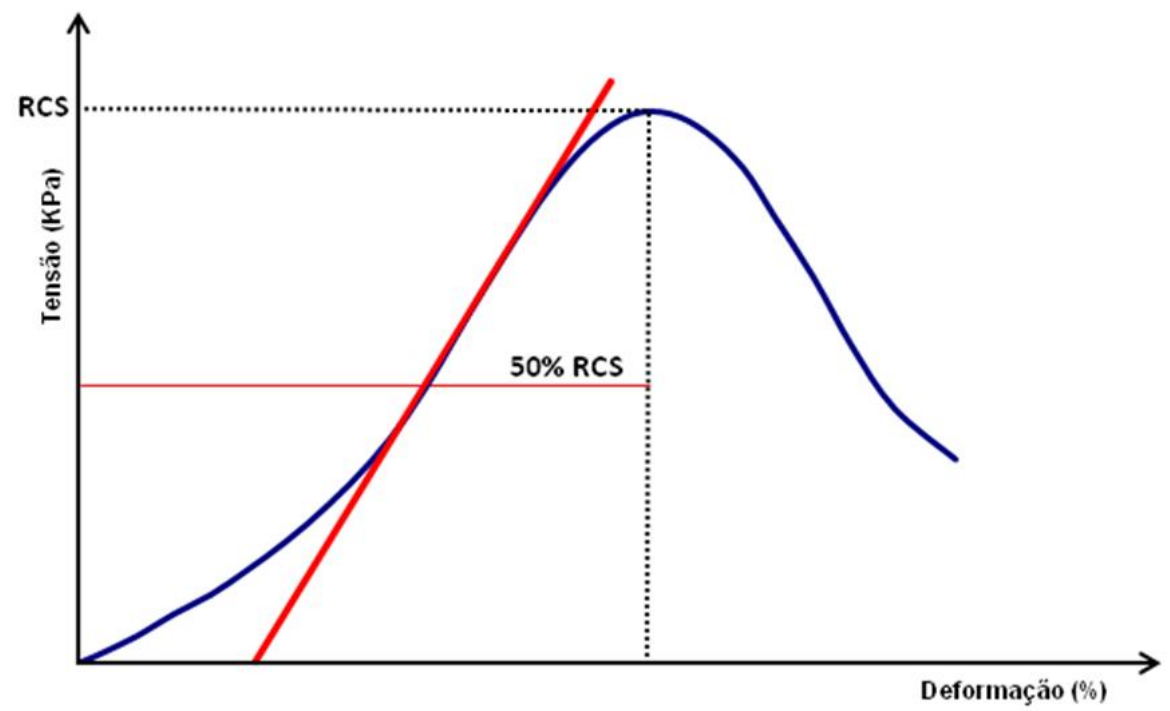

FIGURA 3.12. - Esquema para determinação do módulo tangente a $50 \%$ da tensão de ruptura (Grubba, 2009)

Além dos corpos-de-prova preparados especialmente para a execução dos ensaios de compressão simples, foram também ensaiados corpos-de-prova anteriormente submetidos aos ensaios triaxiais cíclicos. Neste caso, conforme será detalhado no item 4.1.2, foram ensaiados corpos-de-prova usados anteriormente na determinação do módulo de resiliência e corpos-de-prova utilizados no estudo da deformação permanente. A Tabela 3.6 apresenta o programa experimental observado para a realização do ensaio de compressão simples, destacando os materiais ensaiados, tempos de cura, tipos de corpos-de-prova utilizados e número de réplicas.

TABELA 3.6. - Programa experimental do ensaio de Compressão Simples

\begin{tabular}{ccccc}
\hline Mistura & $\begin{array}{c}\text { Tempo de } \\
\text { cura (dias) }\end{array}$ & \multicolumn{3}{c}{ Número de Réplicas } \\
& CS & MR $\rightarrow$ CS & DP $\rightarrow$ CS \\
\hline \multirow{4}{*}{ ARC } & $\mathbf{0}$ & 3 & 2 & 2 \\
& $\mathbf{3}$ & 3 & 2 & - \\
& $\mathbf{7}$ & 3 & 2 & 2 \\
& $\mathbf{2 8}$ & 3 & 2 & 2 \\
& 90 & 3 & 2 & 2 \\
\hline
\end{tabular}




\begin{tabular}{lcccc}
\hline & 180 & 3 & 2 & 2 \\
\hline \multirow{3}{*}{ ARC + Solo } & 0 & 2 & - & - \\
& 7 & 2 & - & - \\
& $\mathbf{2 8}$ & 3 & - & - \\
\hline
\end{tabular}

*Tipo de corpo-de-prova utilizado: CS - cp preparado para o ensaio de compressão simples; MR - $\mathrm{cp}$ utilizado anteriormente para determinação do módulo de resiliência; DP - $\mathrm{cp}$ utilizado anteriormente no estudo da deformação permanente.

\subsubsection{Ensaio Triaxial Cíclico - Módulo de Resiliência}

O módulo de resiliência foi determinado de acordo com o especificado pela norma "Standard Method of Test Determining the Resiliente Modulus of Soils and Aggregate Materials" (AASHTO Designation: T307-99). Esta norma contempla procedimentos de preparação e ensaio de solos de subleito e materiais de base e sub-base não tratados. As cargas aplicadas aos corpos-de-prova reproduzem estados de tensões a que são submetidos os materiais de diferentes localizações da estrutura dos pavimentos flexíveis quando sujeitos ao carregamento dos veículos.

A seqüência de tensões, preconizada por esta norma para materiais de base e sub-base, está apresentada na Tabela 3.7. A freqüência de aplicação de carga é de $1 \mathrm{~Hz}$.

TABELA 3.7. - Tensões empregadas no ensaio triaxial cíclico (AASHTO T 307 99)

\begin{tabular}{cccccc}
\hline $\begin{array}{c}\text { Sequência } \\
\boldsymbol{n} \boldsymbol{0}\end{array}$ & $\begin{array}{c}\text { Tensão } \\
\text { Confinante } \\
\boldsymbol{\sigma 3}(\mathbf{k P a})\end{array}$ & $\begin{array}{c}\text { Tensão } \\
\text { Máxima } \\
\boldsymbol{\sigma a}(\mathbf{k P a})\end{array}$ & $\begin{array}{c}\text { Tensão de } \\
\text { Contato } \boldsymbol{\sigma c} \\
(\mathbf{k P a})\end{array}$ & $\begin{array}{c}\text { Tensão } \\
\text { Desvio } \sigma d \\
(\mathbf{k P a})\end{array}$ & $\begin{array}{c}\text { Número de } \\
\text { Aplicações de } \\
\text { Carga }\end{array}$ \\
\hline 0 & 103,4 & 103,4 & 10,3 & 93,1 & $500-1000$ \\
1 & 20,7 & 20,7 & 2,1 & 78,6 & 100 \\
2 & 20,7 & 41,4 & 4,1 & 37,3 & 100 \\
3 & 20,7 & 62,1 & 6,2 & 55,9 & 100 \\
4 & 34,5 & 34,5 & 3,5 & 31,0 & 100 \\
5 & 34,5 & 68,9 & 6,9 & 62,0 & 100 \\
6 & 34,5 & 103,4 & 10,3 & 93,1 & 100 \\
7 & 68,9 & 68,9 & 6,9 & 62,0 & 100 \\
\hline
\end{tabular}




\begin{tabular}{cccccc}
\hline 8 & 68,9 & 137,9 & 13,8 & 124,1 & 100 \\
9 & 68,9 & 206,8 & 20,7 & 186,1 & 100 \\
10 & 103,4 & 68,9 & 6,9 & 62,0 & 100 \\
11 & 103,4 & 103,4 & 10,3 & 93,1 & 100 \\
12 & 103,4 & 206,8 & 20,7 & 196,1 & 100 \\
13 & 137,9 & 103,4 & 10,3 & 93,1 & 100 \\
14 & 137,9 & 137,9 & 13,8 & 124,1 & 100 \\
15 & 137,9 & 275,8 & 27,6 & 248,2 & 100 \\
\hline
\end{tabular}

Este ensaio foi realizado no equipamento triaxial cíclico do Laboratório de Estradas da EESC/USP, o qual possui um sistema de carregamento pneumático, onde a tensão desvio e as tensões confinantes são controladas por computador e os deslocamentos são medidos por um par de LVDTs. Na Figura 3.13 está apresentado este equipamento.

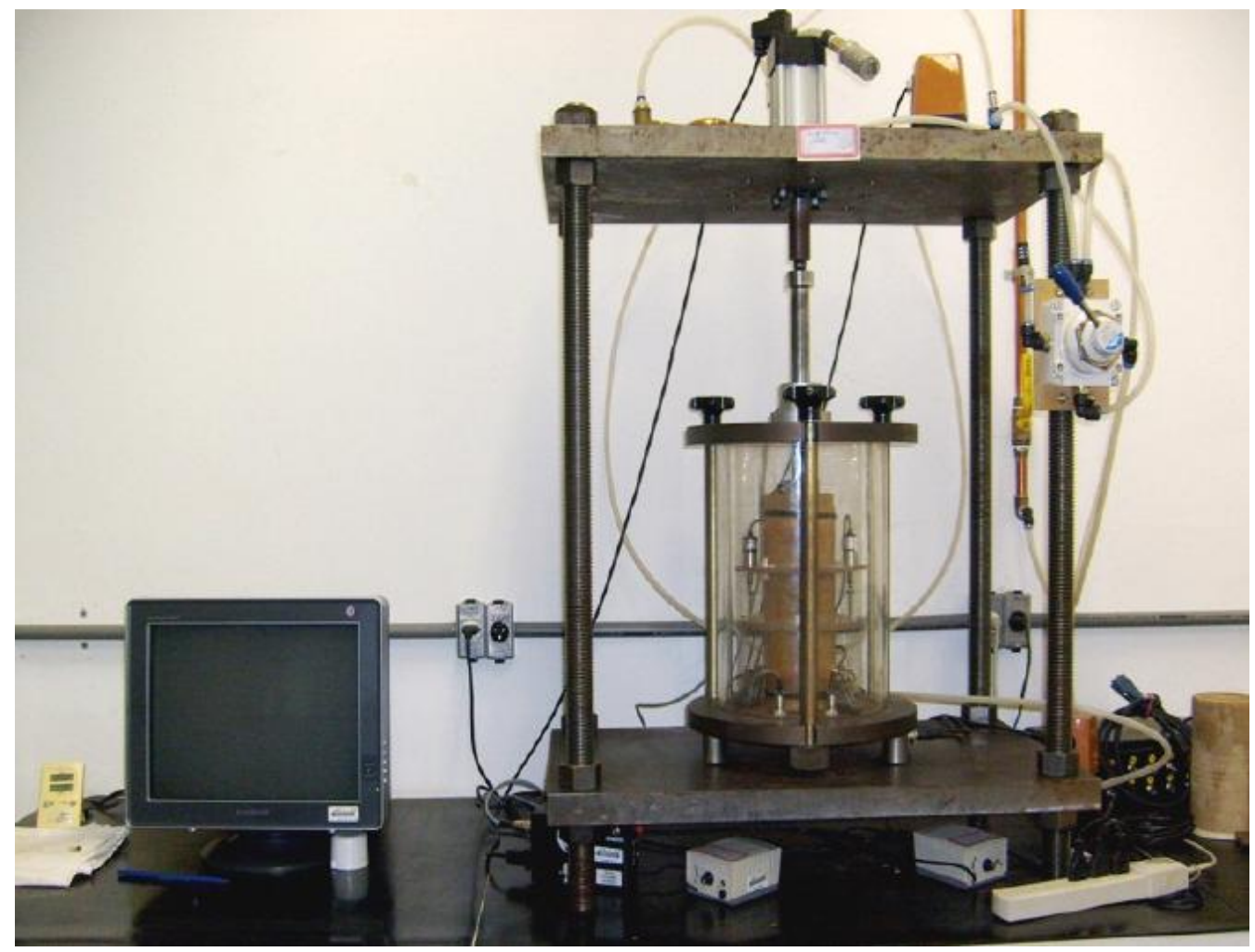

FIGURA 3.13. - Equipamento triaxial

Os resultados dos ensaios são coletados, armazenados e tratados por um programa desenvolvido em Plataforma LabView pelo Prof. Glauco Tulio Pessa 
Fabbri. O deslocamento resiliente de cada ciclo é obtido pela média dos deslocamentos registrados pelo par de LVDTs. A Figura 3.14 apresenta uma tela do programa na fase de controle e aquisição dos dados durante a realização do ensaio.

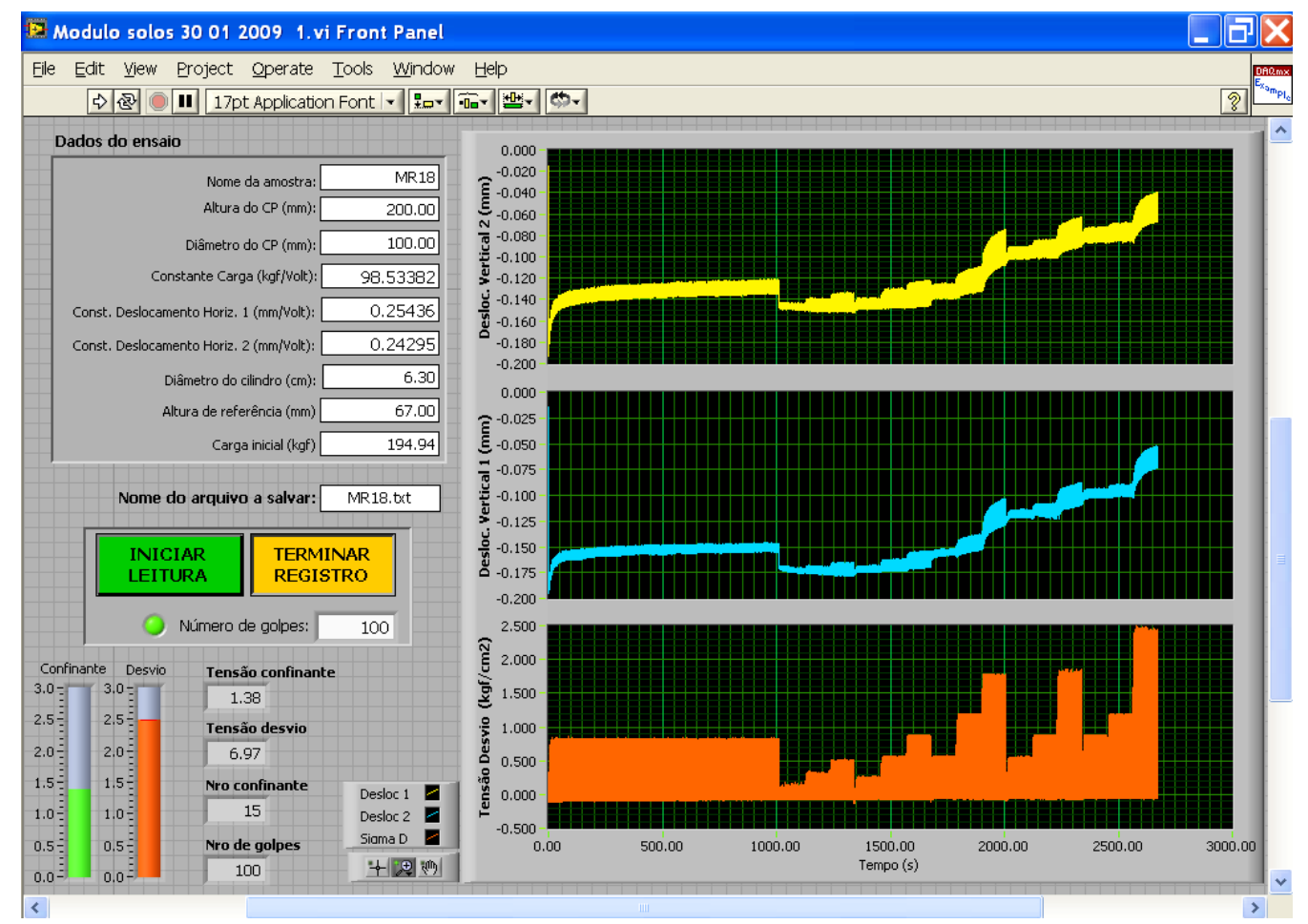

FIGURA 3.14. - Tela principal do programa na fase de controle e aquisição dos dados durante o ensaio triaxial

Na realização dos ensaios triaxiais cíclicos para obtenção do módulo de resiliência, considerou-se 2 corpos-de-prova por condição de ensaio, sendo que o programa experimental contemplou corpos-de-prova curados por $0,7,28,90$ e 180 dias.

\subsubsection{Ensaio Triaxial Cíclico - Deformação Permanente}

Não existem normas que estabeleçam procedimentos para o ensaio de materiais com vistas à determinação de deformações permanentes observadas ao longo de carregamentos repetidos. Na presente pesquisa, para o estudo dos materiais sob este aspecto, procurou-se utilizar o mesmo equipamento e as mesmas condições do 
ensaio triaxial cíclico, restringindo-se o número de pares de tensões considerados, conforme será discutido à frente. Nestes ensaios, a cada ciclo de carga, além da deformação elástica, era também determinada a deformação não recuperável ou permanente.

As deformações permanentes foram consideradas a partir da primeira aplicação do carregamento, dispensando-se a etapa de condicionamento prevista para a obtenção do MR. O programa em Plataforma LabView usado para o controle do ensaio, aquisição e tratamento de dados foi adaptado pelo Prof. Glauco Tulio Pessa Fabbri a partir do programa originalmente desenvolvido para os ensaios de módulo de resiliência. A Figura 3.15 ilustra a tela do programa durante um ensaio.

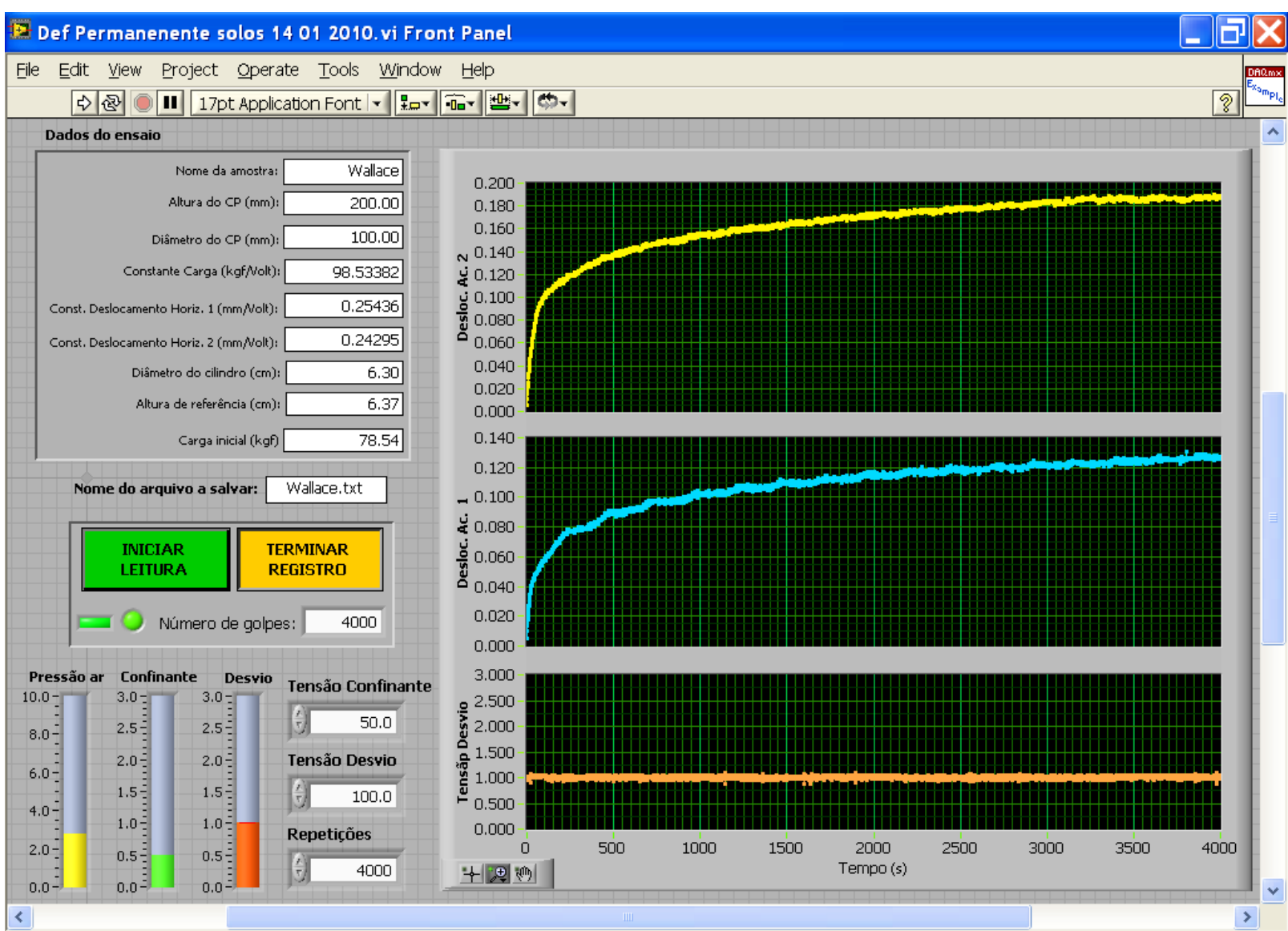

FIGURA 3.15. - Tela principal do programa de aquisição de dados e controle do ensaio de deformação permanente 
Nos ensaios de deformação permanente, utilizou-se a mesma freqüência de carregamento preconizada para a determinação do módulo de resiliência, ou seja, 1 HZ e um número máximo de 100.000 aplicações. O número máximo de aplicações foi escolhido tendo em vista o tempo demandado para cada ensaio e ser este o valor adotado em outras pesquisas, tais como: Guimarães (2001), Fernandes (2004), Leite (2007), Thuler (2005), Bennert (2000), etc.

Ao contrário do ensaio de módulo de resiliência, no ensaio triaxial cíclico para a determinação da deformação permanente é necessário utilizar-se um corpo-deprova por estado de tensão aplicado. Com isso, se todos os estados de tensão considerados no ensaio de módulo de resiliência fossem utilizados para realização dos ensaios de deformação permanente, seria necessário ensaiar-se um grande número de corpos-de-prova, tarefa inexeqüível no âmbito desta pesquisa. Assim, procurou-se limitar em três os estados de tensões analisados, sendo eles escolhidos entre os estados de tensões empregados pela AASHTO T 307 - 99 no ensaio triaxial cíclico para determinação do Módulo de Resiliência.

Para a escolha dos pares de tensões, levou-se em conta principalmente 0 estudo da influência dessa variável sobre a deformação permanente do ARC, desta maneira escolheu-se pares de tensões com significativa diferença entre si, a fim de evidenciar claramente a intensidade ou o efeito da variação de tensão. Os pares de tensões escolhidos estão apresentados na Tabela 3.8. 
TABELA 3.8. - Estados de tensão utilizados para realização dos ensaios triaxiais cíclicos para determinação da deformação permanente em função das aplicações de carga

\begin{tabular}{ccc}
\hline $\begin{array}{c}\text { Estados de } \\
\text { Tensão }\end{array}$ & $\sigma_{\mathrm{c}}(\mathrm{kPa})$ & $\sigma_{\mathrm{d}}(\mathrm{kPa})$ \\
\hline E1 & 34,5 & 93,1 \\
$\mathrm{E} 2$ & 68,9 & 186,1 \\
$\mathrm{E} 3$ & 137,9 & 248,2 \\
\hline
\end{tabular}

$\mathrm{Na}$ realização dos ensaios triaxiais cíclicos para obtenção da deformação permanente, considerou-se 2 réplicas por condição de ensaio. O programa experimental contemplou corpos-de-prova com tempos de cura de $0,7,28,90$ e 180 dias, ensaiados com o par de tensões E2, apresentado na Tabela 3.8. Para análise da influência do estado de tensão sobre a deformação permanente, ainda ensaiouse corpos-de-prova com 28 dias de cura utilizando os pares de tensões E1 e E3.

\subsubsection{CBR}

Complementarmente aos ensaios mecânicos, realizaram-se ensaios de Índice de Suporte Califórnia. Este parâmetro é amplamente utilizado no Brasil para o dimensionamento de pavimentos, e a norma NBR 15115 (2004) estabelece o valor do índice de suporte CBR como um dos valores a serem considerados para o uso do ARC na construção de pavimentos.

O ensaio será realizado segundo o especificado pela norma DNER-ME 049/94. Este ensaio consiste em aplicar um carregamento estático ao corpo-deprova, após a imersão deste em água por quatro dias. O CBR é calculado pela relação entre a força necessária a penetração de um pistão padronizado no corpode-prova e a pressão necessária à penetração deste mesmo pistão a uma brita graduada padrão. 
Nas Figuras 3.16, 3.17 e 3.18 estão apresentadas algumas etapas do ensaio CBR, tais como, a compactação do corpo-de-prova, seguida pela imersão por 4 dias e penetração do pistão de diâmetro padronizado.

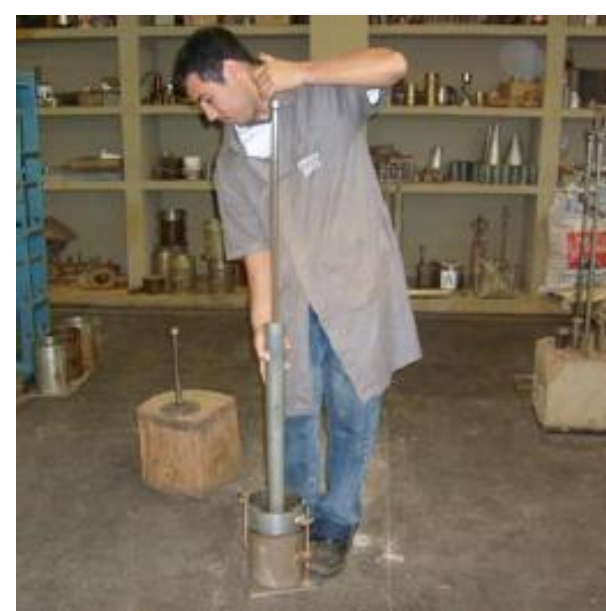

FIGURA 3.16. - Compactação do corpo-de-prova (Grubba, 2009)

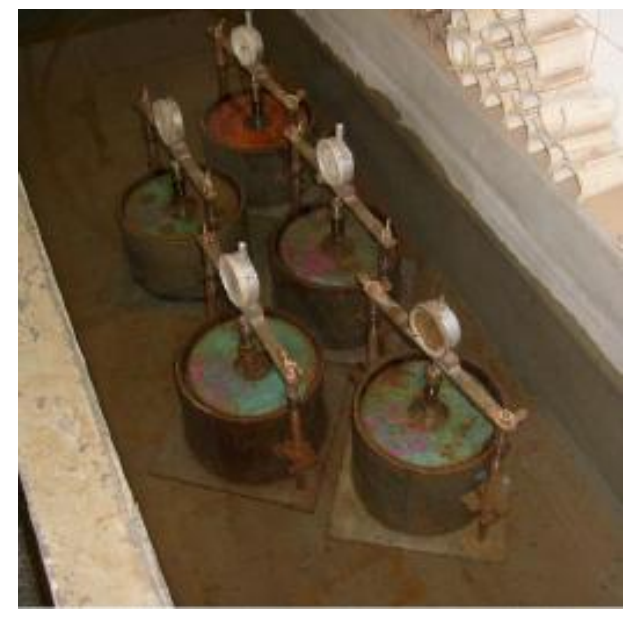

FIGURA 3.17. - Imersão por 4 dias

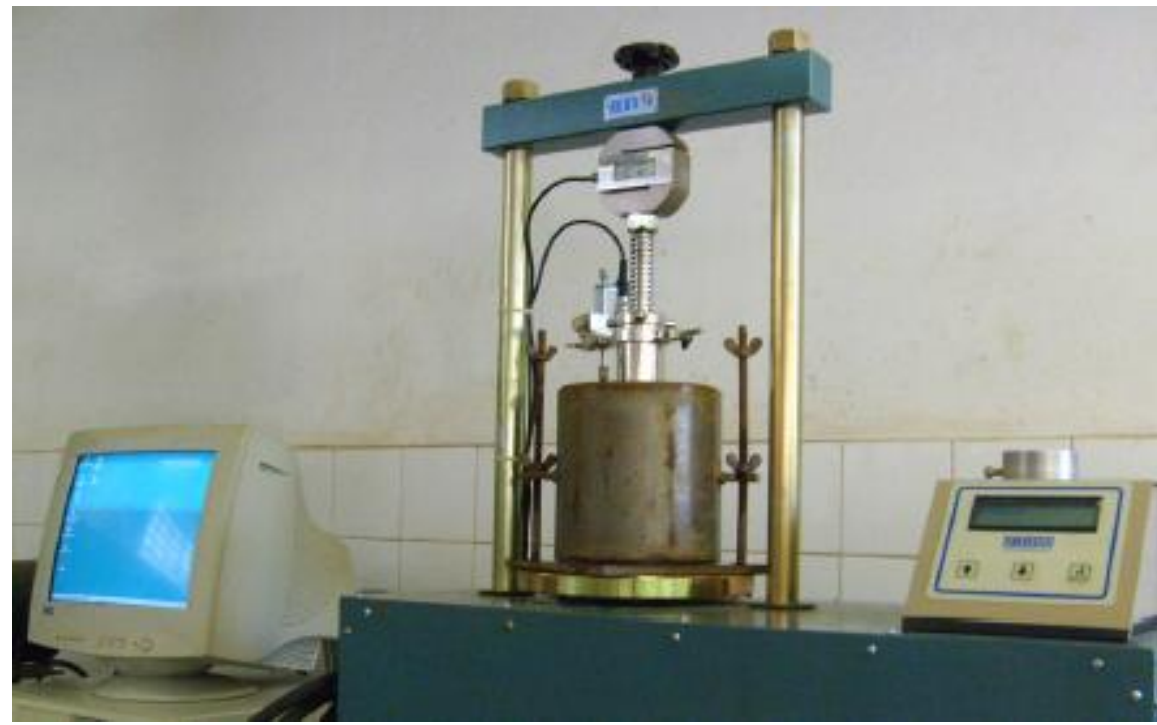

FIGURA 3.18. - Penetração do pistão padronizado na prensa automática 


\subsection{ANÁLISE DOS RESULTADOS}

Nesta pesquisa foram estudadas as propriedades mecânicas do agregado reciclado de concreto, visando o seu emprego em camadas de base e sub-bases de pavimentos. No estudo, foram analisadas:

- A influência do tempo de cura na resistência à compressão simples, módulo tangente, módulo de resiliência, índice de suporte Califórnia e deformação permanente do ARC e da mistura de Solo - ARC.

- A variação da deformação permanente do ARC em função do carregamento aplicado;

- A variação da resistência à compressão simples do ARC após a ação dos carregamentos aplicados nos ensaios de módulo de resiliência e deformação permanente;

- A análise do módulo de resiliência antes e durante o ensaio de deformação permanente. 


\section{APRESENTAÇÃO E DISCUSSÃO DOS RESULTADOS}

Neste capítulo são apresentados e analisados os resultados dos ensaios de resistência à compressão simples, triaxiais cíclicos, no tocante ao módulo de resiliência e à deformação permanente, e índice de suporte Califórnia dos materiais estudados nesta pesquisa.

\subsection{AGREGADO RECICLADO DE CONCRETO}

\subsubsection{Resistência à compressão simples}

A Tabela 4.1 apresenta os valores médios de resistência à compressão simples (RCS) dos corpos-de-prova de ARC submetidos ao ensaio de compressão simples na condição ótima do Proctor na energia intermediária e ensaiados com tempos de cura de $0,3,7,28,90$ e 180 dias. Todos os resultados, com exceção dos que apresentaram erros durante a execução, estão apresentados no Apêndice I. Os valores encontrados na Tabela 4.1 estão ilustrados graficamente na Figura 4.1.

TABELA 4.1. - Resultados de RCS dos corpos-de-prova de ARC ensaiados com diversos tempos de cura e percentual e gradiente de ganho de resistência

\begin{tabular}{cccc}
\hline $\begin{array}{c}\text { Tempo de } \\
\text { Cura (dias) }\end{array}$ & $\boldsymbol{R C S}(\boldsymbol{k P a})$ & $\begin{array}{c}\text { Ganho de } \\
\boldsymbol{R C S}(\%)\end{array}$ & $\begin{array}{c}\text { Ganho de } \\
\boldsymbol{R C S} / \text { dia } \\
(\boldsymbol{k P a} / \text { dia) }\end{array}$ \\
\hline 0 & 225 & - & - \\
3 & 293 & 30 & 97,7 \\
7 & 380 & 69 & 54,3 \\
28 & 580 & 158 & 20,7 \\
90 & 553 & 146 & 6,1 \\
180 & 748 & 232 & 4,2 \\
\hline
\end{tabular}




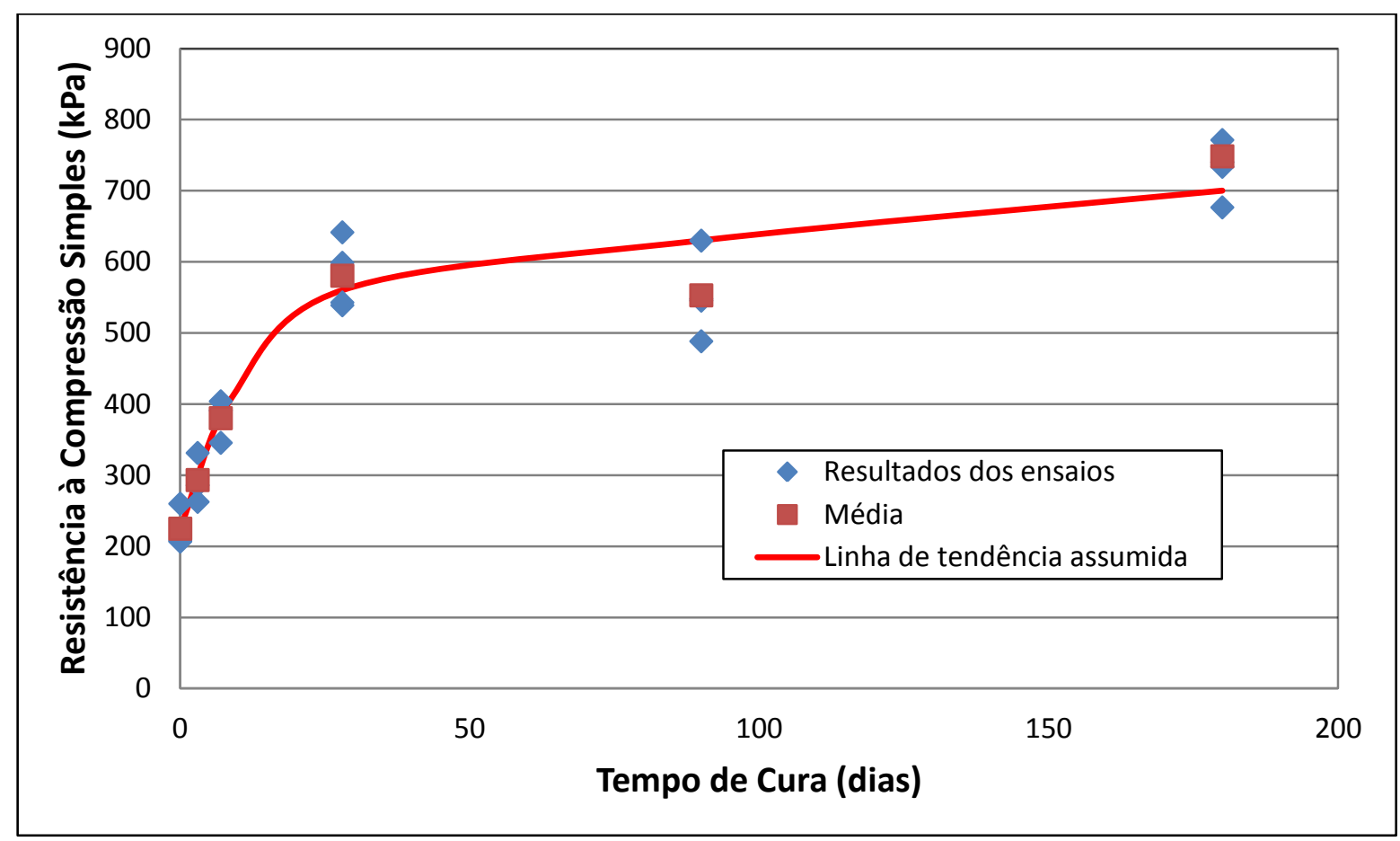

FIGURA 4.1. - Resultados de RCS dos corpos-de-prova de ARC ensaiados em diferentes tempos de cura

Analisando-se a Tabela 4.1 e a Figura 4.1, observa-se que a RCS cresce com o aumento do tempo de cura. Tomando-se as médias de RCS para cada um dos tempos de cura, verifica-se que o ganho de resistência calculado com relação aos corpos-de-prova ensaiados sem cura é de 30\%, 69\%, 158\%, $146 \%$ e $232 \%$, respectivamente para $3,7,28,90$ e 180 dias de cura.

Os corpos-de-prova com 90 dias de cura apresentaram resistência inferior ao esperado, quando se analisa o conjunto dos resultados. A fim de se encontrar explicações para o ocorrido, analisou-se a variação do teor de umidade, o teor de umidade final, a qualidade e o dia da moldagem dos corpos-de-prova estudados nesta pesquisa, no entanto não foi possível encontrá-las.

Portanto, analisando-se a Tabela 4.1 e a Figura 4.1, constata-se que existe um aumento da resistência do agregado reciclado de concreto ao longo do tempo de 
cura. O ganho de resistência é maior nos primeiros dias de cura, sendo que até os 28 dias, a taxa de crescimento da resistência é de aproximadamente $12,7 \mathrm{kPa} / \mathrm{dia}$, enquanto que após os 28 dias, essa taxa é aproximadamente constante, e igual a $1,0 \mathrm{kPa} / \mathrm{dia}$.

Acredita-se que o ganho de resistência e rigidez ao longo do tempo de cura se deva à presença de cimento não hidratado no agregado reciclado de concreto, conforme apresentado anteriormente em pesquisas realizadas por Arm (2001), Blanknagel (2005) e Poon e Chan (2006). Este cimento, que é exposto durante a fase de britagem no processo de reciclagem dos resíduos de concreto e argamassa, quando em contato com a água no processo de moldagem dos corpos-de-prova inicia uma reação cimentante, a qual modifica as características mecânicas do agregado reciclado de concreto.

Contudo, quando se comparam o ganho de resistência com o tempo de cura observado nesta pesquisa com o obtido por Grubba (2009) para o mesmo material até 90 dias de cura, apresentados na Tabela 4.2 e na Figura 4.2, observa-se que o mesmo é significativamente menor.

TABELA 4.2. - Resultados das médias de RCS, percentual de ganho de resistência e diferença entre os ganhos dos corpos-de-prova de ARC, desta pesquisa e da pesquisa de Grubba (2009), ensaiados em diferentes tempos de cura

\begin{tabular}{c|cc|cc|c}
\hline $\begin{array}{c}\text { Tempo } \\
\text { de Cura } \\
\text { (dias) }\end{array}$ & $\begin{array}{c}\text { Resultados desta pesquisa } \\
\text { Ganho de } \\
\text { RCS (\%) }\end{array}$ & Resultados de Grubba (2009) & $\begin{array}{c}\text { Diferença } \\
\text { Ganho de }\end{array}$ & $\begin{array}{c}\text { Re ganho } \\
\text { de RCS (\%) }\end{array}$ \\
\hline 0 & 225 & - & 201 & - & \\
3 & 293 & 30 & 256 & 127 & -2 \\
7 & 380 & 69 & 421 & 209 & 24 \\
28 & 580 & 158 & 673 & 335 & 30 \\
90 & 553 & 146 & 1023 & 509 & 107 \\
180 & 748 & 232 & - & - & \\
\hline
\end{tabular}




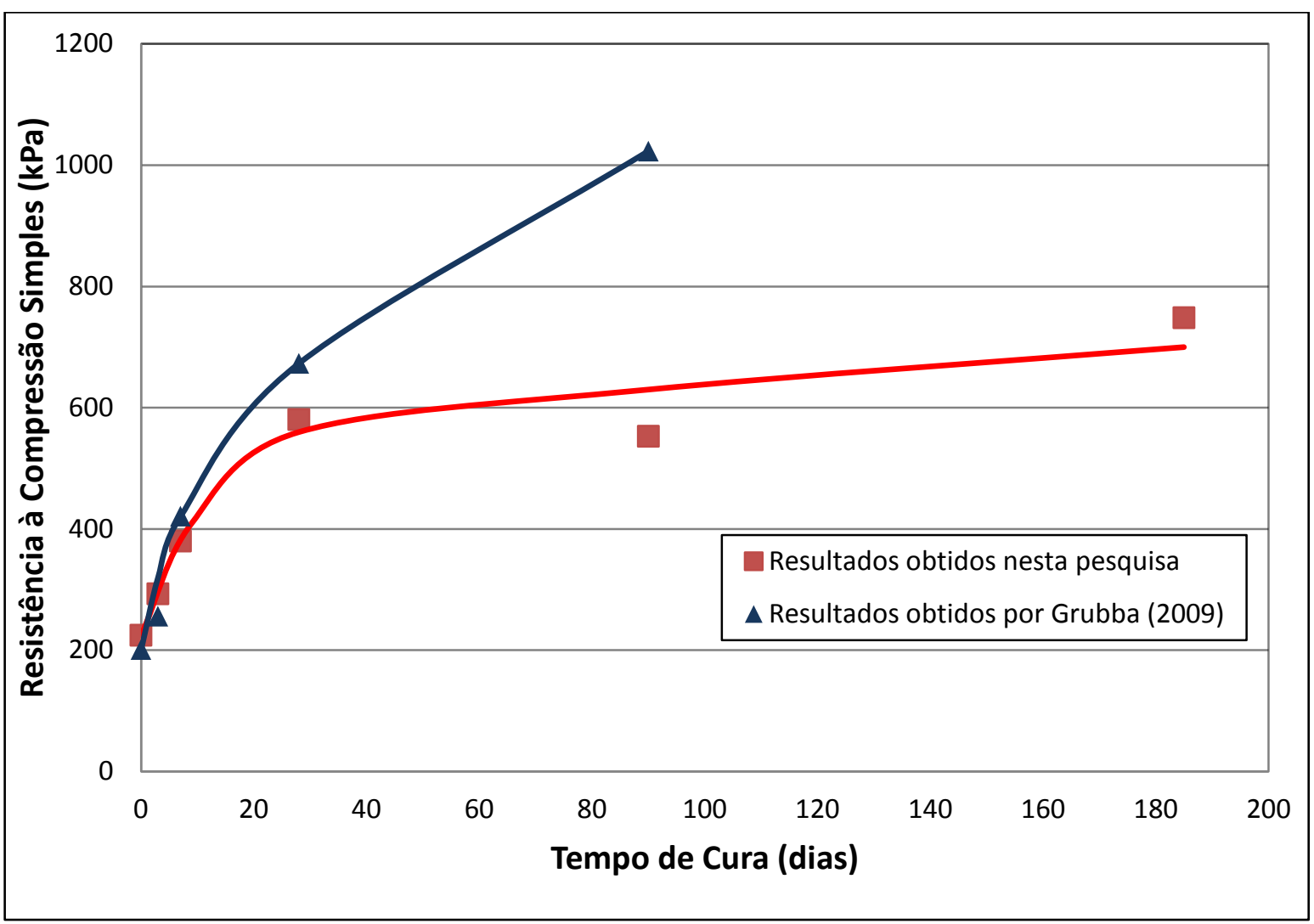

FIGURA 4.2. - Resultados das médias de RCS dos corpos-de-prova de ARC, desta pesquisa e da pesquisa de Grubba (2009), ensaiados em diferentes tempos de cura

Analisando-se a Tabela 4.2 e a Figura 4.2, observa-se, excluindo-se o tempo de cura de três dias, que Grubba (2009) obteve ganhos de resistência, 24\%, 30\% e $107 \%$ superiores aos determinados nesta pesquisa, respectivamente para 7, 28 e 90 dias de cura.

Como o material ensaiado é o mesmo e os procedimentos observados na preparação, compactação e cura dos corpos-de-prova foram iguais em ambas as pesquisas, acredita-se que a diferença observada seja decorrente do tempo decorrido entre a realização das pesquisas.

Durante este intervalo, o agregado reciclado de concreto foi armazenado em sacos plásticos e empilhados sob paletes de madeira em local sem cobertura e com 
o passar do tempo, devido à ação das intempéries, os sacos plásticos trincaram, possibilitando que a água da chuva umedecesse o material, perdendo assim parte da sua ação cimentante.

Portanto, verifica-se que até os 90 dias de cura, o aumento de resistência à compressão simples em função do tempo de cura da pesquisa de Grubba (2009) é maior que o desta pesquisa, no tocante à diferença entre elas, observa-se que se torna mais expressiva após os 7 dias de cura. Acredita-se que o ARC estudado nesta pesquisa, no período em que ficou armazenado, perdeu cimento não hidratado

devido à ação das intempéries. Assim sendo, observa-se que o armazenamento do $A R C$ em locais que promovam o contato com água ou que sofra ação das intempéries não é recomendado, haja vista que suas características cimentantes se modificam, reduzindo assim o ganho de resistência ao longo do tempo de cura.

\subsubsection{Resistência à compressão simples após outros ensaios}

Como citado no Capítulo 3, Materiais e Métodos, além dos corpos-de-prova preparados especialmente para a execução dos ensaios de compressão simples, foram também ensaiados corpos-de-prova anteriormente submetidos aos ensaios triaxiais cíclicos.

A Tabela 4.3 apresenta os valores médios de resistência à compressão simples (RCS) dos corpos-de-prova de ARC, especialmente moldados para o ensaio de compressão simples, e dos corpos-de-prova de ARC usados anteriormente na determinação do módulo de resiliência e deformação permanente, os corpos-deprova foram moldados na condição ótima do Proctor intermediário e ensaiados com tempos de cura de $0,3,7,28$ e 90 dias, e no caso desta pesquisa, apresenta-se 
também com 180 dias de cura. Todos os resultados, com exceção dos que apresentaram erros durante a execução, estão apresentados no Apêndice I. Os valores encontrados na Tabela 4.3 estão ilustrados graficamente na Figura 4.3.

TABELA 4.3. - Resultados de RCS dos corpos-de-prova de ARC, especialmente moldados para o ensaio de compressão simples e dos corpos-de-prova de ARC usados anteriormente nos ensaios triaxiais cíclicos, ensaiados em diferentes tempos de cura

\begin{tabular}{cccc}
\hline $\begin{array}{c}\text { Tempo de } \\
\text { Cura (dias) }\end{array}$ & CS & CS após $\mathbf{M R}$ & CS após $\varepsilon_{\mathrm{p}} \boldsymbol{e}$ MR \\
\hline 0 & 225 & 317 & 454 \\
3 & 293 & 382 & - \\
7 & 380 & 432 & 513 \\
28 & 580 & 540 & 575 \\
90 & 553 & 710 & - \\
180 & 748 & 796 & 809 \\
\hline
\end{tabular}

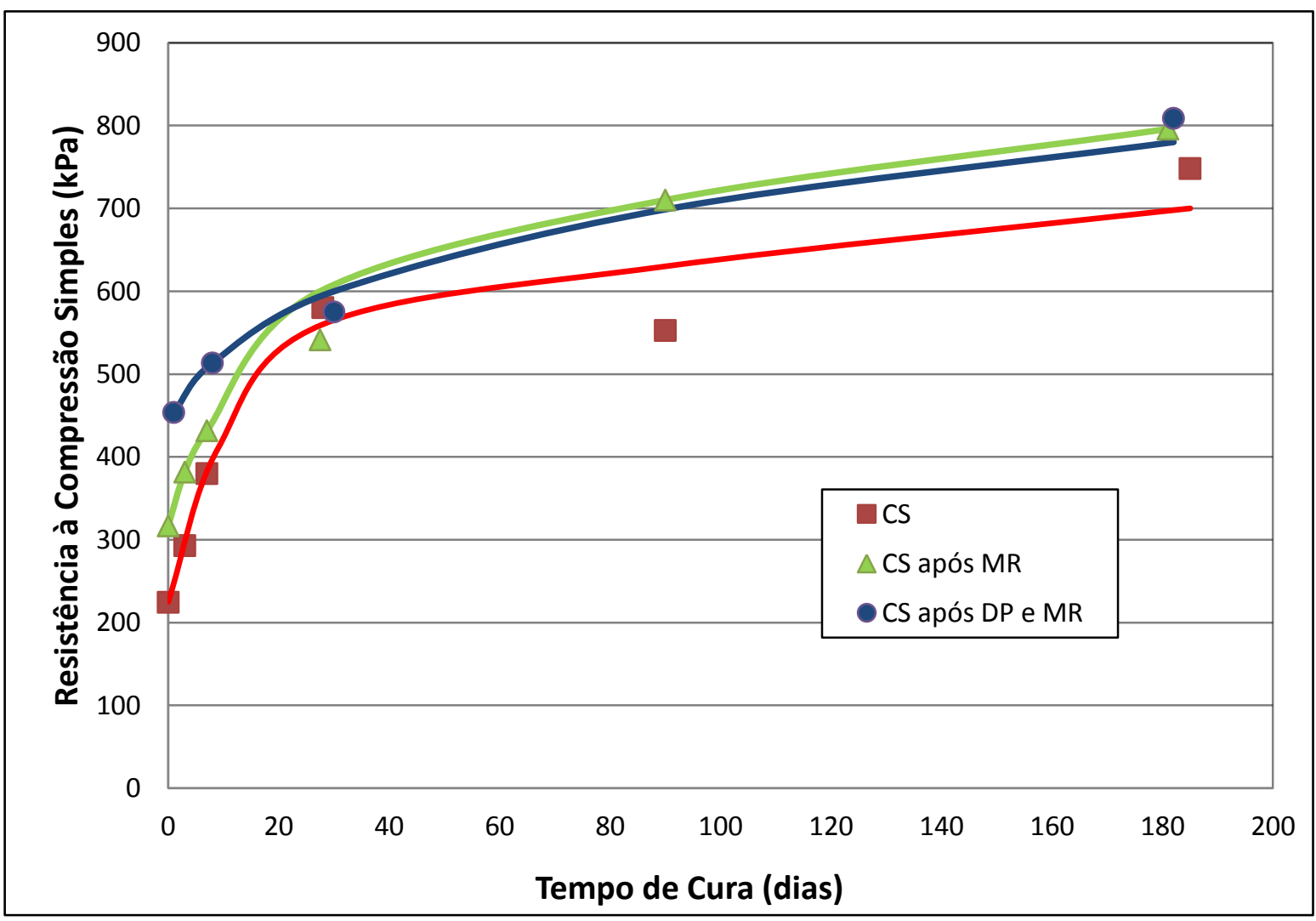

FIGURA 4.3. - Resultados de RCS dos corpos-de-prova de ARC, especialmente moldados para o ensaio de compressão simples e dos corpos-de-prova de ARC usados anteriormente nos ensaios triaxiais cíclicos, ensaiados em diferentes tempos de cura 
Através dos resultados apresentados na Tabela 4.3 e ilustrados na Figura 4.3, observa-se que os corpos-de-prova especialmente preparados para o ensaio de compressão simples apresentaram RCS inferiores a dos corpos-de-prova utilizados anteriormente para determinação do módulo de resiliência e dos corpos-de-prova utilizados anteriormente para determinação da deformação permanente e do módulo de resiliência.

Observa-se também, que os corpos-de-prova utilizados anteriormente para determinação do módulo de resiliência apresentaram, até os 28 dias de cura, RCS inferior aos corpos-de-prova utilizados anteriormente na determinação da deformação permanente e módulo de resiliência, se igualando após os 28 dias de cura.

Portanto, acredita-se que o efeito da sobre-compactação ocorrida nos corposde-prova utilizados nos ensaios triaxiais cíclicos conduz ao aumento da RCS. Relativamente, o efeito da sobre-compactação aumenta a resistência à compressão simples do agregado reciclado de concreto em todos os tempos de cura, sendo maior para os menores tempos de cura.

\subsubsection{Módulo tangente a $50 \%$ da tensão de ruptura}

A Tabela 4.4 apresenta os valores médios de módulo tangente a 50\% da tensão de ruptura dos corpos-de-prova de ARC submetidos ao ensaio de compressão simples na condição ótima do Proctor intermediário e ensaiados com tempos de cura de 0, 3, 7, 28, 90 e 180 dias. Todos os resultados, com exceção dos que apresentaram erros durante a execução, estão apresentados no Apêndice I. Os valores encontrados na Tabela 4.4 estão ilustrados graficamente na Figura 4.4. 
TABELA 4.4. - Resultados de $E_{50 \%}$ dos corpos-de-prova de ARC ensaiados com diversos tempos de cura, percentual e gradiente de ganho de rigidez

\begin{tabular}{cccc}
\hline $\begin{array}{c}\text { Tempo de } \\
\text { Cura (dias) }\end{array}$ & $\begin{array}{c}E_{50 \%} \\
\text { (MPa) }\end{array}$ & $\begin{array}{c}\text { Ganho de } \\
E_{50 \%} \text { (\%) }\end{array}$ & $\begin{array}{c}\text { Ganho de } E_{50 \%} / \text { dia } \\
\text { (MPa/dia) }\end{array}$ \\
\hline 0 & 49 & - & - \\
3 & 58 & 18 & 3,0 \\
7 & 57 & 16 & 1,1 \\
28 & 79 & 61 & 1,1 \\
90 & 95 & 94 & 0,5 \\
180 & 103 & 110 & 0,3 \\
\hline
\end{tabular}

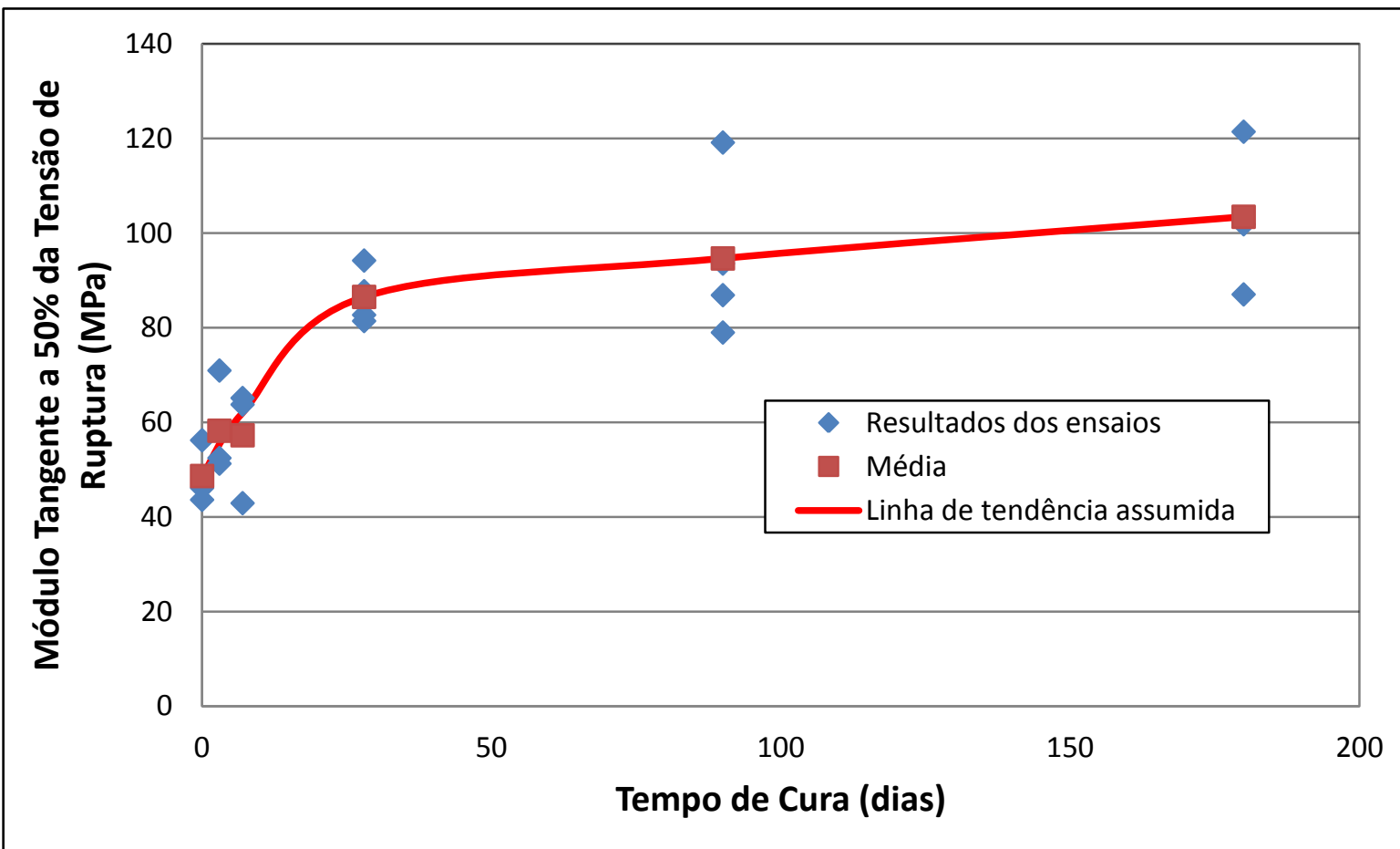

FIGURA 4.4. - Resultados de $E_{50 \%}$ dos corpos-de-prova de ARC ensaiados em diferentes tempos de cura

Analisando-se a Tabela 4.4 e a Figura 4.4, observa-se que o $E_{50 \%}$ cresce com o aumento do tempo de cura. Tomando-se as médias de $E_{50 \%}$ para cada um dos tempos de cura, verifica-se que o ganho de rigidez calculado com relação aos corpos-de-prova ensaiados sem cura é de $18 \%, 16 \%, 61 \%, 94 \%$ e $110 \%$, respectivamente para $3,7,28,90$ e 180 dias de cura. 
Tendo em vista que os corpos-de-prova utilizados para a determinação da RCS são os mesmos utilizados para determinação do $E_{50 \%}$, vale ressaltar que 0 comportamento não esperado para a RCS aos 90 dias de cura, não ocorreu para o $\mathrm{E}_{50 \%}$ neste mesmo período.

Constata-se através das análises dos resultados de $E_{50 \%}$, que existe um aumento da rigidez do agregado reciclado de concreto ao longo do tempo de cura. Do mesmo modo que a resistência, analisando-se a curva de tendência, esse ganho de rigidez com o tempo foi maior nos primeiros dias de cura, sendo que até os 28 dias, a taxa de crescimento da rigidez foi de $1 \mathrm{MPa} / \mathrm{dia}$, enquanto que após os 28 dias a taxa reduziu-se para $0,15 \mathrm{MPa} / \mathrm{dia}$.

Assim como observado para a RCS, o ganho de rigidez do agregado reciclado de concreto ao longo do tempo de cura se deve a presença de cimento não hidratado que é exposto durante a fase de britagem, no processo de reciclagem dos resíduos de concreto e argamassa.

Comparando-se os ganhos de resistência e rigidez ao longo do tempo de cura, observa-se que a resistência é mais sensível com esta variável, visto que a RCS e $\circ E_{50 \%}$ apresentaram uma porcentagem de variação de $232 \%$ e $110 \%$, respectivamente para corpos-de-prova curados durante 180 dias com relação aos corpos-de-prova sem cura.

Como observado para a RCS, quando se comparam o ganho de rigidez com o tempo de cura observado nesta pesquisa com o obtido por Grubba (2009) para o mesmo material até 90 dias de cura, apresentados na Tabela 4.5 e na Figura 4.5, observa-se que o mesmo é significativamente menor. 
TABELA 4.5. - Resultados das médias de $E_{50 \%}$, percentual de ganho de rigidez e diferença entre os ganhos dos corpos-de-prova de ARC, desta pesquisa e da pesquisa de Grubba (2009), ensaiados em diferentes tempos de cura

\begin{tabular}{|c|c|c|c|c|c|}
\hline \multirow{2}{*}{$\begin{array}{c}\text { Tempo } \\
\text { de Cura } \\
\text { (dias) }\end{array}$} & \multicolumn{2}{|c|}{ Resultados desta pesquisa } & \multicolumn{2}{|c|}{ Resultados de Grubba (2009) } & \multirow{2}{*}{$\begin{array}{l}\text { Diferença } \\
\text { de ganho } \\
\text { de } E_{50 \%}(\%)\end{array}$} \\
\hline & $E_{50 \%}(\mathrm{kPa})$ & $\begin{array}{c}\text { Ganho de } \\
E_{50 \%}(\%)\end{array}$ & $E_{50 \%}(k P a)$ & $\begin{array}{c}\text { Ganho de } \\
E_{50 \%}(\%)\end{array}$ & \\
\hline 0 & 49 & - & 62 & - & - \\
\hline 3 & 58 & 120 & 81 & 131 & 9 \\
\hline 7 & 57 & 118 & 96 & 155 & 32 \\
\hline 28 & 79 & 163 & 119 & 192 & 18 \\
\hline 90 & 95 & 195 & 166 & 268 & 38 \\
\hline 180 & 103 & 213 & - & - & - \\
\hline
\end{tabular}

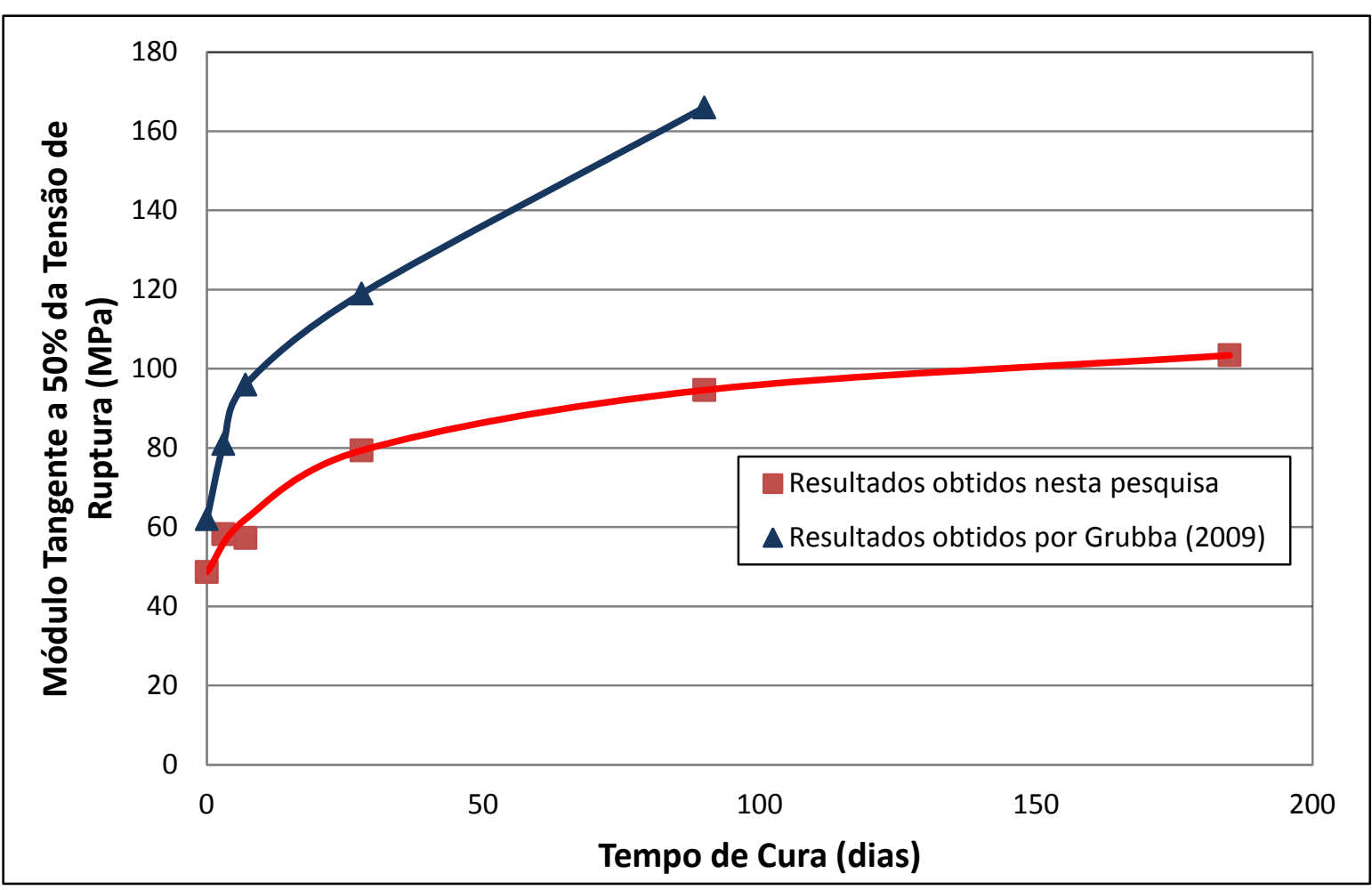

FIGURA 4.5. - Resultados das médias de $\mathrm{E}_{50 \%}$ dos corpos-de-prova de ARC, desta pesquisa e da pesquisa de Grubba (2009), ensaiados em diferentes tempos de cura

Analisando-se a Tabela 4.5 e a Figura 4.5, Grubba (2009) obteve ganhos de rigidez, $9 \%, 32 \%, 18 \%$ e $38 \%$ superiores aos determinados nesta pesquisa, respectivamente para 3, 7, 28 e 90 dias de cura. 
Portanto, assim como observado para a resistência, verifica-se que até os 90 dias de cura, o aumento de módulo tangente a 50\% da tensão de ruptura em função do tempo de cura da pesquisa de Grubba (2009) é maior que o desta pesquisa, no tocante à diferença entre elas, observa-se que se torna mais expressiva após os 7 dias de cura. Acredita-se que o ARC estudado nesta pesquisa, no período em que ficou armazenado, perdeu cimento não hidratado devido à ação das intempéries. Assim sendo, observa-se que o armazenamento do ARC em locais que promovam o contato com água ou que sofra ação das intempéries não é recomendado, haja vista que suas características cimentantes se modificam, reduzindo assim o ganho de rigidez ao longo do tempo de cura.

Ao contrário da RCS, não foi possível analisar o $E_{50 \%}$ após outros ensaios, pois a pré-execução dos ensaios triaxiais cíclicos, para determinação da deformação permanente e do módulo de resiliência, acarretaram em alterações significativas nos resultados de $\mathrm{E}_{50 \%}$, diferentemente dos resultados de RCS.

\subsubsection{Módulo de resiliência}

O valor do módulo de resiliência pode ser influenciado, entre outros fatores, pelo estado de tensão. Existem muitos modelos matemáticos que representam o módulo de resiliência em função desta variável. Para esta pesquisa foram utilizadas expressões que consideram o efeito da tensão confinante (Equação 4.1), da tensão desvio (Equação 4.2), das tensões confinante e desvio simultaneamente, modelo composto (Equação 4.3), e das tensões volumétricas e cisalhantes octaédricas, modelo universal da AASTHO (Equação 4.4).

$$
M R=K_{1} \sigma_{c}{ }^{K_{2}}
$$




$$
\begin{array}{cc}
M R=K_{1} \sigma_{d} K_{3} & \text { Equação 4.2. } \\
M R=K_{1} \sigma_{c}{ }^{K_{2}} \sigma_{d} K_{3} & \text { Equação 4.3. } \\
M R=K_{1} p_{a}\left(\frac{\theta}{p_{a}}\right)^{K_{2}}\left(\frac{\tau_{o c t}}{p_{a}}+1\right)^{K_{3}} & \text { Equação 4.4. }
\end{array}
$$

Onde:

MR: módulo de resiliência (MPa);

$\sigma_{d}$ : tensão desvio $(\mathrm{kPa})$;

$\sigma_{c}$ : tensão confinante $(\mathrm{kPa})$;

$\theta$ : primeiro invariante de tensão = tensão volumétrica $(\mathrm{kPa})$;

$\tau_{\text {oct }}$ : tensão cisalhante octaédrica $(\mathrm{kPa})$;

$p_{a}:$ pressão atmosférica $=101 \mathrm{kPa}$;

$K_{1}, K_{2}, K_{3}$ : parâmetros de regressão.

A Tabela 4.6 apresenta as constantes de calibração dos modelos de módulo de resiliência e os respectivos coeficientes de determinação dos corpos-de-prova de ARC submetidos ao ensaio triaxial cíclico na condição ótima do Proctor intermediário e ensaiados com tempos de cura de 0,7,28, 90 e 180 dias. Considerando-se que foram ensaiados diversos corpos-de-prova, a Tabela 4.6 apresenta para cada um dos modelos analisados, os resultados das constantes de calibração obtidos para os ensaios que conduziram aos maiores coeficientes de determinação, referentes ao modelo composto. 
TABELA 4.6. - Constantes de calibração e $R^{2}$ dos modelos de módulo de resiliência dos corpos-de-prova de ARC ensaiados em diversos tempos de cura

\begin{tabular}{|c|c|c|c|c|c|}
\hline Modelo & $\begin{array}{l}\text { Tempo de } \\
\text { Cura (dias) }\end{array}$ & $K 1$ & $K 2$ & $\kappa 3$ & $R^{2}$ \\
\hline \multirow{5}{*}{$M R=K_{1} \sigma_{c}^{K_{2}}$} & 0 & 12,09 & 0,68 & - & 0,93 \\
\hline & 7 & 91,21 & 0,30 & - & 0,90 \\
\hline & 28 & 17,73 & 0,68 & - & 0,98 \\
\hline & 90 & 67,97 & 0,47 & - & 0,96 \\
\hline & 180 & 133,79 & 0,33 & - & 0,85 \\
\hline \multirow{5}{*}{$M R=K_{1} \sigma_{d}^{K_{3}}$} & 0 & 48,39 & - & 0,37 & 0,47 \\
\hline & 7 & 78,96 & - & 0,31 & 0,63 \\
\hline & 28 & 74,75 & - & 0,34 & 0,46 \\
\hline & 90 & 193,30 & - & 0,24 & 0,40 \\
\hline & 180 & 157,47 & - & 0,27 & 0,48 \\
\hline \multirow{5}{*}{$M R=K_{1} \sigma_{c}^{K_{2}} \sigma_{d}{ }^{K_{3}}$} & 0 & 7,02 & 0,72 & 0,08 & 0,91 \\
\hline & 7 & 83,33 & 0,33 & $-0,00$ & 0,91 \\
\hline & 28 & 13,23 & 0,76 & $-0,02$ & 0,97 \\
\hline & 90 & 58,92 & 0,50 & 0,01 & 0,98 \\
\hline & 180 & 121,00 & 0,35 & 0,00 & 0,87 \\
\hline \multirow{5}{*}{$M R=K_{1} p_{a}\left(\frac{\theta}{p_{a}}\right)^{K_{2}}\left(\frac{\tau_{o c t}}{p_{a}}+1\right)^{K_{3}}$} & 0 & 0,86 & 0,98 & $-0,47$ & 0,89 \\
\hline & 7 & 2,34 & 0,47 & $-0,51$ & 0,92 \\
\hline & 28 & 1,34 & 1,04 & $-0,82$ & 0,96 \\
\hline & 90 & 2,83 & 0,67 & $-0,49$ & 0,96 \\
\hline & 180 & 3,65 & 0,47 & $-0,38$ & 0,86 \\
\hline
\end{tabular}

Analisando-se os coeficientes de correlação e tomando-os como medida da capacidade de cada um dos modelos de representar a variação do módulo de resiliência com o estado de tensão, os modelos composto, universal e tensão confinante apresentam desempenhos altos e relativamente iguais, enquanto 0 modelo tensão desvio apresenta desempenho baixo.

Tomando-se o modelo composto, por apresentar bom desempenho e também por ser bastante difundido no meio científico, e comparando os valores assumidos por $\mathrm{K}_{2}$ e $\mathrm{K}_{3}$, respectivamente expoentes das tensões confinante e desvio, verifica-se que o módulo de resiliência cresce com o aumento da tensão confinante e praticamente não varia com o aumento da tensão desvio. E também, considerando- 
se que as variações de ambas as tensões são de mesma ordem, os maiores valores assumidos pelo expoente da tensão confinante são indicativos que esta variável tem maior influência no módulo de resiliência que a tensão desvio. O melhor desempenho da Equação 4.1 quando comparado ao da Equação 4.2, modelos expressos apenas em função de uma única tensão, confinante e desvio respectivamente, é decorrente deste fato. Não foi possível identificar um padrão para a variação dos expoentes com a variação do tempo de cura.

Com o objetivo de se analisar a influência do tempo de cura na variação do MR em uma situação onde o ARC poderia ser utilizado na construção da camada de base de um pavimento, considerou-se a estrutura analisada anteriormente por Grubba (2009). A Figura 4.6 apresenta a estrutura em questão dimensionada para um volume de tráfego de baixo a médio, conforme recomendado pela norma NBR 15115 (ABNT, 2004) para o emprego de resíduos de construção e demolição em camadas de base e sub-base de pavimentos $\left(\mathrm{N} \leq 10^{6}\right.$ repetições do eixo padrão de $80 \mathrm{kN}$ no período de projeto). 


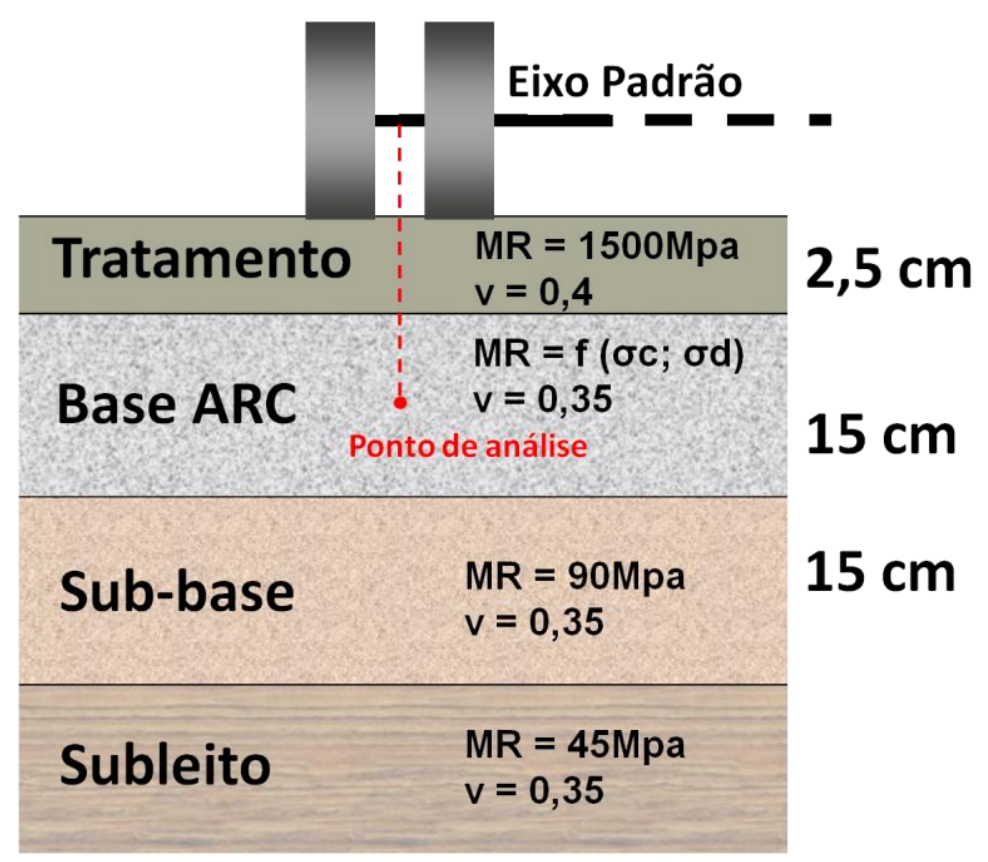

FIGURA 4.6. - Estrutura de pavimento utilizada para determinação do módulo de resiliência no centro da camada de base

Calculou-se então, a partir do modelo composto, no centro da camada de base, o módulo de resiliência do ARC para os diferentes tempos de cura. Aplicou-se o eixo padrão de $80 \mathrm{KN}$ como carregamento da estrutura, sendo escolhido para análise, o ponto entre duas rodas.

As tensões foram determinadas usando o programa computacional ELSYM 5, que permite apenas análises lineares. Para contornar esta limitação, utilizou-se um processo interativo de cálculo, onde se adotava inicialmente um valor de módulo de resiliência para o material de base e calculavam-se as tensões no ponto escolhido. Com estas tensões e o modelo composto, determinava-se um novo módulo de resiliência. Em seguida, usando este módulo de resiliência, alimentava-se novamente o programa numérico e novas tensões no ponto escolhido eram determinadas. O procedimento prosseguia até ocorrer a convergência do processo. A Tabela 4.7 e a Figura 4.7 apresentam os valores de módulo de resiliência, desta 
pesquisa e da pesquisa de Grubba (2009), determinados no centro da camada de base da estrutura proposta através do processo interativo de cálculo.

TABELA 4.7. - Valores de módulo de resiliência do ARC, desta pesquisa e da pesquisa de Grubba (2009), determinados no centro da camada de base da estrutura proposta

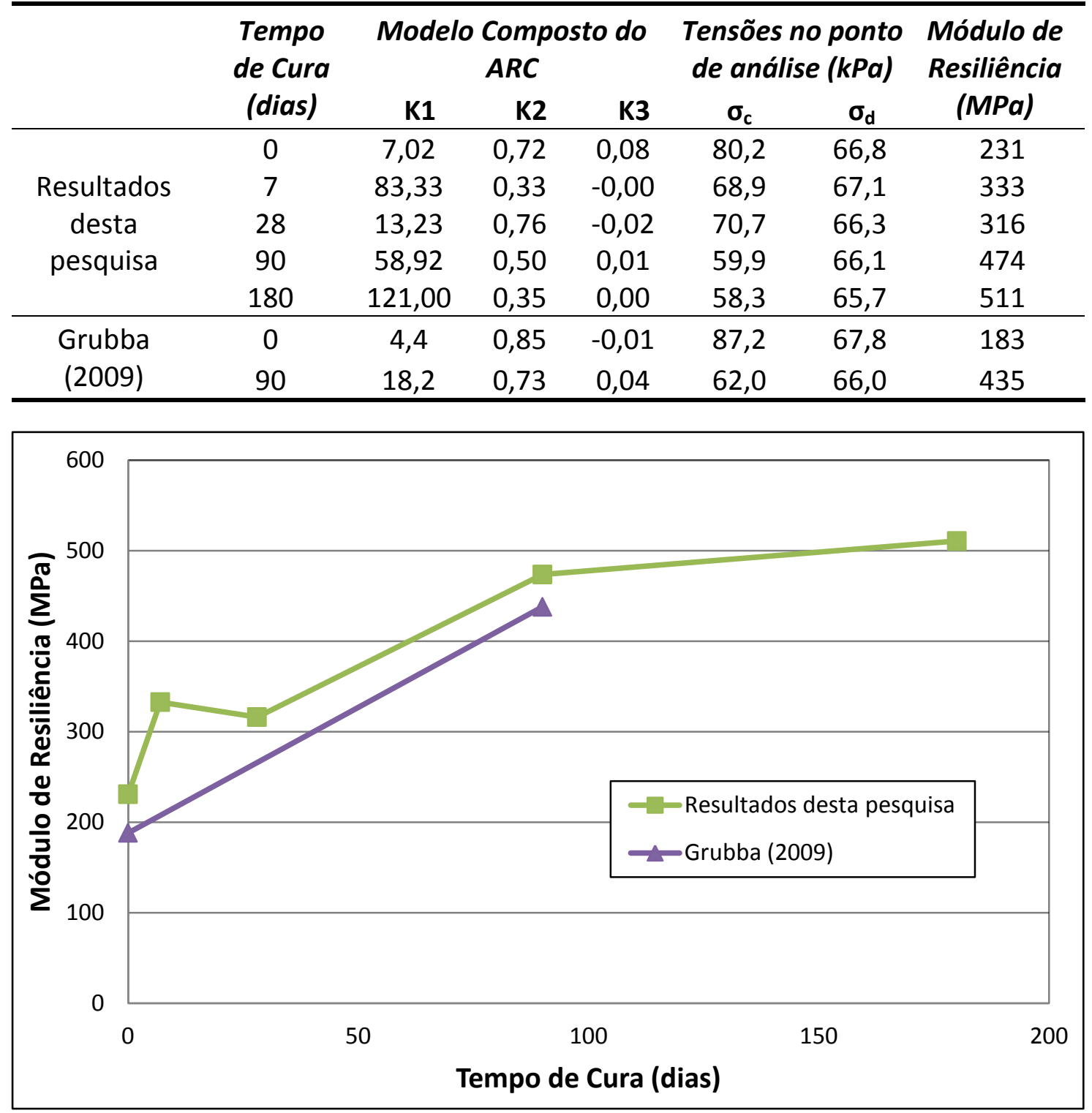

FIGURA 4.7. - Valores de módulo de resiliência do ARC, desta pesquisa e da pesquisa de Grubba (2009), determinados no centro da camada de base da estrutura proposta

Analisando-se a Tabela 4.7 e a Figura 4.7, observa-se, no geral, que o módulo de resiliência aumentou ao longo do tempo de cura. Tomando-se os 
resultados de MR do ARC desta pesquisa, determinados no centro da camada de base da estrutura proposta, com relação ao MR obtido com os parâmetros do modelo composto do corpo-de-prova sem cura, o acréscimo de MR é de $44 \%, 37 \%$, $105 \%$ e $121 \%$, respectivamente para 7, 28, 90 e 180 dias de cura. Ressalta-se, que o módulo de resiliência obtido aos 7 dias de cura foi superior ao obtido para 28 dias, conforme discutido anteriormente, este comportamento não era esperado.

Comparando-se os resultados de RCS e $\mathrm{E}_{50 \%}$ com os resultados de MR ao longo do tempo de cura, verifica-se que as porcentagens de ganho no valor destas variáveis calculadas para corpos-de-prova curados durante 180 dias com relação aos corpos-de-prova sem cura é de $232 \%, 110 \%$ e $121 \%$, respectivamente para RCS, $E_{50 \%}$ e MR. É importante destacar, que o valor relativo ao MR refere-se ao calculado para as tensões observadas na estrutura proposta. Portanto, o ganho de rigidez representado pelo MR, é intermediário aos valores observados para a RCS e $E_{50 \%}$.

Comparando-se os resultados obtidos nesta pesquisa com os obtidos por Grubba (2009), observa-se que estes são superiores $26 \%$ e $9 \%$, respectivamente para 0 e 90 dias de cura. Considerando-se a dispersão associada a estes ensaios e à moldagem dos corpos-de-prova, os resultados obtidos nas duas pesquisas podem ser considerados compatíveis. No tocante ao ganho de rigidez aos 90 dias de cura, $137 \%$ e $105 \%$, obtidos por Grubba (2009) e nesta pesquisa, estes valores também podem ser considerados compatíveis.

Portanto, no caso do MR, não se repete o observado com relação à RCS e $E_{50 \%}$, onde Grubba (2009) obteve valores superiores aos desta pesquisa. Acredita- 
se que este fato seja decorrente de Grubba (2009) ter realizado os ensaios triaxiais cíclicos ao final de sua pesquisa, decorrido quase um ano após a execução dos ensaios de compressão simples. Portanto, igualmente ao ocorrido nesta pesquisa, o efeito da cimentação teria sido minimizado, devido à perda de cimento não hidratado durante a armazenagem.

\subsubsection{Deformação permanente}

A deformação permanente dos materiais é influenciada por diversos fatores, dentre eles, destaca-se o número de aplicações de carga $(\mathrm{N})$. Para efeito de representação matemática da deformação permanente em função desta variável, utilizou-se o modelo proposto por Monismith et al. (1975), Equação 4.5, o qual foi escolhido em meio a inúmeros modelos matemáticos, por representar bem o comportamento dos materiais, e também, por ser bastante utilizado e difundido nos meios científicos.

$$
\varepsilon_{p}=A N^{B}
$$

Onde:

$\varepsilon_{\mathrm{p}}$ : deformação plástica ou deformação permanente;

A e B: parâmetros de calibração;

$\mathrm{N}$ : número de repetições de carga.

Conforme apresentado no Capítulo 3, Materiais e Métodos, os ensaios para a determinação da deformação permanente foram realizados observando os pares de tensão apresentados na Tabela 4.8, sendo que E1 e E3 foram utilizados apenas 
para corpos-de-prova ensaiados aos 28 dias de cura, e E2, para todos os tempos de cura, ou seja, $0,7,28,90$ e 180 dias.

TABELA 4.8. - Estados de tensão utilizados para realização dos ensaios triaxiais cíclicos para determinação da deformação permanente em função das aplicações de carga

\begin{tabular}{ccc}
\hline $\begin{array}{c}\text { Estados de } \\
\text { Tensão }\end{array}$ & $\sigma_{\mathrm{c}}(\mathrm{kPa})$ & $\sigma_{\mathrm{d}}(\mathrm{kPa})$ \\
\hline E1 & 34,5 & 93,1 \\
E2 & 68,9 & 186,1 \\
E3 & 137,9 & 248,2 \\
\hline
\end{tabular}

A Figura 4.8 apresenta as curvas de deformação permanente $\left(\varepsilon_{p}\right)$ em função do número de aplicações do par de tensões, E2: $\sigma \mathrm{c}=68,9 \mathrm{kPa}$ e $\sigma \mathrm{d}=186,1 \mathrm{kPa}$, para os corpos-de-prova de ARC submetidos ao ensaio triaxial cíclico na condição ótima do Proctor intermediário e ensaiados com tempos de cura de $0,7,28,90$ e 180 dias. A partir destas curvas, determinaram-se as constantes de calibração do modelo de Monismith et al. (1975) e os seus respectivos coeficientes de determinação $\left(\mathrm{R}^{2}\right)$, que estão apresentados na Tabela 4.9. 


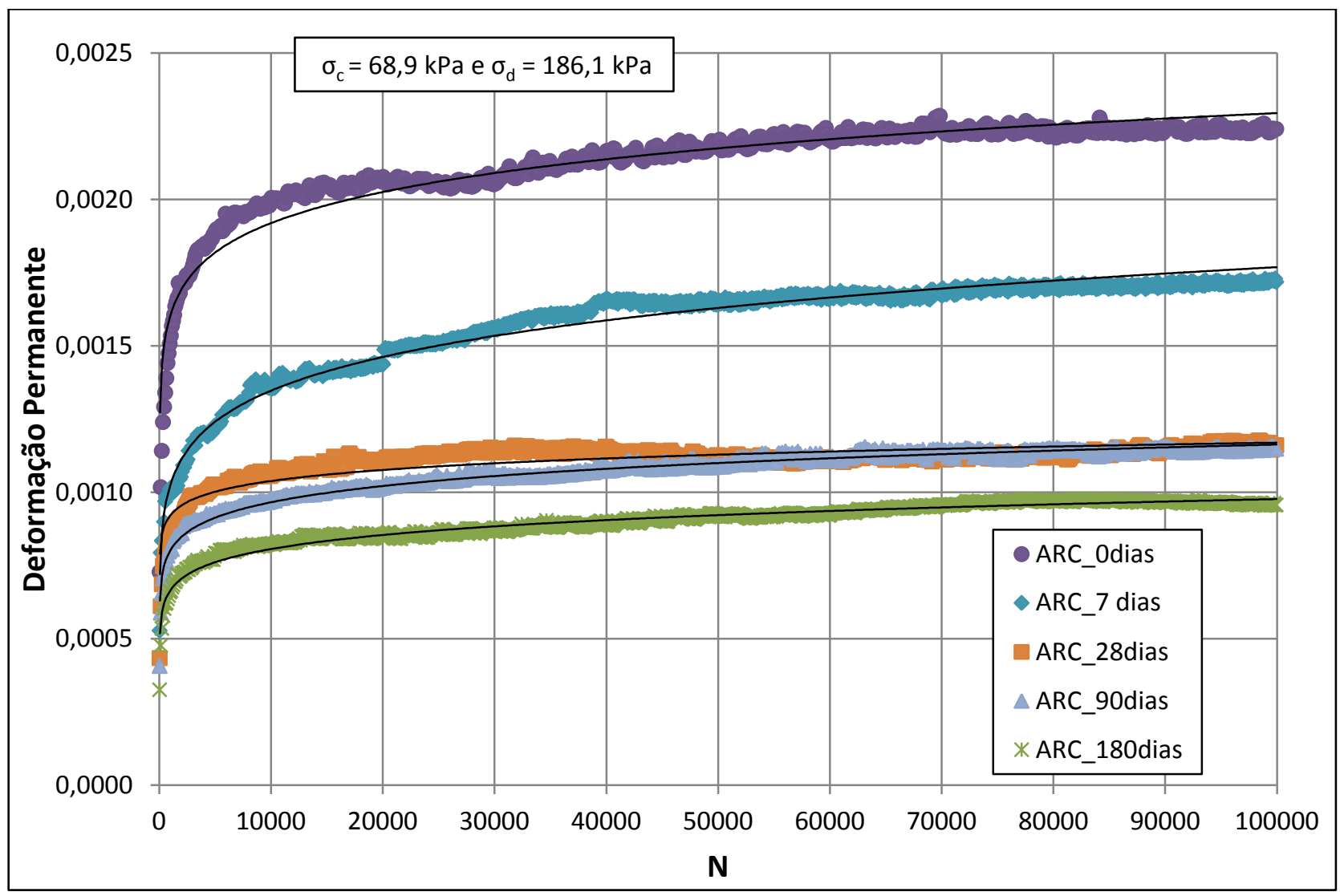

FIGURA 4.8. - Curvas de deformação permanente em função do número de aplicações de carga para corpos-de-prova de ARC ensaiados com diversos tempos de cura

TABELA 4.9. - Constantes de calibração e $\mathbf{R}^{2}$ do modelo de Monismith et al. (1975) aplicado as curvas de deformação permanente em função do número de aplicações de carga para corpos-de-prova de ARC ensaiados com diversos tempos de cura

\begin{tabular}{cccc}
\hline Tempo de & \multicolumn{3}{c}{ Modelo de Monismith } \\
Cura (dias) & $\boldsymbol{A}$ & $\boldsymbol{B}$ & $\boldsymbol{R}^{\mathbf{2}}$ \\
\hline 0 & 0,0009 & 0,0776 & 0,88 \\
7 & 0,0005 & 0,1183 & 0,97 \\
28 & 0,0006 & 0,0517 & 0,68 \\
90 & 0,0005 & 0,0807 & 0,95 \\
180 & 0,0004 & 0,0833 & 0,94 \\
\hline
\end{tabular}

Analisando-se a Figura 4.8 e a Tabela 4.9, considerando-se os coeficientes de determinação $\left(R^{2}\right)$, pode-se afirmar que o modelo de Monismith et al. (1975) representa bem a variação da deformação permanente com o número de aplicações de carga. Os coeficientes de determinação das calibrações desse modelo foram de 
$88 \%, 97 \%, 68 \%, 95 \%$ e $94 \%$, respectivamente para os corpos-de-prova ensaiados com $0,7,28,90$ e 180 dias de cura.

Analisando-se ainda, os coeficientes A e B do modelo de Monismith et al. (1975), apresentados na Tabela 4.9, não foi possível identificar um padrão para a variação desses coeficientes em função do tempo de cura. No entanto, observa-se na Figura 4.8, que quanto maior o tempo de cura, menor é a deformação permanente ao longo das aplicações. Esse comportamento pode ser observado e discutido quando se analisa a deformação permanente no início e no final da curva. Neste sentido, a Tabela 4.10 apresenta os valores de deformação permanente, obtidos no início e no final das aplicações de carga, para tempos de cura de 0, 7, 28, 90 e 180 dias. Estes valores estão ilustrados respectivamente nas Figuras 4.9 e 4.10.

Ressalta-se, que deformação permanente obtida no início das aplicações de carga, denominada deformação inicial, refere-se a esta variável observada após as 50 primeiras aplicações de carga, condição na qual as variações das leituras de deslocamentos associadas às imprecisões que ocorrem no início do ensaio deixam de ser representativas.

TABELA 4.10. - Deformações permanentes iniciais e finais, para diferentes tempos de cura e suas respectivas reduções em relação aos resultados sem cura

\begin{tabular}{ccccc}
\hline $\begin{array}{c}\text { Tempo de } \\
\text { Cura (dias) }\end{array}$ & \multicolumn{2}{c}{$\begin{array}{c}\text { Inicial } \\
\text { Redução de } \\
\varepsilon_{\mathrm{p}}(\%)\end{array}$} & $\varepsilon_{\mathrm{p}}$ & $\begin{array}{c}\text { Final } \\
\text { Redução de } \\
\varepsilon_{\mathrm{p}} \text { (\%) }\end{array}$ \\
\hline 0 & 0,00073 & - & 0,00224 & - \\
7 & 0,00053 & 27 & 0,00172 & 23 \\
28 & 0,00043 & 40 & 0,00116 & 48 \\
90 & 0,00041 & 44 & 0,00115 & 49 \\
180 & 0,00033 & 55 & 0,00096 & 57 \\
\hline
\end{tabular}




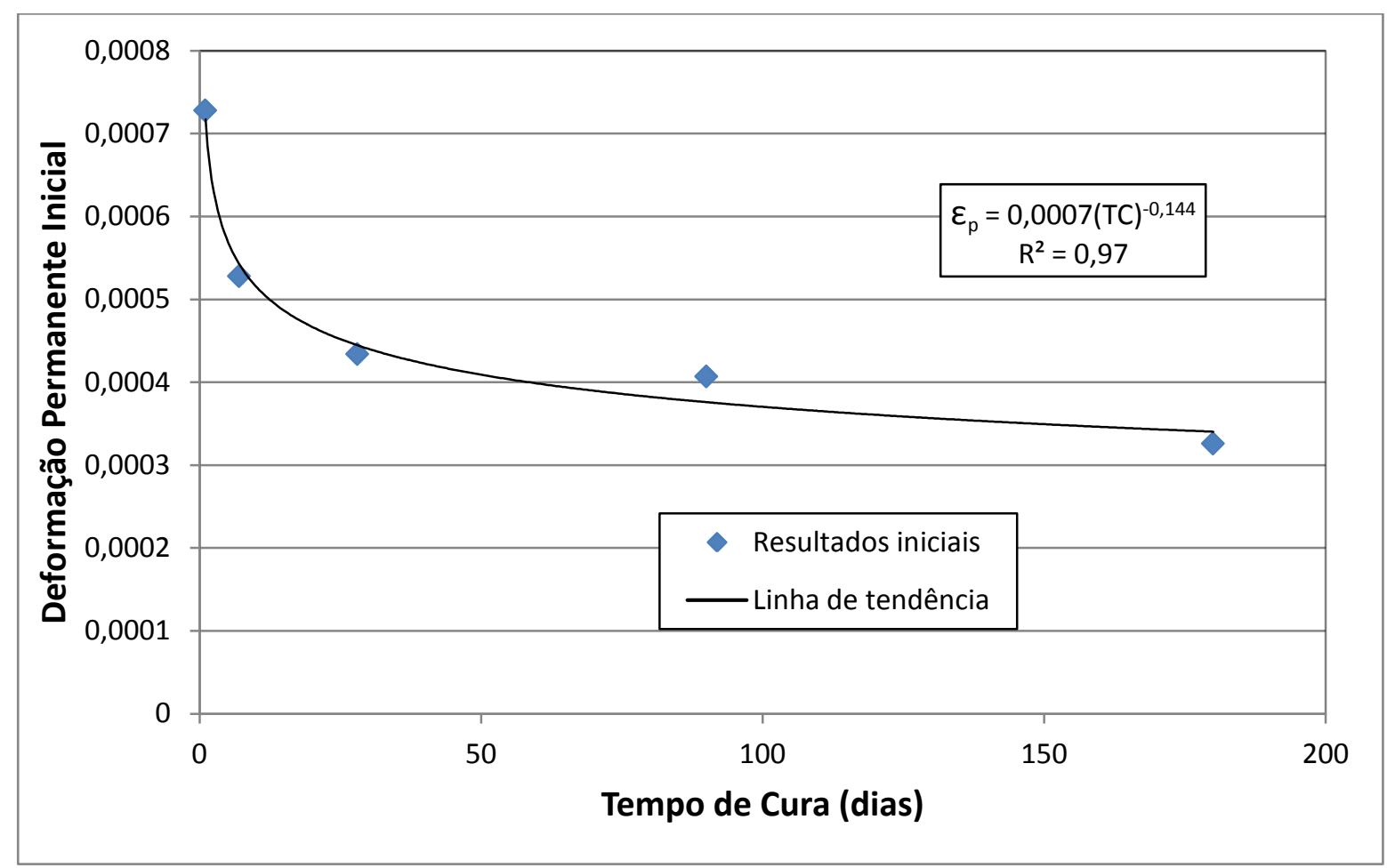

FIGURA 4.9. - Deformação permanente inicial do ARC em função do tempo de cura

Analisando-se a Tabela 4.10 e a Figura 4.9, observa-se que a deformação permanente inicial reduziu-se com o aumento do tempo de cura, essa redução, com relação ao corpo-de-prova ensaiado sem cura, é de $27 \%, 40 \%, 44 \%$ e $55 \%$, respectivamente para $7,28,90$ e 180 dias de cura. 


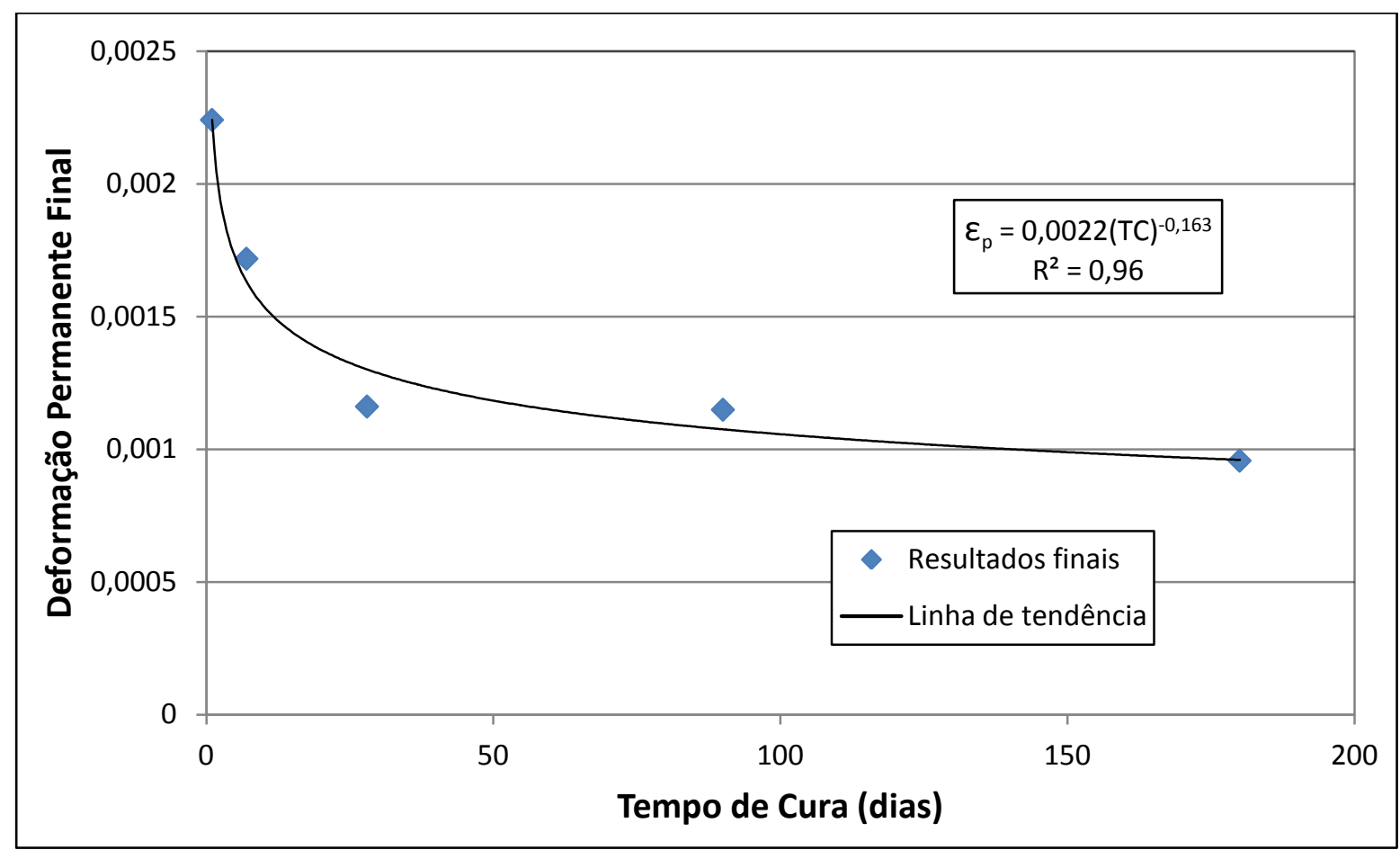

FIGURA 4.10. - Deformação permanente final do ARC em função do tempo de cura

Analisando-se a Figura 4.10, observa-se que a deformação permanente final reduziu-se com o aumento do tempo de cura, essa redução, com relação ao corpode-prova ensaiado sem cura, é de $23 \%, 48 \%, 49 \%$ e $57 \%$, respectivamente para 7 , 28,90 e 180 dias de cura.

Comparando-se as reduções das deformações permanentes iniciais e finais decorrentes da cura do ARC calculadas em relação ao corpo-de-prova ensaiado sem cura, observa-se que as mesmas apresentam valores muito próximos entre si para os diversos tempos de cura considerados. Portanto, a cimentação do material oriunda da cura do ARC, promove a redução das deformações permanentes a uma proporção relativamente constante no decorrer das aplicações de carga.

Para se comparar o efeito do tempo de cura na deformação permanente com o seu efeito na resistência à compressão simples, módulo tangente a $50 \%$ da tensão 
de ruptura e módulo de resiliência, foram consideradas as porcentagens de ganho no valor destas variáveis calculadas para corpos-de-prova ensaiados após 180 dias com relação aos ensaiados sem cura. Os ganhos assim determinados foram de $57 \%, 232 \%, 110 \%$ e $121 \%$, respectivamente para a $\varepsilon_{p}, R C S, E_{50 \%}$ e MR. É importante destacar, que o valor relativo ao MR refere-se ao calculado para as tensões observadas na estrutura proposta no item 4.1.4. Deste modo, constata-se que o efeito da cimentação é menor na deformação permanente que nas demais variáveis.

Para se analisar o efeito da variação das tensões no desenvolvimento das deformações permanentes, foram ensaiados corpos-de-prova curados por 28 dias para os três pares de tensões apresentados anteriormente na Tabela 4.8.

A Figura 4.11 apresenta as curvas de deformação permanente em função do número de aplicações de carga, para três pares de tensões (E1, E2 e E3), dos corpos-de-prova de ARC submetidos ao ensaio triaxial cíclico na condição ótima do Proctor intermediário e ensaiados com tempo de cura de 28 dias. A partir destas curvas, determinaram-se as constantes de calibração do modelo de Monismith et al. (1975) e os seus respectivos coeficientes de determinação, que estão apresentados na Tabela 4.11. 


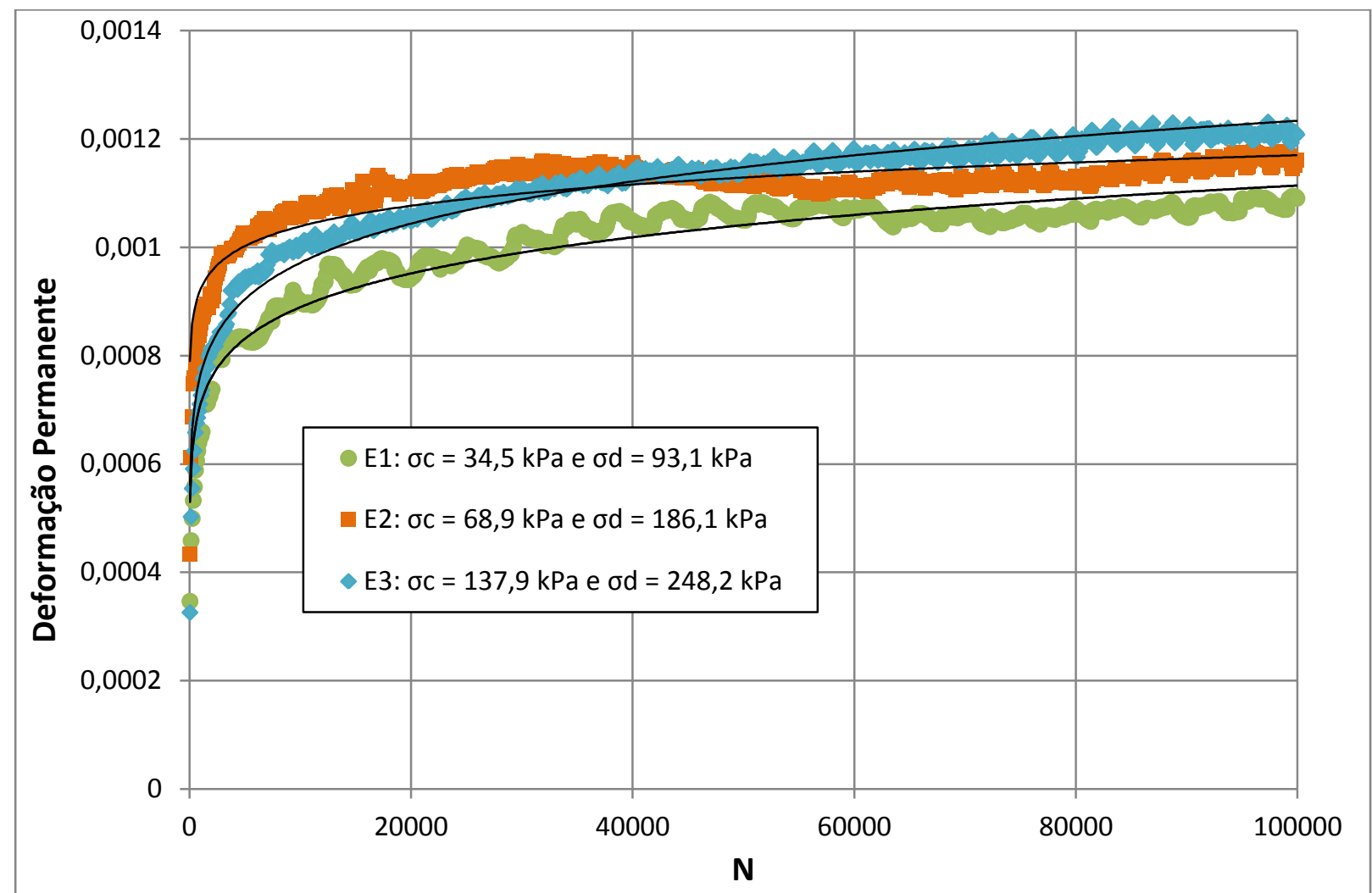

FIGURA 4.11. - Deformação permanente em função do número de aplicações de carga, para três pares de tensões (E1, E2 e E3), de corpos-de-prova de ARC ensaiados aos 28 dias de cura

TABELA 4.11. - Constantes de calibração e $\mathbf{R}^{2}$ do modelo de Monismith et al. (1975) aplicados aos resultados dos ensaios de deformação permanente em função do número de aplicações de carga, para três pares de tensões (E1, E2 e E3), de corpos-de-prova de ARC ensaiados aos 28 dias de cura

\begin{tabular}{cccc}
\hline Tensões & \multicolumn{3}{c}{ Modelo de Monismith } \\
aplicadas & $\boldsymbol{A}$ & $\boldsymbol{B}$ & $\boldsymbol{R}^{\mathbf{2}}$ \\
\hline E1 & 0,0004 & 0,0978 & 0,90 \\
E2 & 0,0006 & 0,0517 & 0,68 \\
E3 & 0,0004 & 0,1038 & 0,94 \\
\hline
\end{tabular}

Analisando-se a Figura 4.11 e a Tabela 4.11 e considerando-se os coeficientes de determinação, pode-se afirmar que o modelo de Monismith et al. (1975) representa bem a variação da deformação permanente com o número de aplicações de carga. Os coeficientes de determinação das calibrações desse modelo foram de $90 \%, 68 \%$ e $94 \%$, respectivamente para os corpos-de-prova ensaiados sob os pares de tensões E1, E2 e E3. 
Analisando-se ainda, os coeficientes A e B do modelo de Monismith et al. (1975), não foi possível identificar um padrão para a variação desses coeficientes em função dos pares de tensões aplicados.

A Tabela 4.12 apresenta as deformações permanentes iniciais e finais, para os três pares de tensão estudados, e a variação percentual das mesmas considerando-se o menor estado de tensão. Analisando-se estes valores, observase que para a deformação permanente inicial não foi identificado um comportamento em função do aumento do estado de tensão, visto que aumenta e reduz-se com o estado de tensão intermediário e o maior, respectivamente. Quanto à deformação permanente final, esta cresce com o aumento do estado de tensão, entretanto a variação é muito reduzida, com o valor máximo igual a 11\%.

TABELA 4.12. - Deformação permanente inicial e final do ARC para os três pares de tensões estudados (E1, E2 e E3)

\begin{tabular}{c|cc|cc}
\hline Tensões aplicadas & \multicolumn{2}{|c|}{ Inicial } & \multicolumn{2}{c}{ Final } \\
& $\varepsilon_{\mathrm{p}}$ & Variação (\%) & $\varepsilon_{\mathrm{p}}$ & Variação (\%) \\
\hline $\mathrm{E} 1: \sigma_{\mathrm{c}}=34,5 \mathrm{kPa}$ e $\sigma_{\mathrm{d}}=93,1 \mathrm{kPa}$ & 0,000346 & - & 0,001090 & - \\
$\mathrm{E} 2: \sigma_{\mathrm{c}}=68,9 \mathrm{kPa}$ e $\sigma_{\mathrm{d}}=186,1 \mathrm{kPa}$ & 0,000434 & 25 & 0,001161 & 7 \\
$\mathrm{E} 3: \sigma_{\mathrm{c}}=137,9 \mathrm{kPa}$ e $\sigma_{\mathrm{d}}=248,2 \mathrm{kPa}$ & 0,000326 & -6 & 0,001208 & 11 \\
\hline
\end{tabular}

Comparando-se os efeitos do estado de tensão e do tempo de cura na deformação permanente final, verifica-se que as porcentagens máximas de variação foram $11 \%$ e $57 \%$, respectivamente. Portanto, para as condições da pesquisa, constata-se que o efeito do estado de tensão na deformação permanente é reduzido frente ao efeito do tempo de cura. 


\subsubsection{Módulo de resiliência determinado ao longo do ensaio de deformação permanente}

Durante os ensaios triaxiais cíclicos para determinação da deformação permanente, além das leituras dos deslocamentos plásticos, foram também realizadas as leituras dos deslocamentos elásticos, a fim de se acompanhar o comportamento do módulo de resiliência ao longo dos ensaios.

A Figura 4.12 apresenta as curvas de módulo de resiliência em função do número de aplicações para o par de tensões E2, obtidas ao longo dos ensaios triaxiais cíclicos realizados para estudo do efeito do tempo de cura nas deformações permanentes de corpos-de-prova de ARC preparados na condição ótima do Proctor intermediário e ensaiados com $0,7,28,90$ e 180 dias. A Tabela 4.13 apresenta os valores de módulo de resiliência inicial e final, calculados a partir de equações polinomiais de $2^{\mathrm{a}}$ ordem obtidas através das linhas de tendência provenientes dos valores de MR ao longo das aplicações de carga. Ressalta-se que estas linhas de tendência foram traçadas apenas para servirem como critério na adoção dos valores de MR inicial e final, devido à dispersão destes resultados associada à execução do ensaio. 


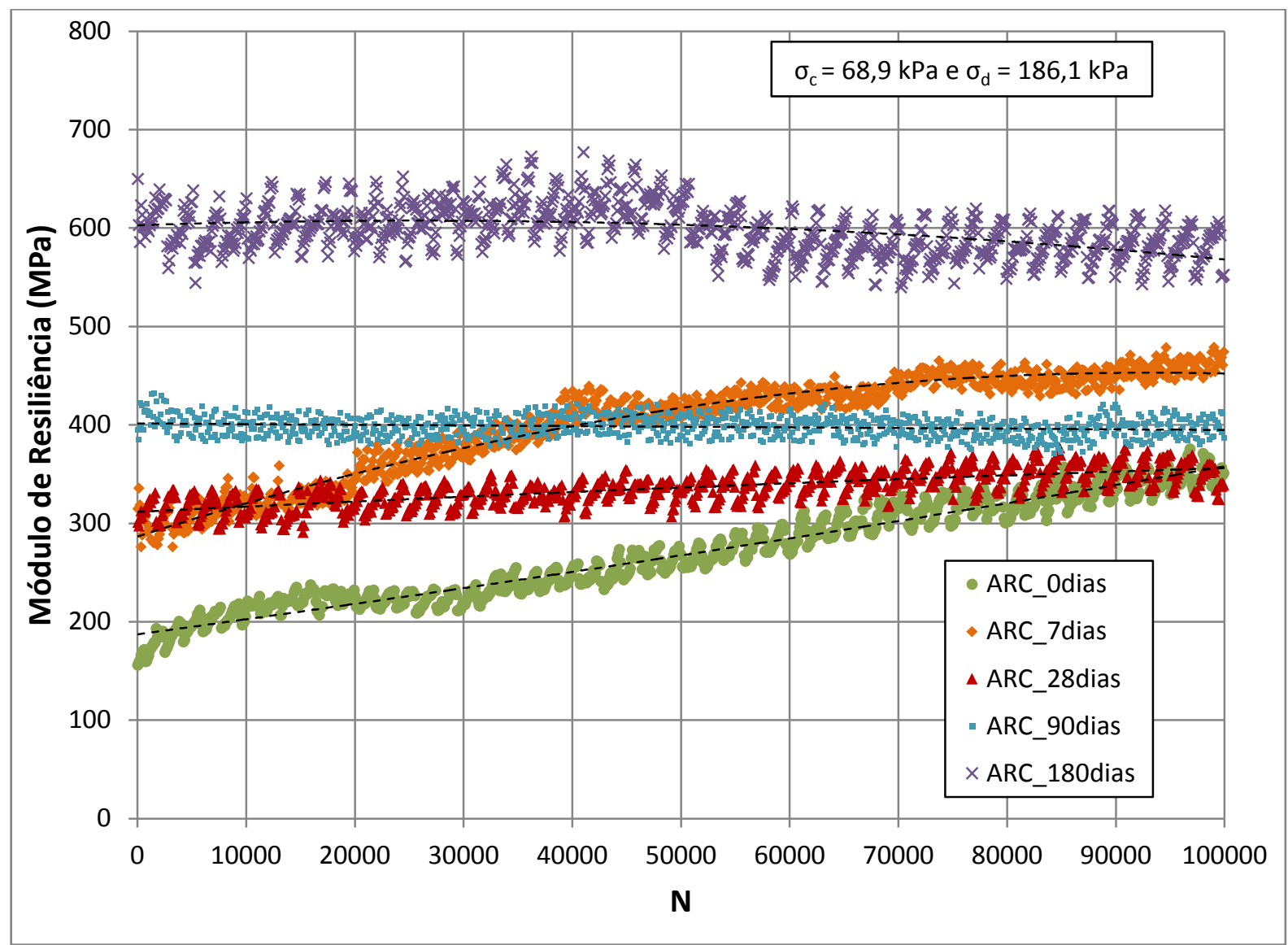

FIGURA 4.12. - Módulo de resiliência com o número de aplicações de carga para corpos-de-prova de ARC ensaiados em diversos tempos de cura

TABELA 4.13. - Magnitudes e variações do módulo de resiliência inicial e final para corpos-de-prova de ARC ensaiados em diversos tempos de cura

\begin{tabular}{c|cc|cc|c}
\hline $\begin{array}{c}\text { Tempo de } \\
\text { Cura (dias) }\end{array}$ & \multicolumn{2}{|c|}{$\begin{array}{c}\text { Inicial } \\
\text { Ganho de }\end{array}$} & \multicolumn{2}{c|}{ Final } & $\begin{array}{c}\text { Variação do MR } \\
\text { final em relação } \\
\text { ar inicial (\%) }\end{array}$ \\
\hline 0 & 187 & - & 358 & - & 91 \\
7 & 287 & 53 & 452 & 26 & 58 \\
28 & 312 & 66 & 356 & 0 & 14 \\
90 & 402 & 114 & 395 & 10 & -2 \\
180 & 603 & 222 & 568 & 59 & -6 \\
\hline
\end{tabular}

Analisando-se a Figura 4.12 e a Tabela 4.13, observa-se que, no geral, o módulo de resiliência inicial cresce com o aumento do tempo de cura. Tomando-se os valores de módulo de resiliência inicial para cada um dos tempos de cura, verifica-se que o ganho de rigidez calculado com relação ao corpo-de-prova 
ensaiado sem cura é de 53\%,66\%, 114\% e 222\%, respectivamente para 7, 28, 90 e 180 dias de cura.

Quanto ao módulo de resiliência final, não foi possível identificar um comportamento ao longo do tempo de cura. Tomando-se os valores de módulo de resiliência final para cada um dos tempos de cura, verifica-se que o ganho de rigidez calculado com relação ao corpo-de-prova ensaiado sem cura é de $26 \%, 0 \%, 10 \%$ e $59 \%$, respectivamente para $7,28,90$ e 180 dias de cura.

Ainda, analisando-se a Figura 4.12 e a Tabela 4.13, observa-se que o módulo de resiliência do ARC varia ao longo das aplicações de carga. Tomando-se os valores de módulo de resiliência inicial e final para cada tempo de cura, verifica-se que a variação do módulo de resiliência final em relação ao módulo de resiliência inicial foi de $91 \%, 58 \%, 14 \%,-2 \%$ e $-6 \%$, respectivamente para 0, 7, 28, 90 e 180 dias de cura.

Portanto, a variação do módulo de resiliência ao longo das aplicações de carga diminui com o aumento do tempo de cura, tornando-se praticamente nula aos 90 dias. Acredita-se que essa variação ocorra devido ao rearranjo das partículas de $\mathrm{ARC}$, oriundo das deformações permanentes do corpo-de-prova ao longo das aplicações de carregamento no ensaio triaxial cíclico, que ocorre em maiores taxas para tempos de cura menores, como visto anteriormente no item 4.1.5. Deste modo, como a deformação permanente observada para tempos de cura acima de 90 dias são relativamente pequenas, devido ao efeito da cimentação do $A R C$, o rearranjo das partículas também ocorre, mas a taxas muito pequenas que não puderam ser 
detectadas devido à dispersão associada ao ensaio, resultando assim em baixas variações do MR ao longo das aplicações de carga no ensaio triaxial cíclico.

Supondo-se a aplicação do ARC na construção da camada de base de pavimentos e levando-se em conta que o módulo de resiliência final varia pouco com o tempo de cura, ou seja, o efeito da cimentação no módulo de resiliência é reduzido com o aumento da solicitação do tráfego, pode-se concluir que o beneficio mecânico fornecido pela cimentação do $A R C$ ao longo do tempo de cura é mais expressivo para a redução das deformações permanentes, do que para a redução da fadiga.

A Figura 4.13 apresenta as curvas de módulo de resiliência em função do número de aplicações de carga, para os três pares de tensões (E1, E2 e E3), obtidas ao longo dos ensaios triaxiais cíclicos realizados para estudo do efeito do estado de tensão nas deformações permanentes de corpos-de-prova de ARC preparados na condição ótima do Proctor intermediário e ensaiados com tempo de cura de 28 dias. A Tabela 4.14 apresenta os valores de módulo de resiliência inicial e final, calculados a partir de equações polinomiais de $2^{\mathrm{a}}$ ordem obtidas através das linhas de tendência provenientes dos valores de MR calculados ao longo das aplicações de carga. 


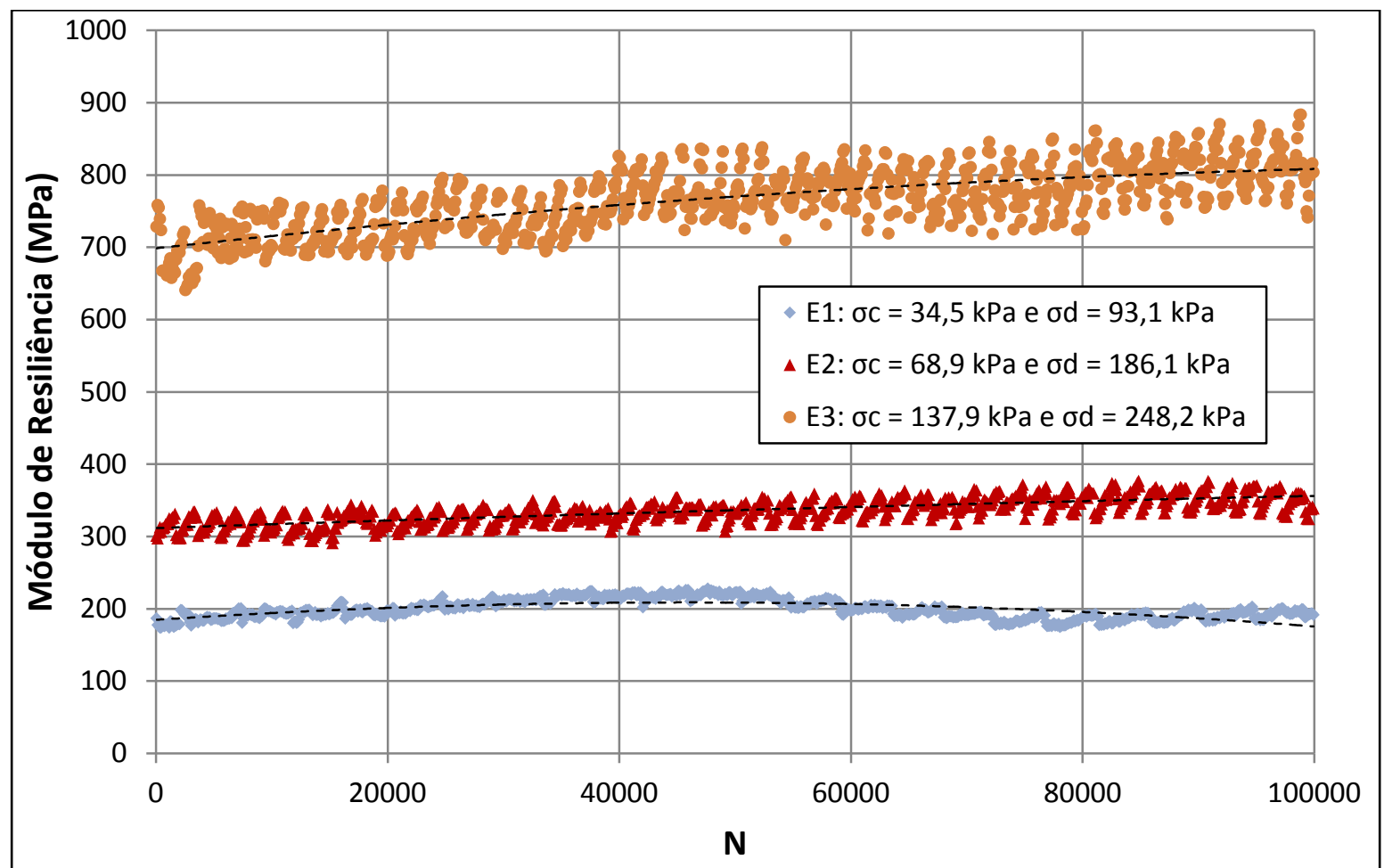

FIGURA 4.13. - Módulo de resiliência com o número de aplicações de carga para corpos-de-prova de ARC ensaiados com 28 dias de cura para três estados de tensão (E1, E2 e E3)

TABELA 4.14. - Magnitudes e variações do módulo de resiliência inicial e final para corpos-de-prova de ARC ensaiados com 28 dias de cura para três estados de tensão (E1, E2 e E3)

\begin{tabular}{|c|c|c|c|c|c|}
\hline \multirow[b]{2}{*}{ Tensões aplicadas } & \multicolumn{2}{|c|}{ Inicial } & \multicolumn{2}{|c|}{ Final } & \multirow{2}{*}{$\begin{array}{c}\text { Variação do MR } \\
\text { final em relação } \\
\text { ao inicial (\%) }\end{array}$} \\
\hline & $\begin{array}{c}M R \\
(M P a)\end{array}$ & $\begin{array}{c}\text { Ganho de } \\
\text { MR (\%) }\end{array}$ & $\begin{array}{c}M R \\
(M P a)\end{array}$ & $\begin{array}{c}\text { Ganho de } \\
\text { MR (\%) }\end{array}$ & \\
\hline $\mathrm{E} 1: \sigma_{\mathrm{c}}=34,5 \mathrm{kPa}$ e $\sigma_{\mathrm{d}}=93,1 \mathrm{kPa}$ & 185 & - & 176 & - & -5 \\
\hline $\mathrm{E} 2: \sigma_{\mathrm{c}}=68,9 \mathrm{kPa}$ e $\sigma_{\mathrm{d}}=186,1 \mathrm{kPa}$ & 312 & 69 & 356 & 103 & 14 \\
\hline E3: $\sigma_{c}=137,9 \mathrm{kPa}$ e $\sigma_{d}=248,2 \mathrm{kPa}$ & 699 & 278 & 808 & 360 & 16 \\
\hline
\end{tabular}

Analisando-se a Figura 4.13 e a Tabela 4.14, observa-se que os módulos de resiliência iniciais e finais crescem com o aumento do estado de tensão. Tomandose os valores de módulo de resiliência inicial, verifica-se que as variações calculadas com relação ao menor estado de tensão (E1), foi de $69 \%$ e $278 \%$, respectivamente para o estado de tensão intermediário (E2) e o maior (E3). Quanto ao módulo de resiliência final, essas variações foram de $103 \%$ e $360 \%$, respectivamente. 
Ainda na Figura 4.13 e na Tabela 4.14, quando são comparados os módulos de resiliência inicial e final para cada um dos estados de tensão, observa-se que apesar de ocorrer uma variação, esta é muito pequena. Calculando-se a variação do módulo de resiliência final em relação ao inicial para os três estados de tensão, verifica-se que estas foram de $-5 \%, 14 \%$ e $16 \%$, respectivamente para os estados de tensão E1, E2 e E3.

Como observado e discutido anteriormente, acredita-se que a variação do módulo de resiliência em relação às aplicações de carga esteja atrelada ao rearranjo das partículas oriundo das deformações permanentes, observou-se também que a magnitude das deformações permanentes para os três estados de tensão foi relativamente baixa e que estas cresceram com o aumento das tensões.

\subsection{7. Índice de suporte Califórnia}

A Tabela 4.15 apresenta os valores médios de índice de suporte Califórnia (CBR) dos corpos-de-prova de ARC preparados na condição ótima do Proctor na energia intermediária e ensaiados com tempos de cura de 0, 7 e 28 dias. Ressalta-se ainda, que a imersão dos corpos-de-prova deu-se depois de decorridos os tempos de cura em questão. Os valores encontrados na Tabela 4.15 estão ilustrados graficamente na Figura 4.14. 
TABELA 4.15. - Resultados de CBR dos corpos-de-prova de ARC ensaiados com diversos tempos de cura

\begin{tabular}{ccc}
\hline $\begin{array}{c}\text { Tempo de } \\
\text { Cura (dias) }\end{array}$ & $\begin{array}{c}\text { Resultados } \\
\text { de CBR (\%) }\end{array}$ & $\begin{array}{c}\text { Média dos } \\
\text { CBR (\%) }\end{array}$ \\
\hline \multirow{2}{*}{0} & 77 & 93 \\
& 110 & 114 \\
\hline \multirow{2}{*}{7} & 94 & \\
& 134 & 127 \\
\hline \multirow{2}{*}{28} & 150 & \\
& 124 & \\
\hline
\end{tabular}

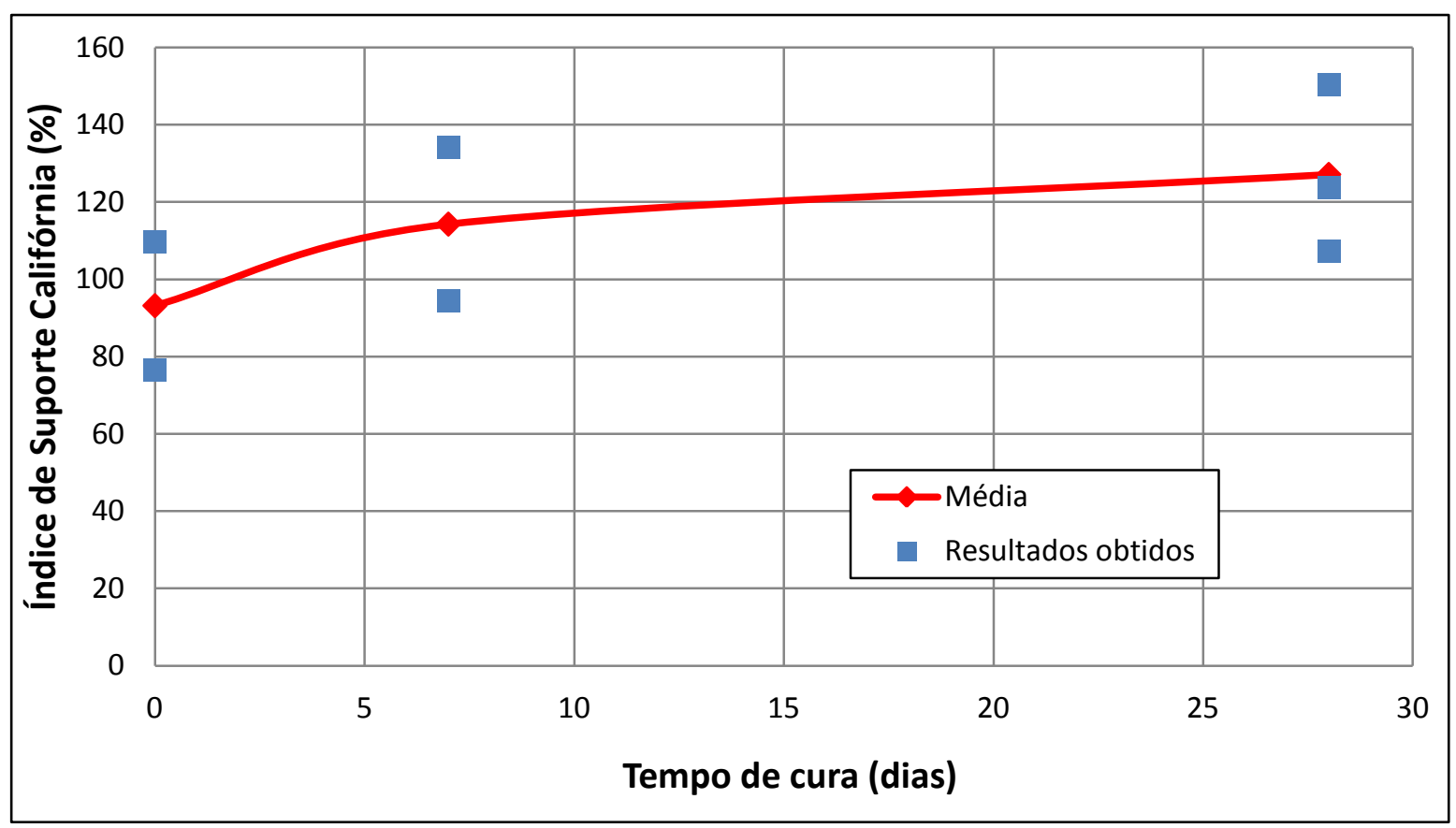

FIGURA 4.14. - Resultados de CBR dos corpos-de-prova de ARC ensaiados com diversos tempos de cura

Analisando-se a Tabela 4.15 e a Figura 4.14, observa-se que as médias dos resultados de CBR cresceram com o aumento do tempo de cura, este crescimento calculado com relação aos corpos-de-prova ensaiados sem cura foi de $23 \%$ e $37 \%$, respectivamente para 7 e 28 dias de cura. No entanto, observa-se que os resultados de CBR apresentaram uma grande variabilidade entre si, que chegou a $43 \%$ no caso dos corpos-de-prova ensaiados sem cura. 
Portanto, como a variação máxima observada para as médias dos resultados de CBR em relação ao tempo de cura é menor que a própria variabilidade do ensaio, não é possível afirmar que a cura do ARC leva a ganhos de suporte CBR. Contudo, os valores de CBR encontrados são superiores aos limites de $20 \%$ e $60 \%$ especificados pela norma NBR 15115 (ABNT, 2004) para emprego de agregados reciclados de resíduos sólidos da construção em camadas de sub-base e base, respectivamente.

\subsection{MISTURA SOLO - ARC}

É importante salientar, como apresentado e justificado no Capítulo 3, Materiais e Métodos, que a mistura solo - ARC foi compactada na energia modificada e ensaiada com tempos de cura de 0, 7 e 28 dias, diferentemente do ARC. Destaca-se ainda, que as comparações referentes aos dois materiais serão apresentadas ao final deste capítulo, no item 4.3.

\subsubsection{Resistência à compressão simples}

A Tabela 4.16 apresenta os valores médios de resistência à compressão simples (RCS) dos corpos-de-prova da mistura solo - ARC submetidos ao ensaio de compressão simples na condição ótima do Proctor modificado e ensaiados com tempos de cura de 0,7 e 28 dias. Todos os resultados, com exceção dos que apresentaram erros durante a execução, estão apresentados no Apêndice I. Os valores encontrados na Tabela 4.16 estão ilustrados graficamente na Figura 4.15. 
TABELA 4.16. - Resultados de RCS dos corpos-de-prova da mistura solo - ARC ensaiados com diversos tempos de cura e percentual e gradiente de resistência

\begin{tabular}{cccc}
\hline $\begin{array}{c}\text { Tempo de } \\
\text { Cura (dias) }\end{array}$ & $\begin{array}{c}\text { RCS } \\
(\mathbf{k P a})\end{array}$ & $\begin{array}{c}\text { Ganho de } \\
\boldsymbol{R C S}(\%)\end{array}$ & $\begin{array}{c}\text { Ganho de RCS / } \\
\text { dia (kPa/dia) }\end{array}$ \\
\hline 0 & 319 & - & - \\
7 & 375 & 18 & 8,0 \\
28 & 614 & 92 & 10,5 \\
\hline
\end{tabular}

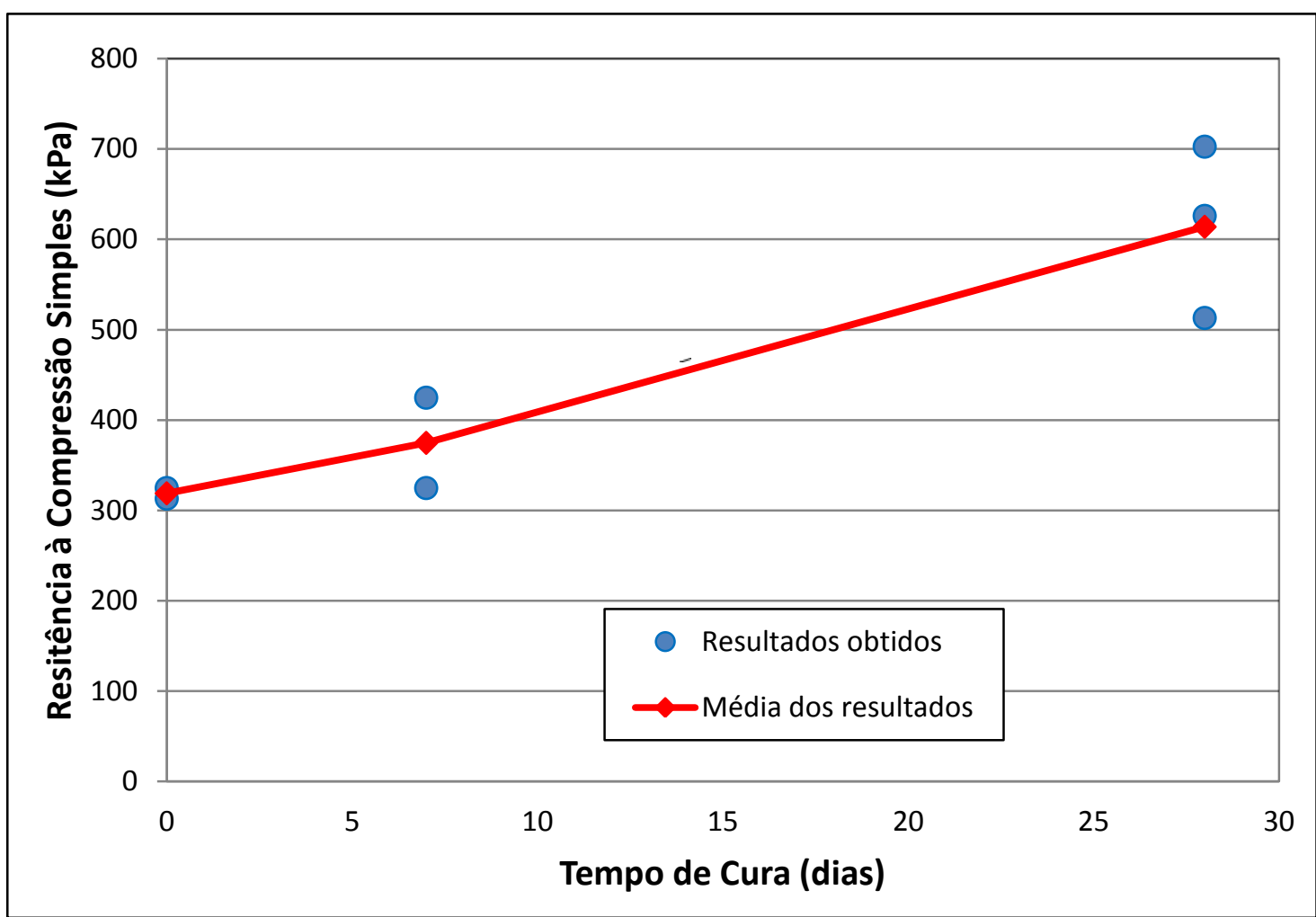

FIGURA 4.15. - Resultados de RCS dos corpos-de-prova da mistura solo - ARC ensaiados em diferentes tempos de cura

Analisando-se a Tabela 4.16 e a Figura 4.15, observa-se que a RCS do soloARC cresce com o aumento do tempo de cura. Tomando-se as médias de RCS para cada um dos tempos de cura, verifica-se que o ganho de resistência calculado com relação aos corpos-de-prova ensaiados sem cura é de 18\% e 92\%, respectivamente para 7 e 28 dias de cura. 
Portanto, verifica-se que existe um aumento da resistência da mistura solo $\mathrm{ARC}$ ao longo do tempo de cura, sendo que até os 28 dias, sua taxa de crescimento

é aproximadamente constante e igual a $10,5 \mathrm{kPa} / \mathrm{dia}$. Assim como para o ARC, acredita-se que o ganho de resistência se deva a presença de cimento não hidratado que é exposto durante a britagem, no processo de reciclagem dos resíduos de concreto e argamassa.

\subsubsection{Módulo tangente a $50 \%$ da tensão de ruptura}

A Tabela 4.17 apresenta os valores médios de módulo tangente a $50 \%$ da tensão de ruptura dos corpos-de-prova da mistura solo - ARC submetidos ao ensaio de compressão simples na condição ótima do Proctor modificado e ensaiados com tempos de cura de 0,7 e 28 dias. Todos os resultados, com exceção dos que apresentaram erros durante a execução, estão apresentados no Apêndice I. Os valores encontrados na Tabela 4.17 estão ilustrados graficamente na Figura 4.16.

TABELA 4.17. - Resultados de $E_{50 \%}$ dos corpos-de-prova da mistura solo - ARC ensaiados com diversos tempos de cura, percentual e gradiente de ganho de rigidez

\begin{tabular}{cccc}
\hline $\begin{array}{c}\text { Tempo de } \\
\text { Cura (dias) }\end{array}$ & $\begin{array}{c}E_{50 \%} \\
(\mathrm{MPa})\end{array}$ & $\begin{array}{c}\text { Ganho de } \\
\boldsymbol{E}_{50 \%}(\%)\end{array}$ & $\begin{array}{c}\text { Ganho de } E_{50 \%} / \\
\text { dia }\end{array}$ \\
\hline 0 & 46 & - & - \\
7 & 50 & 9 & 0,6 \\
28 & 72 & 56 & 0,9 \\
\hline
\end{tabular}




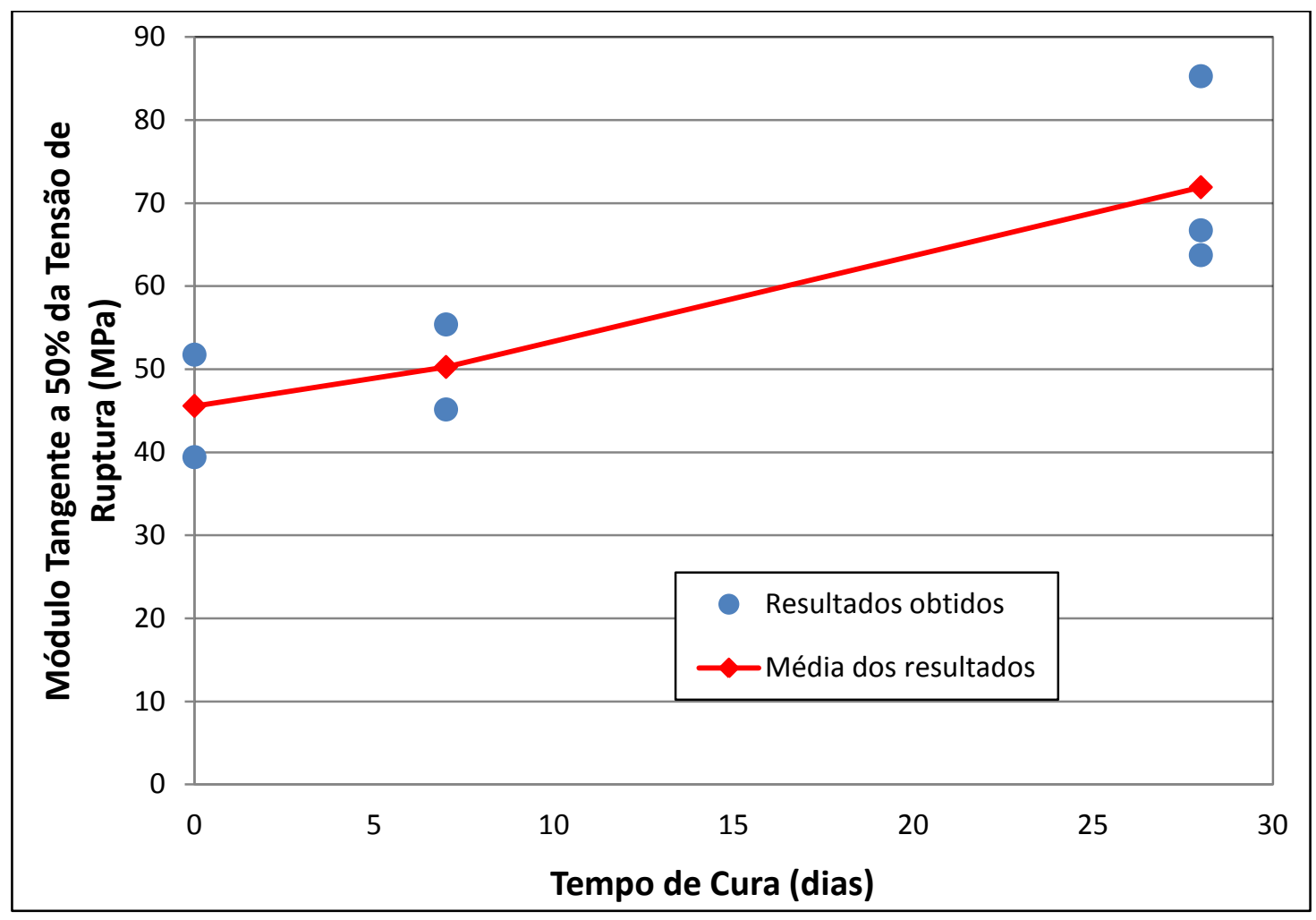

FIGURA 4.16. - Resultados de $\mathrm{E}_{50 \%}$ dos corpos-de-prova da mistura solo - ARC ensaiados em diferentes tempos de cura

Analisando-se a Tabela 4.17 e a Figura 4.16, observa-se que o $\mathrm{E}_{50 \%}$ do solo $A R C$ cresce com o aumento do tempo de cura. Tomando-se as médias de $E_{50 \%}$ para cada um dos tempos de cura, verifica-se que o ganho de rigidez calculado com relação aos corpos-de-prova ensaiados sem cura é de $9 \%$ e $56 \%$, respectivamente para 7 e 28 dias de cura.

Portanto, verifica-se que existe um aumento de rigidez da mistura solo - ARC ao longo do tempo de cura, sendo que até os 28 dias, sua taxa de crescimento é aproximadamente constante e igual a 0,9 MPa/dia.

Comparando-se os ganhos de resistência e rigidez ao longo do tempo de cura, observa-se que a resistência é mais sensível a esta variável, visto que a RCS e $0 E_{50 \%}$ apresentaram uma porcentagem de variação de $92 \%$ e $56 \%$, 
respectivamente para corpos-de-prova curados durante 28 dias com relação aos corpos-de-prova sem cura.

\subsubsection{Módulo de resiliência}

A Tabela 4.18 apresenta as constantes de calibração dos modelos de módulo de resiliência e os respectivos coeficientes de determinação dos corpos-de-prova da mistura solo - ARC submetidos ao ensaio triaxial cíclico na condição ótima do Proctor modificado e ensaiados com tempos de cura de 0,7 e 28 dias. Considerando-se que foram ensaiados diversos corpos-de-prova, a Tabela 4.18 apresenta para cada um dos modelos analisados, os resultados das constantes de calibração obtidos para os ensaios que conduziram aos maiores coeficientes de determinação, referentes ao modelo composto.

TABELA 4.18. - Constantes de calibração e $\mathbf{R}^{2}$ dos modelos de módulo de resiliência dos corpos-de-prova da mistura solo - ARC ensaiados em diferentes tempos de cura

\begin{tabular}{|c|c|c|c|c|c|}
\hline Modelo & $\begin{array}{l}\text { Tempo de } \\
\text { Cura (dias) } \\
\end{array}$ & $K 1$ & $K 2$ & $\kappa 3$ & $R^{2}$ \\
\hline \multirow{3}{*}{$\begin{array}{l}M R=K_{1} \sigma_{c}{ }^{K_{2}} \\
\text { Equação } 4.1\end{array}$} & 0 & 188,59 & 0,23 & - & 0,32 \\
\hline & 7 & 299,38 & 0,17 & - & 0,16 \\
\hline & 28 & 4130,02 & $-0,35$ & - & 0,31 \\
\hline \multirow{3}{*}{$\begin{array}{l}M R=K_{1} \sigma_{d}^{K_{3}} \\
\text { Equação } 4.2\end{array}$} & 0 & 2786,76 & - & $-0,34$ & 0,73 \\
\hline & 7 & 2672,33 & - & $-0,30$ & 0,53 \\
\hline & 28 & 16745,06 & - & $-0,62$ & 0,72 \\
\hline \multirow{3}{*}{$\begin{array}{c}M R=K_{1} \sigma_{c}{ }^{K_{2}} \sigma_{d}{ }^{K_{3}} \\
\text { Equação } 4.3\end{array}$} & 0 & 2826,64 & 0,36 & $-0,71$ & 0,93 \\
\hline & 7 & 2557,59 & 0,30 & $-0,60$ & 0,95 \\
\hline & 28 & 7858,26 & 0,49 & $-0,92$ & 0,92 \\
\hline \multirow{2}{*}{$M R=K_{1} p_{a}\left(\frac{\theta}{p_{a}}\right)^{K_{2}}\left(\frac{\tau_{o c t}}{p_{a}}+1\right)^{K_{3}}$} & 0 & 5,19 & 0,52 & $-1,51$ & 0,73 \\
\hline & 7 & 9,24 & 0,36 & $-2,12$ & 0,84 \\
\hline Equação 4.4 & 28 & 27,27 & 0,60 & $-4,78$ & 0,90 \\
\hline
\end{tabular}

Analisando-se os coeficientes de correlação e tomando-os como medida da capacidade de cada um dos modelos de representar a variação do módulo de 
resiliência com o estado de tensão, o modelo composto apresenta 0 melhor desempenho, seguido dos modelos universal, tensão desvio e tensão confinante.

Tomando-se o modelo composto, de melhor desempenho, e comparando os valores assumidos por $k_{2}$ e $k_{3}$, expoentes das tensões confinante e desvio respectivamente, verifica-se que o módulo de resiliência cresce com o aumento da tensão confinante e decresce com o aumento da tensão desvio. E também, considerando-se que as variações de ambas as tensões são de mesma ordem, os maiores valores assumidos pelo expoente da tensão desvio são indicativos que esta variável tem maior influência no módulo de resiliência que a tensão confinante. $O$ melhor desempenho da Equação 4.2 quando comparada ao da Equação 4.1, modelos expressos apenas em função de uma única tensão, desvio e confinante respectivamente, é decorrente deste fato. Não foi possível identificar um padrão para a variação dos expoentes das tensões com a variação do tempo de cura.

Para se analisar a influência do tempo de cura no módulo de resiliência da mistura solo - ARC, utilizou-se a mesma estrutura do pavimento apresentada no item 4.1.4 deste capítulo, como exemplo. A Tabela 4.19 apresenta os valores de módulo de resiliência determinados no centro da camada de base da estrutura proposta através do processo interativo de cálculo também descrito no item 4.1.4, estes valores estão ilustrados na Figura 4.17. 
TABELA 4.19. - Valores de módulo de resiliência da mistura solo - ARC determinados no centro da camada de base da estrutura proposta para diferentes tempos de cura

\begin{tabular}{cccccccc}
\hline \multirow{2}{*}{$\begin{array}{c}\text { Tempo de } \\
\text { Cura (dias) }\end{array}$} & \multicolumn{3}{c}{ Modelo Composto } & \multicolumn{4}{c}{ Tensões no ponto de } \\
análise (kPa) & MR \\
& K1 & K2 & K3 & \multicolumn{1}{c}{$\boldsymbol{\sigma}_{\mathrm{c}}$} & $\boldsymbol{\sigma}_{\mathrm{d}}$ & \\
\hline $\mathbf{M P a}$ ) \\
\hline 0 & 2826,64 & 0,36 & $-0,71$ & 54,6 & 65,4 & 614 \\
7 & 2557,59 & 0,30 & $-0,60$ & 52,2 & 64,8 & 706 \\
28 & 7858,26 & 0,49 & $-0,92$ & 47,7 & 59,3 & 1191 \\
\hline
\end{tabular}

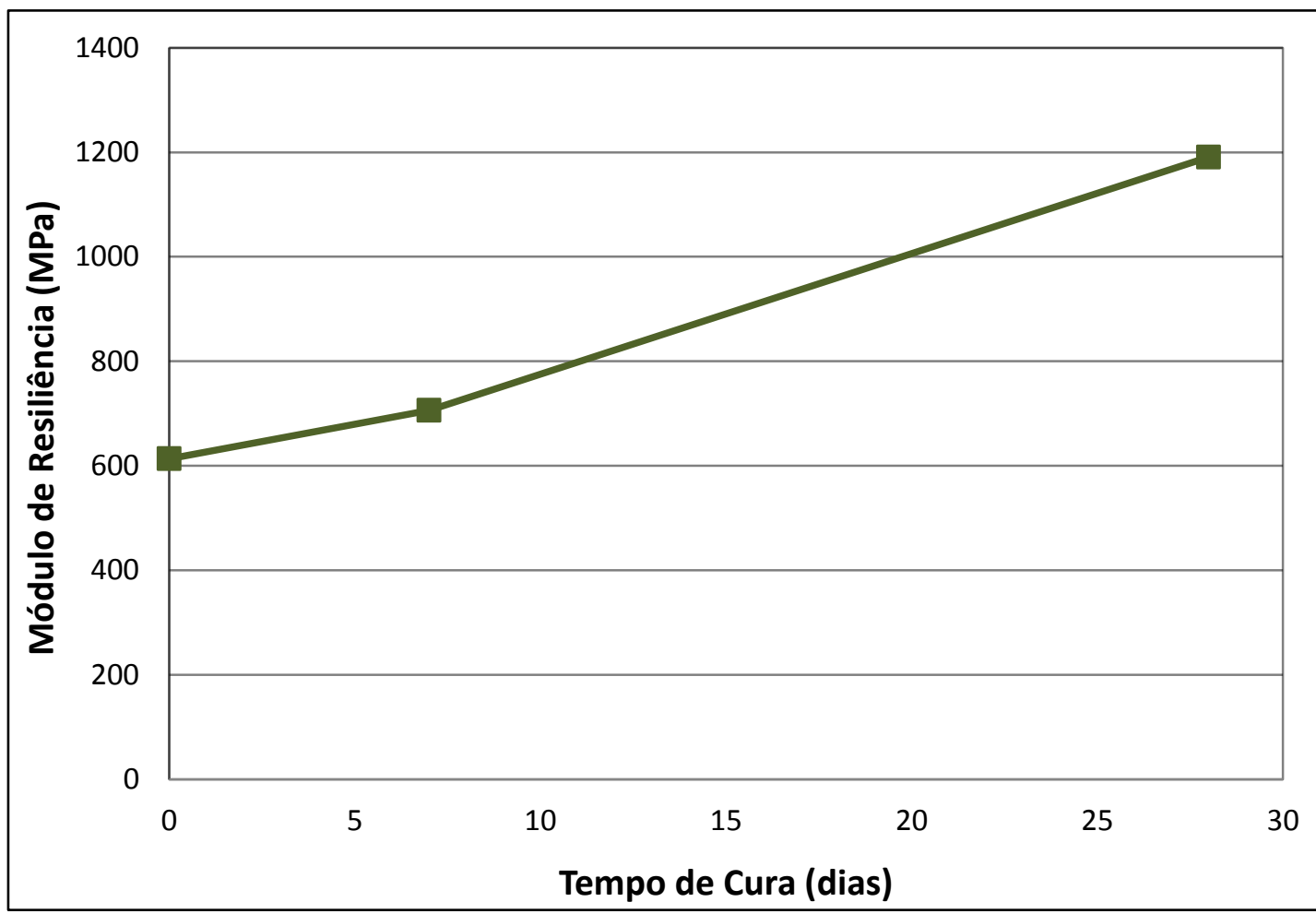

FIGURA 4.17. - Valores de módulo de resiliência da mistura solo - ARC determinados no centro da camada de base da estrutura proposta para diferentes tempos de cura

Analisando-se a Tabela 4.19 e a Figura 4.17, observa-se que o MR cresce com o aumento do tempo de cura. Tomando-se os valores de MR para cada um dos tempos de cura, verifica-se que o ganho de rigidez calculado com relação ao corpode-prova ensaiado sem cura é de $15 \%$ e $94 \%$, respectivamente para 7 e 28 dias de cura. 
Para se comparar o efeito do tempo de cura no módulo de resiliência com o seu efeito na resistência à compressão simples e módulo tangente a 50\% da tensão de ruptura, foram consideradas as porcentagens de ganho no valor destas variáveis calculadas para corpos-de-prova ensaiados após 28 dias com relação aos ensaiados sem cura. Os ganhos assim determinados foram de $92 \%$, 56\% e 94\%, respectivamente para a $\mathrm{RCS}, \mathrm{E}_{50 \%}$ e MR. É importante destacar, que o valor relativo ao MR refere-se ao observado para a estrutura proposta. Deste modo, constata-se que o efeito da cimentação é maior no módulo de resiliência do que nas demais variáveis aqui apresentadas.

\subsubsection{Deformação permanente}

Vale salientar, que para a mistura solo - ARC estudou-se somente o efeito do tempo de cura na deformação permanente, diferentemente do ARC que contemplou ainda em seu estudo o efeito da variação das tensões aplicadas.

A Figura 4.18 apresenta as curvas de deformação permanente acumulada em função do número de aplicações do par de tensões, E2: $\sigma \mathrm{c}=68,9 \mathrm{kPa}$ e $\sigma \mathrm{d}=186,1$ $\mathrm{kPa}$, para os corpos-de-prova da mistura solo - ARC submetidos ao ensaio triaxial cíclico na condição ótima do Proctor modificado e ensaiados com tempos de cura de 0, 7 e 28 dias. A partir destas curvas, determinaram-se as constantes de calibração do modelo de Monismith (1975) e os coeficientes de determinação $\left(R^{2}\right)$, que estão apresentados na Tabela 4.20. 


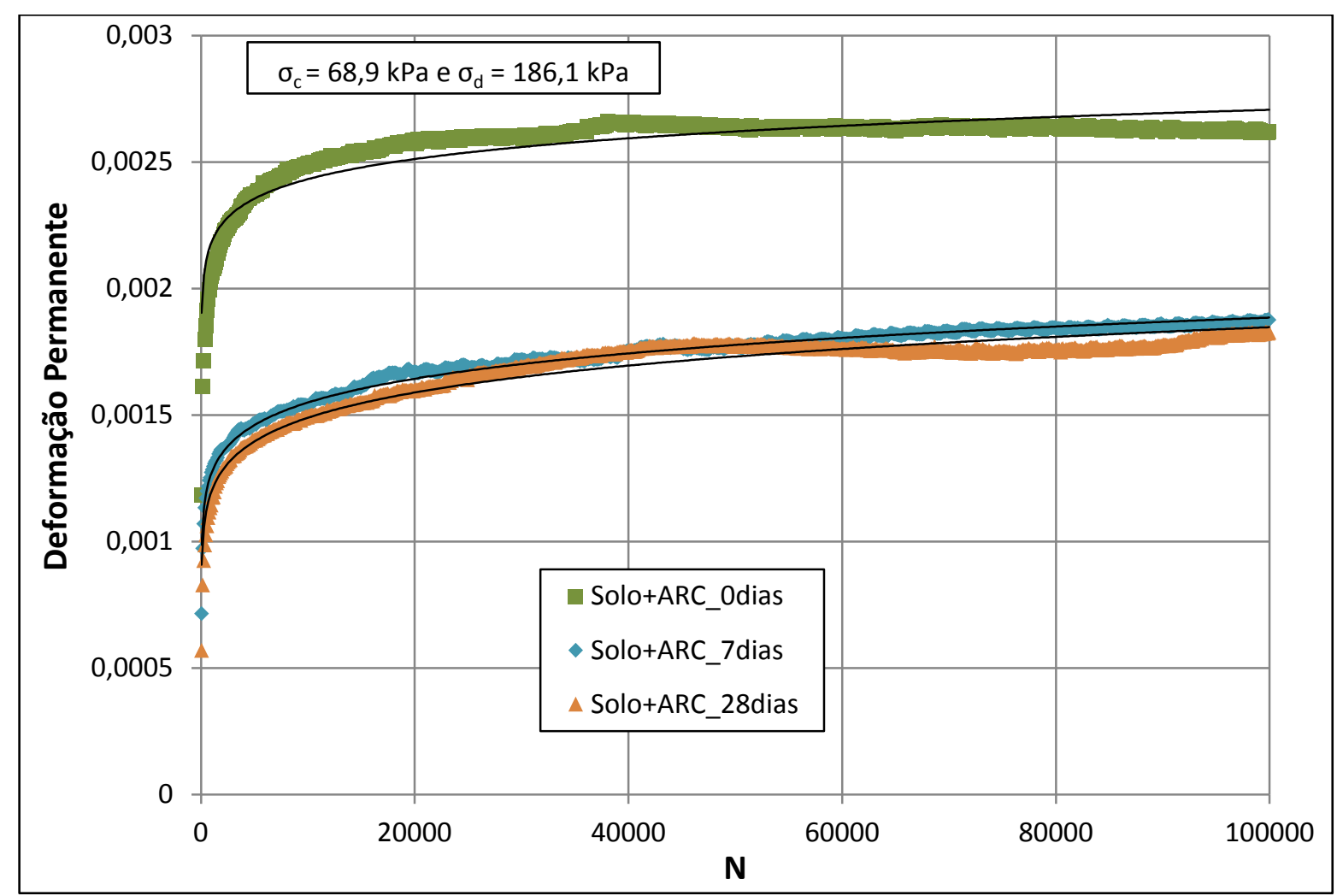

FIGURA 4.18. - Curvas de deformação permanente em função do número de aplicações de carga para corpos-de-prova da mistura solo - ARC ensaiados em diferentes tempos de cura

TABELA 4.20. - Constantes de calibração e $R^{2}$ da deformação permanente em função do número de aplicações de carga para corpos-de-prova da mistura solo - ARC ensaiados em diferentes tempos de cura

\begin{tabular}{cccc}
\hline Tempo de & \multicolumn{3}{c}{ Modelo de Monismith } \\
Cura (dias) & $\boldsymbol{A}$ & $\boldsymbol{B}$ & $\boldsymbol{R}^{\mathbf{2}}$ \\
\hline 0 & 0,0016 & 0,0464 & 0,74 \\
7 & 0,0007 & 0,0852 & 0,98 \\
28 & 0,0006 & 0,0935 & 0,92 \\
\hline
\end{tabular}

Analisando-se a Figura 4.18 e a Tabela 4.20 e considerando-se os coeficientes de determinação $\left(R^{2}\right)$, pode-se afirmar que o modelo de Monismith et al. (1975) representa bem a variação da deformação permanente com o número de aplicações de carga. Os coeficientes de determinação das calibrações desse modelo foram de $74 \%$, $98 \%$ e $92 \%$, respectivamente para 0,7 e 28 dias de cura. 
Analisando-se ainda a Tabela 4.20, observa-se que o coeficiente B do modelo de Monismith et al. (1975) cresceu com o aumento do tempo de cura e o coeficiente A decresceu. Estas variações demonstram respectivamente, para as condições desta pesquisa, que o efeito do tempo de cura na mistura solo - ARC, ao mesmo tempo, eleva a taxa de crescimento e reduz a magnitude das deformações permanentes ao longo das aplicações de carga.

Observa-se na Figura 4.18, que quanto maior o tempo de cura, menor é a deformação permanente ao longo das aplicações de carga. Esse comportamento pode ser observado e discutido quando se analisa a deformação permanente no início e no final da curva. Neste sentido, a Tabela 4.21 apresenta os valores de deformação permanente, obtidos no início e no final das aplicações de carga, para tempos de cura de 0,7 e 28 dias. Estes valores estão ilustrados respectivamente nas Figuras 4.19 e 4.20 .

TABELA 4.21. - Deformações permanentes iniciais e finais da mistura solo ARC para diferentes tempos de cura e suas respectivas reduções em relação aos resultados sem cura

\begin{tabular}{c|cc|cc}
\hline $\begin{array}{c}\text { Tempo de } \\
\text { Cura (dias) }\end{array}$ & \multicolumn{2}{|c|}{$\begin{array}{c}\text { Inicial } \\
\text { Redução de } \\
\varepsilon_{\mathrm{p}} \text { (\%) }\end{array}$} & \multicolumn{2}{c}{$\begin{array}{c}\text { Final } \\
\text { Redução de } \\
\varepsilon_{\mathrm{p}} \text { (\%) }\end{array}$} \\
\hline 0 & 0,001184 & - & 0,002619 & - \\
7 & 0,000750 & 37 & 0,001876 & 28 \\
28 & 0,000570 & 52 & 0,001827 & 30 \\
\hline
\end{tabular}




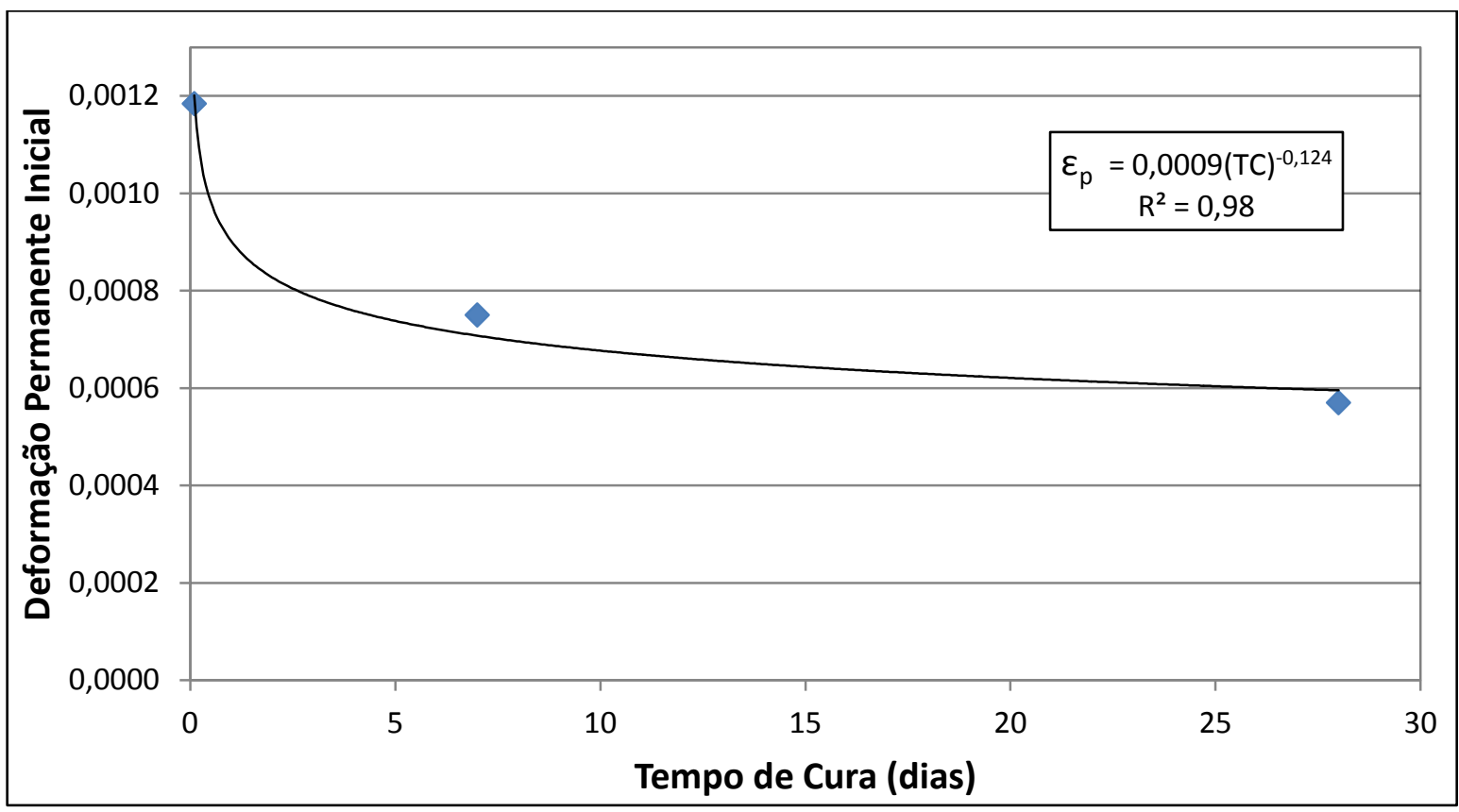

FIGURA 4.19. - Deformação permanente inicial da mistura solo - ARC em função do tempo de cura

Analisando-se a Tabela 4.21 e a Figura 4.19, observa-se que a deformação permanente inicial reduziu-se com o aumento do tempo de cura, essa redução, com relação ao corpo-de-prova ensaiado sem cura, é de $37 \%$ e $52 \%$, respectivamente para 7 e 28 dias de cura. 


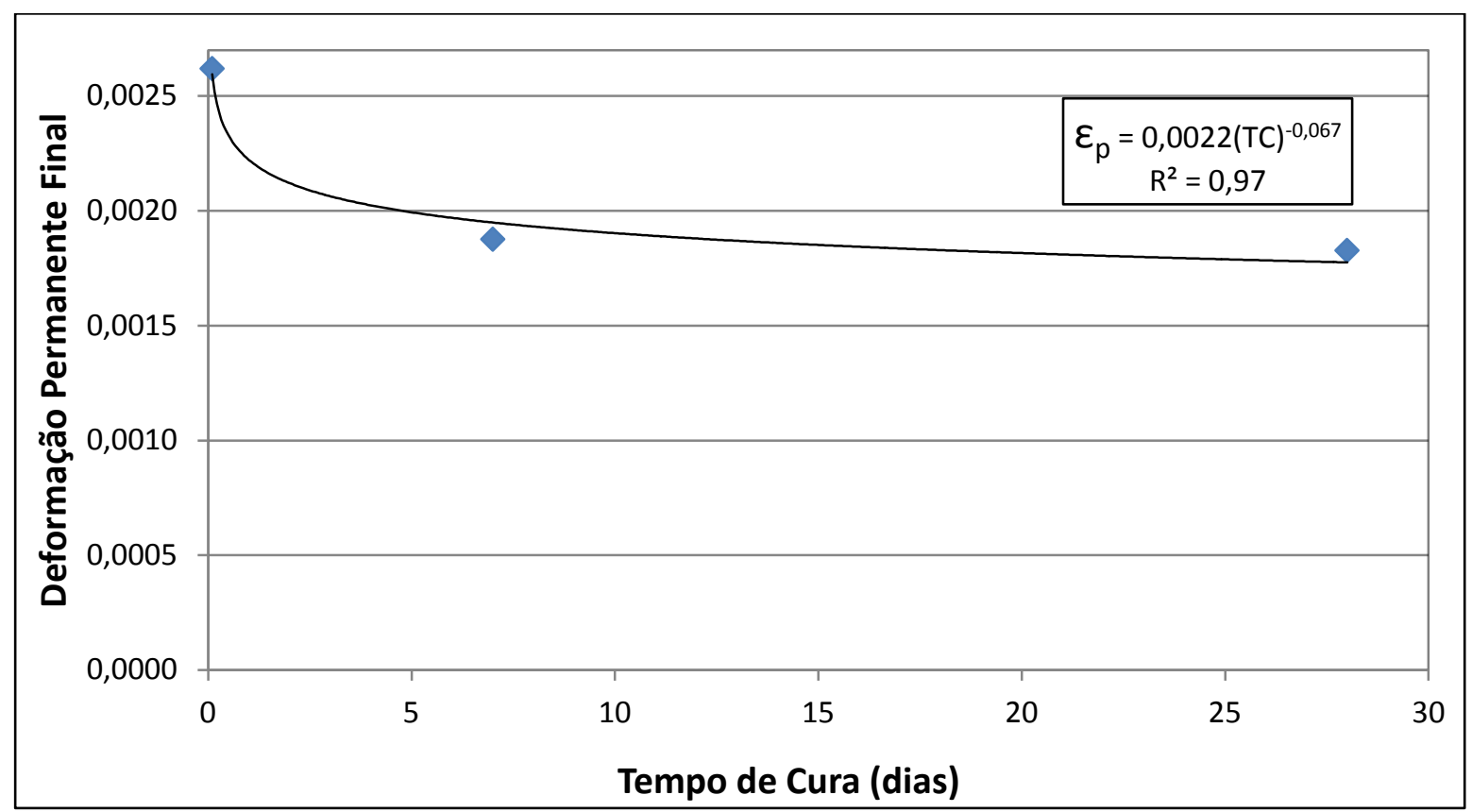

FIGURA 4.20. - Deformação permanente final da mistura solo - ARC em função do tempo de cura

Analisando-se a Tabela 4.21 e a Figura 4.20, observa-se que a deformação permanente final reduziu-se com o aumento do tempo de cura, essa redução, com relação ao corpo-de-prova ensaiado sem cura, é de $28 \%$ e $30 \%$, respectivamente para 7 e 28 dias de cura.

Comparando-se as reduções das deformações permanentes iniciais e finais decorrentes da cura da mistura solo - ARC calculadas em relação ao corpo-deprova ensaiado sem cura, observa-se que as reduções iniciais são maiores que as finais. Portanto, o efeito do tempo de cura na mistura solo - ARC reduz-se ao longo das aplicações de carga.

Para se comparar o efeito do tempo de cura na deformação permanente com o seu efeito na resistência à compressão simples, módulo tangente a $50 \%$ da tensão de ruptura e módulo de resiliência, foram consideradas as porcentagens de ganho no valor destas variáveis calculadas para corpos-de-prova ensaiados após 28 dias 
com relação aos ensaiados sem cura. Os ganhos assim determinados foram de $92 \%, 56 \%, 94 \%$ e $30 \%$, respectivamente para a RCS, $E_{50 \%}$, MR e $\varepsilon_{p}$. É importante destacar, que o valor relativo ao MR refere-se ao calculado para as tensões observadas na estrutura proposta. Deste modo, constata-se que o efeito da cimentação é menor na deformação permanente do que nas demais variáveis.

\subsubsection{Módulo de resiliência determinado ao longo do ensaio de deformação permanente}

A Figura 4.21 apresenta os valores de módulo de resiliência em função do número de aplicações para o par de tensões E2, obtidos ao longo dos ensaios triaxiais cíclicos realizados para determinação das deformações permanentes de corpos-deprova da mistura solo - ARC preparados na condição ótima do Proctor modificado e ensaiados com tempos de cura de 0,7 e 28 dias. A Tabela 4.22 apresenta os valores de módulo de resiliência inicial e final, calculados de partir de equações polinomiais de $2^{\mathrm{a}}$ ordem obtidas através das linhas de tendência provenientes dos valores de MR ao longo das aplicações de carga. 


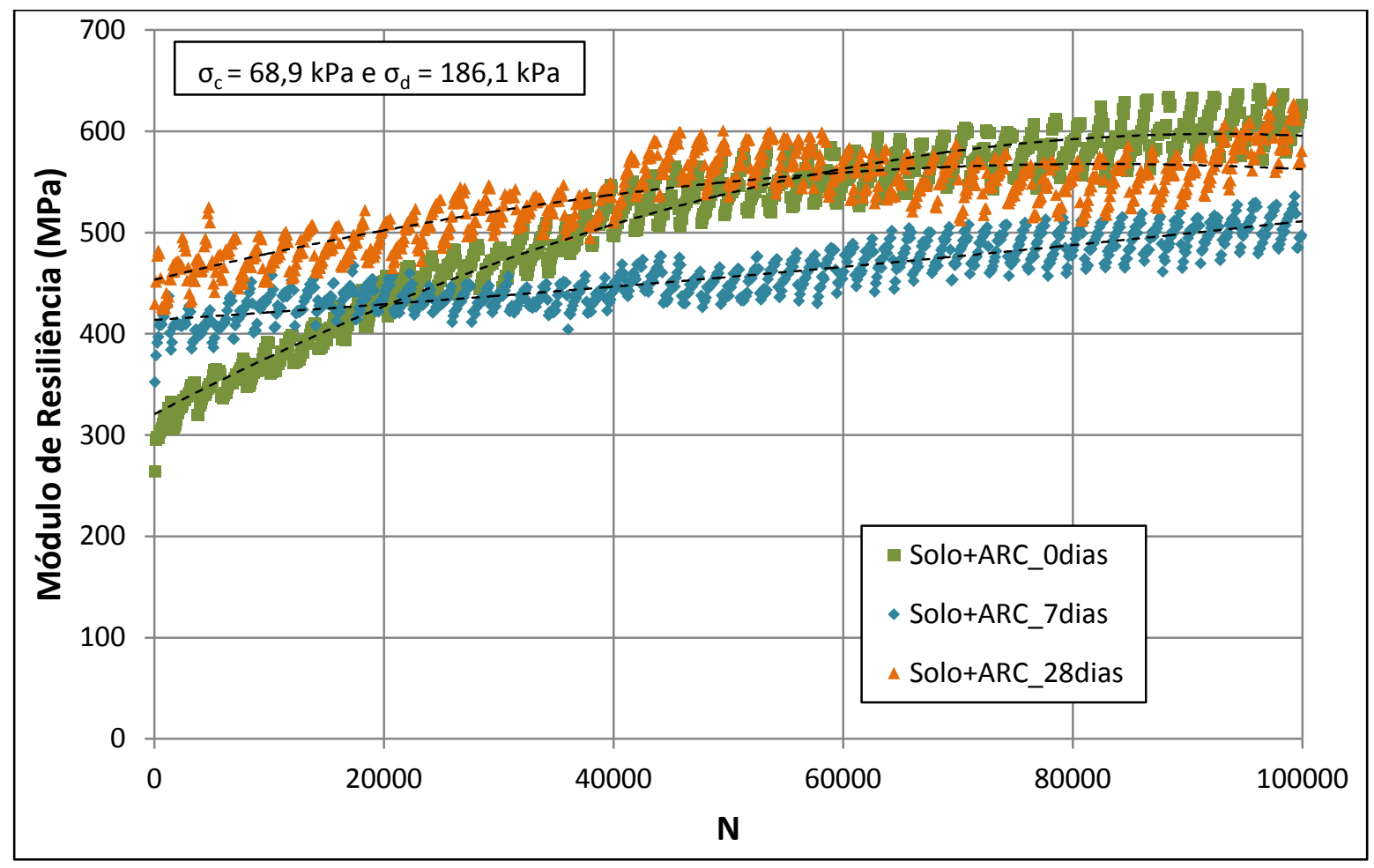

FIGURA 4.21. - Módulo de resiliência em função do número de aplicações de carga para corpos-de-prova da mistura solo - ARC ensaiados em diferentes tempos de cura

TABELA 4.22. - Magnitude e variações do módulo de resiliência inicial e final para corpos-de-prova de ARC ensaiados em diferentes tempos de cura

\begin{tabular}{|c|c|c|c|c|c|}
\hline \multirow{2}{*}{$\begin{array}{l}\text { Tempo de } \\
\text { Cura (dias) }\end{array}$} & \multicolumn{2}{|c|}{ Inicial } & \multicolumn{2}{|c|}{ Final } & \multirow{2}{*}{$\begin{array}{c}\text { Variação do MR } \\
\text { final em relação } \\
\text { ao inicial (\%) }\end{array}$} \\
\hline & $M R(M P a)$ & $\begin{array}{c}\text { Variação } \\
\operatorname{de~MR~(\% )~}\end{array}$ & $M R(M P a)$ & $\begin{array}{c}\text { Variação de } \\
\text { MR (\%) }\end{array}$ & \\
\hline 0 & 321 & - & 596 & - & 86 \\
\hline 7 & 414 & 29 & 511 & -14 & 24 \\
\hline 28 & 453 & 41 & 562 & -6 & 24 \\
\hline
\end{tabular}

Analisando-se a Figura 4.21 e a Tabela 4.22, observa-se que o módulo de resiliência inicial cresce com o aumento do tempo de cura. Tomando-se os valores de módulo de resiliência inicial para cada um dos tempos de cura, verifica-se que o ganho de rigidez calculado com relação ao corpo-de-prova ensaiado sem cura é de $29 \%$ e $41 \%$, respectivamente para 7 e 28 dias de cura.

Quanto ao módulo de resiliência final, observa-se, considerando a dispersão associada aos ensaios, que as mesmas podem ser consideradas iguais. Tomando- 
se os valores de módulo de resiliência final para cada um dos tempos de cura, verifica-se que a variação de rigidez calculada com relação ao corpo-de-prova ensaiado sem cura é de $-14 \%$ e $-6 \%$, respectivamente para 7 e 28 dias de cura.

Ainda, analisando-se a Figura 4.21 e a Tabela 4.22, observa-se que o módulo de resiliência do $A R C$ varia ao longo das aplicações de carga. Tomando-se os valores de módulo de resiliência inicial e final para cada tempo de cura, verifica-se que a variação do módulo de resiliência final em relação ao módulo de resiliência inicial foi de $86 \%, 24 \%$ e $24 \%$, respectivamente para 0, 7 e 28 dias de cura.

Portanto, a variação do módulo de resiliência ao longo das aplicações de carga diminui com a cura da mistura, sendo iguais para 7 e 28 dias. Acredita-se que essa variação ocorra devido ao rearranjo das partículas da mistura solo - ARC, oriundo das deformações permanentes do corpo-de-prova ao longo das aplicações de carregamento no ensaio triaxial cíclico, que para o corpo-de-prova sem cura ocorre a uma taxa superior ao dos corpos-de-prova curados, sendo que estes últimos apresentam deformações permanentes praticamente iguais, fato o qual justifica a igualdade das variações do módulo de resiliência ao longo das aplicações de carga para os corpos-de-prova curados com 7 e 28 dias.

\subsection{6. Índice de suporte Califórnia}

A Tabela 4.23 apresenta os valores médios de índice de suporte Califórnia (CBR) dos corpos-de-prova da mistura solo - ARC preparados na condição ótima do Proctor na energia modificada e ensaiados com tempos de cura de 0, 7 e 28 dias. Ressalta-se ainda, que a imersão dos corpos-de-prova deu-se depois de decorridos 
os tempos de cura em questão. Os valores encontrados na Tabela 4.23 estão ilustrados graficamente na Figura 4.22.

TABELA 4.23. - Resultados de CBR dos corpos-de-prova da mistura solo ARC ensaiados em diferentes tempos de cura

\begin{tabular}{ccc}
\hline $\begin{array}{c}\text { Tempo de } \\
\text { Cura (dias) }\end{array}$ & $\begin{array}{c}\text { Resultados } \\
\text { de CBR (\%) }\end{array}$ & $\begin{array}{c}\text { Média de } \\
\text { CBR (\%) }\end{array}$ \\
\hline \multirow{2}{*}{0} & 210 & 228 \\
& 246 & 227 \\
\hline \multirow{2}{*}{7} & 210 & \\
& 243 & 242 \\
\hline \multirow{2}{*}{28} & 222 & \\
& 240 & \\
\hline
\end{tabular}

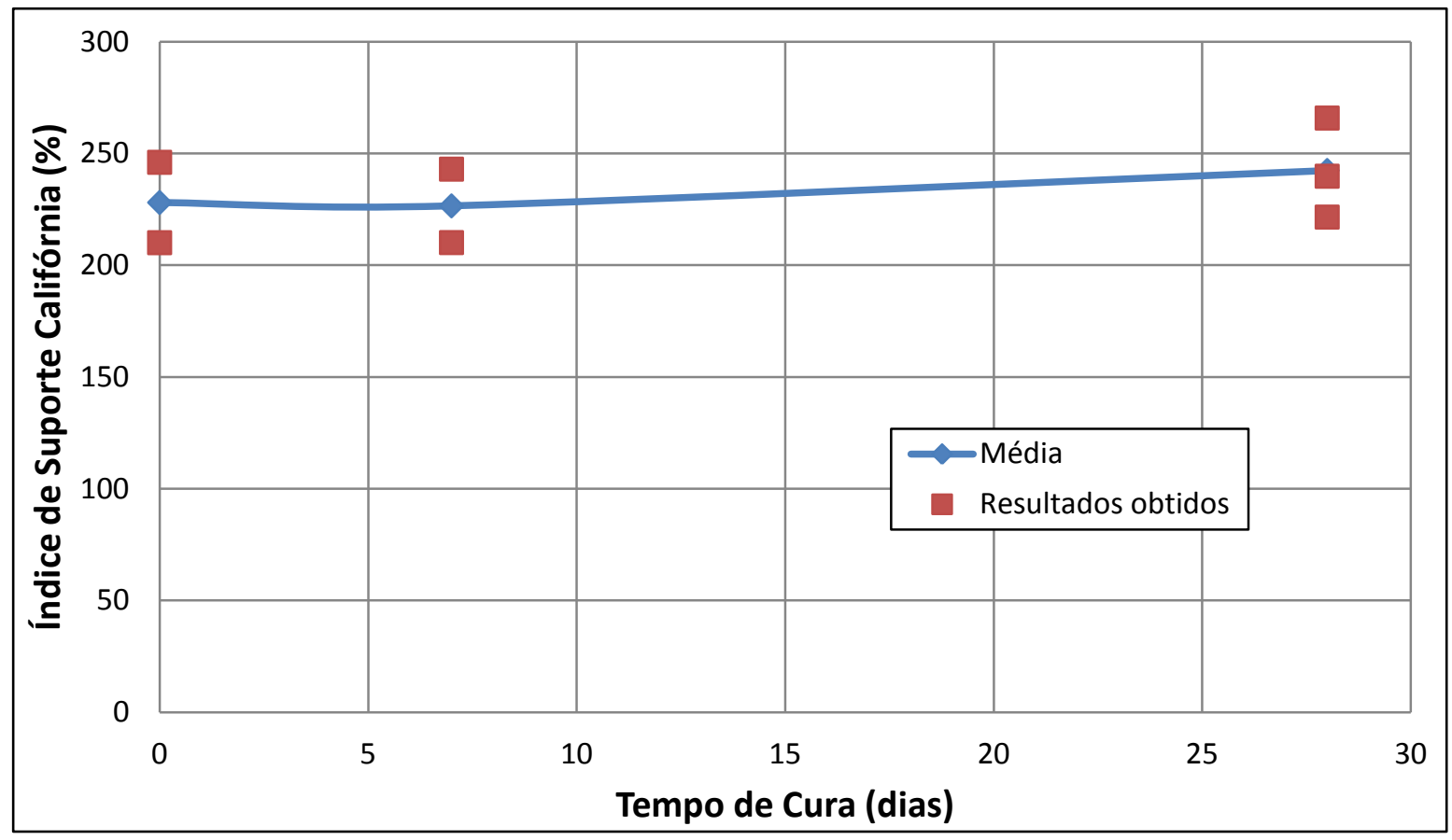

FIGURA 4.22. - Resultados de CBR dos corpos-de-prova da mistura solo - ARC ensaiados em diferentes tempos de cura

Analisando-se a Tabela 4.23 e a Figura 4.22, observa-se que as médias dos resultados de CBR variaram com o aumento do tempo de cura, essa variação calculada com relação aos corpos-de-prova ensaiados sem cura foi de $0 \%$ e $6 \%$, respectivamente para 7 e 28 dias de cura. Portanto, verifica-se que a cura da 
mistura solo - ARC não leva a ganhos de suporte CBR. Contudo, os valores de CBR encontrados são superiores ao recomendado por Nogami e Villibor (1995) para utilização de solo - brita como camada de base de pavimentos, $80 \%$.

\subsection{COMPARAÇÃO ENTRE O ARC E A MISTURA SOLO - ARC}

A comparação entre os materiais estudados nesta pesquisa, o ARC e a mistura solo - ARC, será realizada entre os resultados obtidos para tempos de cura de 0,7 e 28 dias, devido a estes serem comuns em ambos os materiais pesquisados. Ressaltase ainda, que esta comparação é meramente ilustrativa, haja vista que os materiais possuem graduação diferente e principalmente por terem sido compactados em energias diferentes, intermediária e modificada, respectivamente para o ARC e para a mistura solo - ARC.

A Figura 4.23 e a Figura 4.24 apresentam respectivamente as médias dos resultados de resistência à compressão simples e de módulo tangente a 50\% da tensão de ruptura, para os corpos-de-prova de ARC e da mistura solo - ARC ensaiados à compressão simples. 


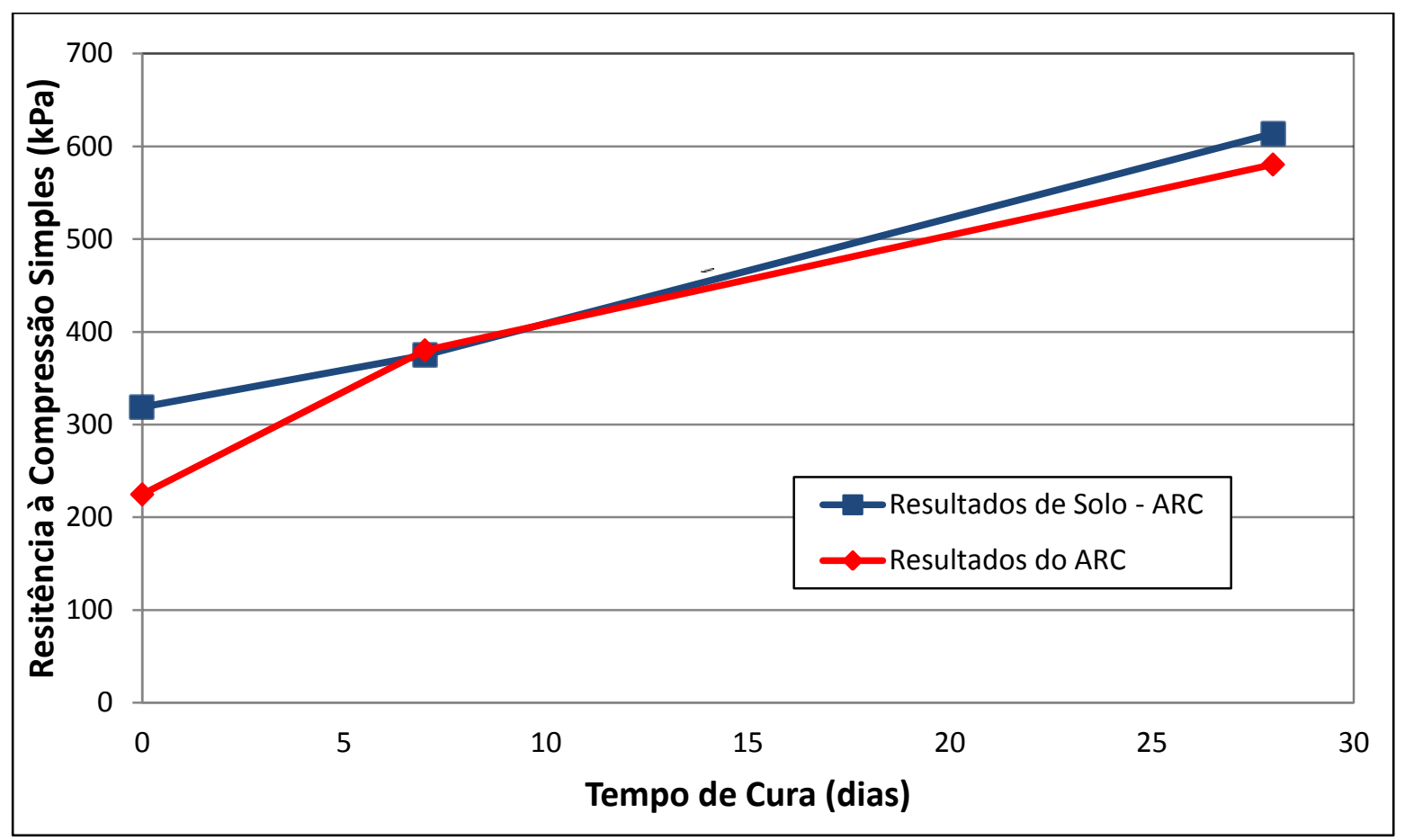

FIGURA 4.23. - Médias dos resultados de RCS do ARC e da mistura solo - ARC para tempos de cura até 28 dias

Analisando-se a magnitude das resistências do ARC e da mistura solo - ARC para diferentes tempos de cura, observa-se na Figura 4.23 que as diferenças de RCS da mistura solo - ARC em relação à do $A R C$ para os tempos de cura estudados são de $42 \%,-1 \%$ e $6 \%$, respectivamente para 0,7 e 28 dias. A diminuição das diferenças demonstra que no período inicial de cura, até 7 dias, o efeito da cimentação é mais efetivo para o $A R C$, haja vista que sua resistência cresce a uma taxa superior a da mistura solo - ARC, se igualando após os 7 dias de cura. Este comportamento poderia ser explicado quando se considera que o ARC possui maior quantidade de cimento não hidratado, devido a sua composição ser $100 \%$ de ARC e ainda conter grande quantidade de argamassa em sua fração miúda, onde há maior presença de cimento. 


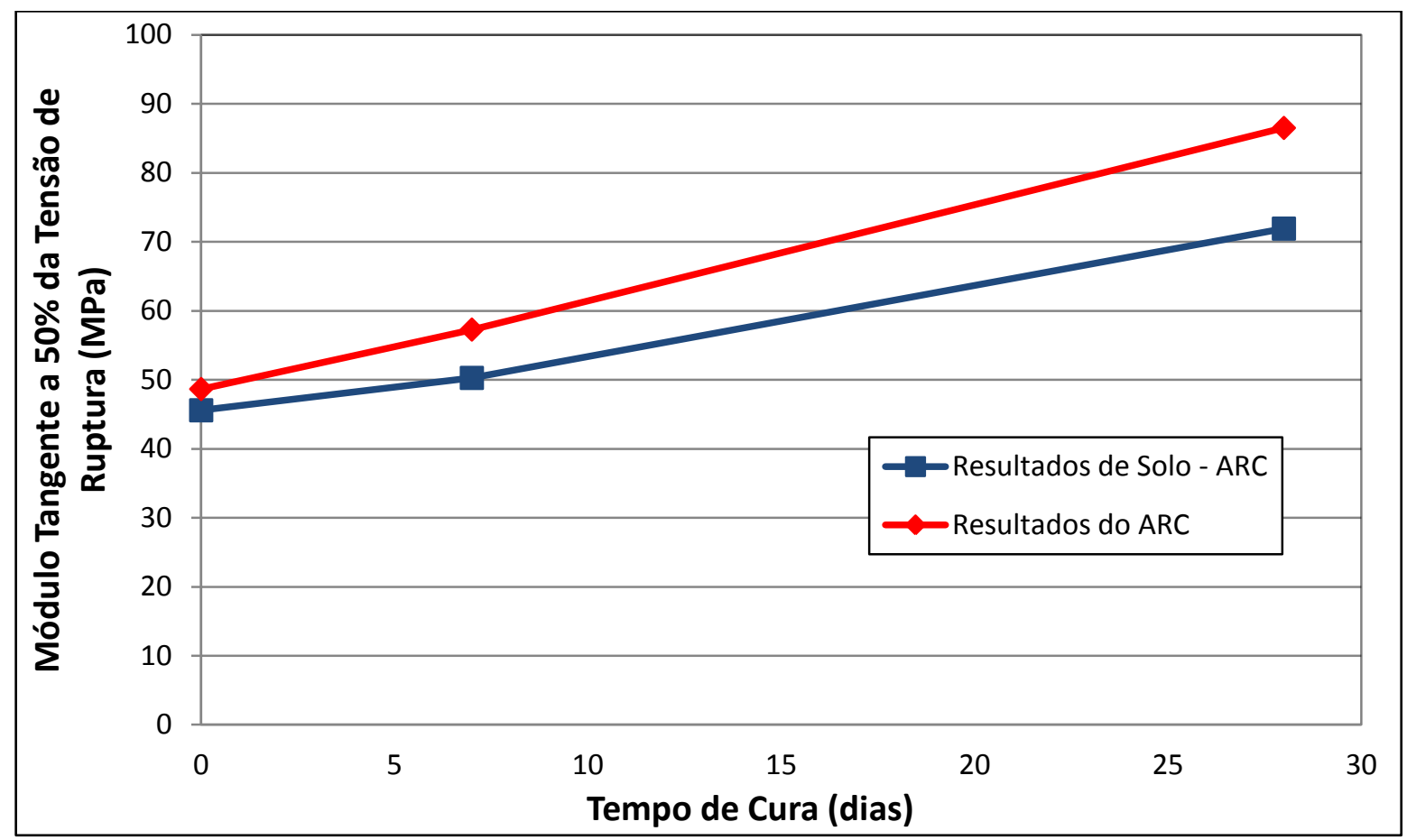

FIGURA 4.24. - Médias dos resultados de $\mathrm{E}_{50 \%}$ do ARC e da mistura solo - ARC para tempos de cura até 28 dias

Analisando-se a Figura 4.24, observa-se que os valores de $E_{50 \%}$ do $A R C$ são superiores aos da mistura solo - ARC para todos os tempos de cura. Tomando-se os valores de $E_{50 \%}$ do $A R C$ em relação aos da mistura solo - $A R C$, verifica-se que suas diferenças calculadas para cada tempo de cura são de 7\%, 14\% e 20\%, respectivamente para 0,7 e 28 dias de cura.

Portanto, o aumento das variações com a cura demonstra novamente que o efeito da cimentação é mais efetivo para o $A R C$, haja vista que sua rigidez cresce a uma taxa superior a da mistura solo - ARC. No entanto, ao contrário do observado para a RCS, os valores de $E_{50 \%}$ da mistura solo - ARC foram inferiores aos do $A R C$. Acredita-se que a ocorrência deste comportamento esteja ligada ao fato do módulo tangente, que é igual à variação das tensões em relação à variação das deformações totais, ter sido calculado a $50 \%$ da tensão de ruptura, nesta condição existe uma contribuição importante da deformação permanente no cômputo das 
deformações totais. Deste modo, como será apresentado posteriormente, a deformação permanente da mistura solo - ARC é superior a do ARC, o que explica então o comportamento observado entre os dois materiais.

A Tabela 4.24 apresenta as constantes de calibração e os coeficientes de determinação do modelo composto para os módulos de resiliência do ARC e da mistura solo - ARC, a Figura 4.25 apresenta os valores de módulo de resiliência calculados a partir do modelo composto e das tensões obtidas no centro da camada de base do pavimento proposto no item 4.1.4 deste capítulo. Neste caso, foram também incluídos os resultados de MR referente ao ARC curado por 90 dias, haja vista o comportamento observado aos 28 dias de cura.

TABELA 4.24. - Constantes de calibração e $R^{2}$ do modelo composto do ARC e da mistura solo - ARC

\begin{tabular}{cccccc}
\hline \multirow{2}{*}{ Material } & Tempo de & \multicolumn{4}{c}{ Modelo Composto } \\
& Cura (dias) & $\boldsymbol{K} \mathbf{1}$ & $\boldsymbol{K} \mathbf{2}$ & $\boldsymbol{K} \mathbf{3}$ & $\boldsymbol{R}^{\mathbf{2}}$ \\
\hline \multirow{4}{*}{ ARC } & 0 & 7,02 & 0,72 & 0,08 & 0,91 \\
& 7 & 83,33 & 0,33 & 0,00 & 0,91 \\
& 28 & 13,23 & 0,76 & $-0,02$ & 0,97 \\
& 90 & 58,92 & 0,5 & 0,01 & 0,98 \\
\hline \multirow{3}{*}{ Solo-ARC } & 0 & 2826,64 & 0,36 & $-0,71$ & 0,93 \\
& 7 & 2557,59 & 0,30 & $-0,60$ & 0,95 \\
& 28 & 7858,26 & 0,49 & $-0,92$ & 0,92 \\
\hline
\end{tabular}




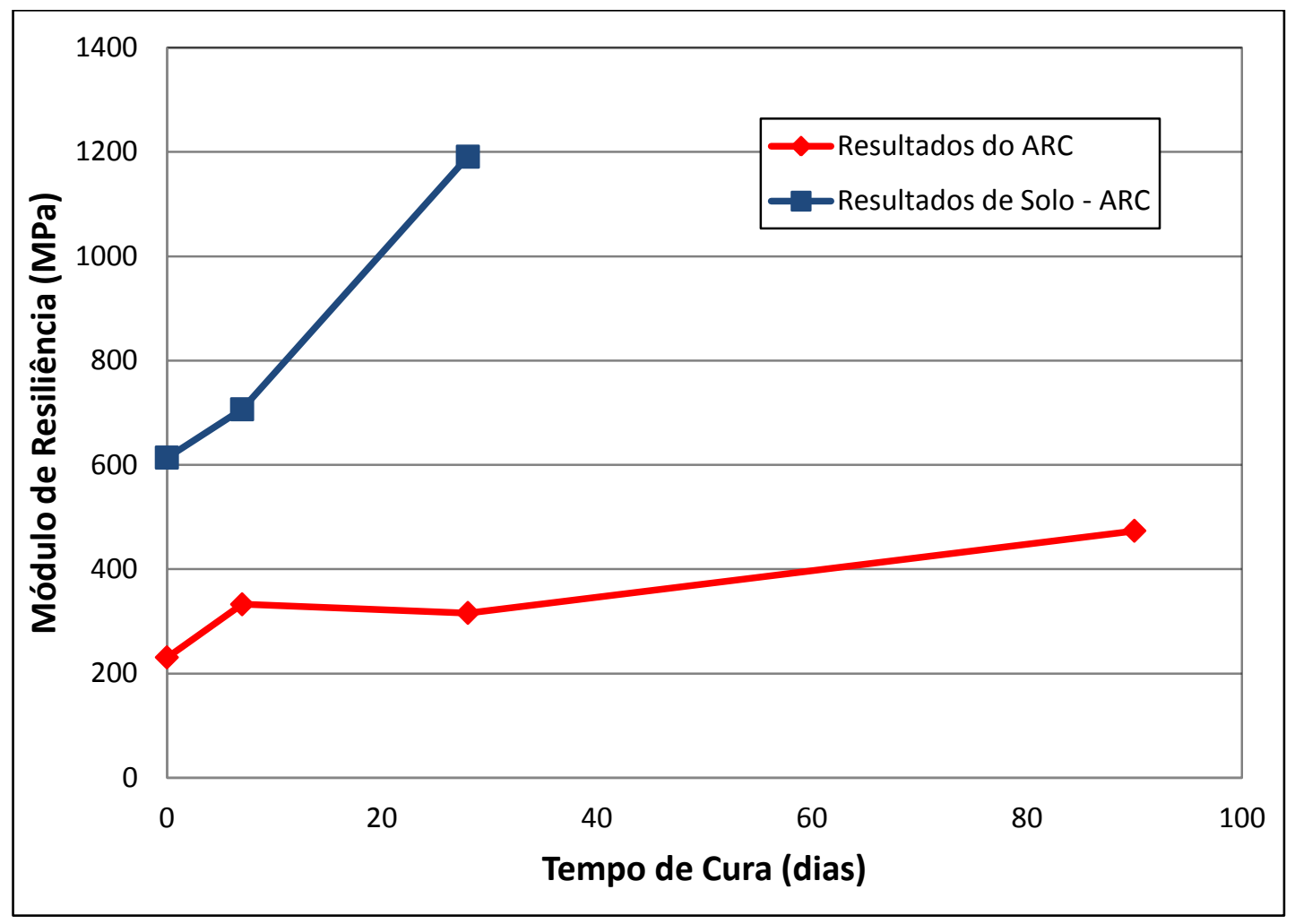

FIGURA 4.25. - Valores de MR do ARC e da mistura solo - ARC calculados a partir do pavimento proposto

Analisando-se a Tabela 4.24, verifica-se que o modelo composto apresentou boa correlação com os resultados de módulo de resiliência obtidos para o ARC e para a mistura solo - ARC. Ainda, tomando-se os valores assumidos por K2 e K3 para os dois materiais, sendo estes, respectivamente expoentes das tensões confinante e desvio, verifica-se que o valor de módulo de resiliência do ARC é mais influenciado pela tensão confinante do que pela tensão desvio, o que para a mistura solo - ARC ocorre o inverso. Este comportamento era esperado, visto que como a mistura solo - ARC incorpora o solo, a sua granulometria contém uma quantidade de finos superior à do $A R C$, portanto a influência da tensão desvio é maior a da tensão confinante, conforme o comportamento dos solos finos.

Analisando-se a Figura 4.25, observa-se que os valores de módulo de resiliência calculados para a mistura solo - ARC são superiores aos do ARC. 
Tomando-se os valores de MR calculados para a mistura solo-ARC em relação aos do ARC para cada tempo de cura, verifica-se que as diferenças são de $166 \%, 112 \%$ e $276 \%$, respectivamente para 0,7 e 28 dias de cura. Portanto, pode-se concluir, considerando-se as condições desta pesquisa, que a mistura solo - ARC apresenta melhor comportamento mecânico que o ARC, quando analisado a fadiga para o pavimento proposto nesta pesquisa.

A Figura 4.26 apresenta os valores de deformações permanentes finais obtidos para corpos-de-prova de ARC e da mistura solo - ARC submetidos ao ensaio triaxial cíclico e ensaiados sob o estado de tensão E2: $\sigma \mathrm{c}=68,9 \mathrm{kPa}$ e $\sigma \mathrm{d}=$ $186,1 \mathrm{kPa}$.

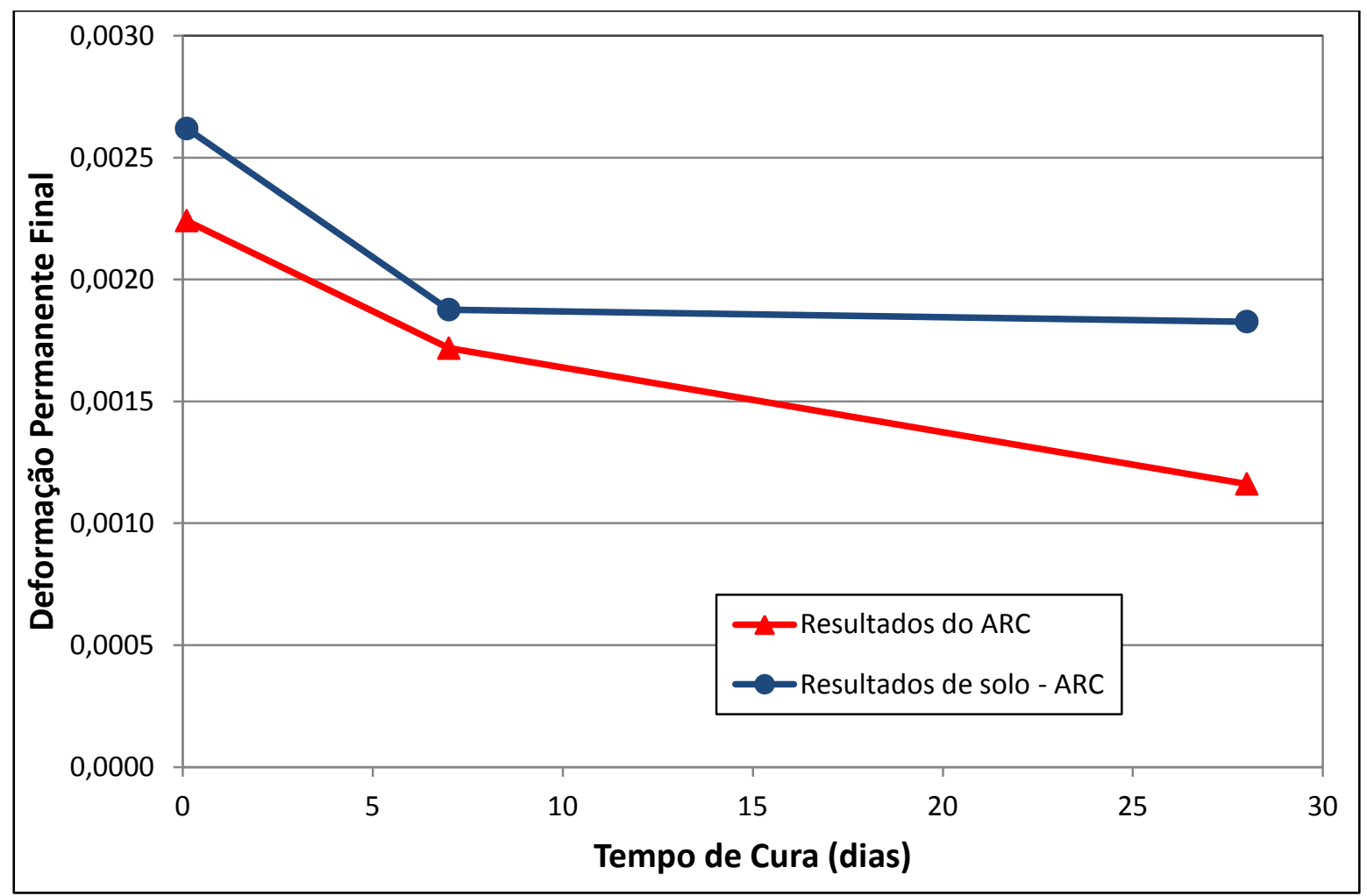

FIGURA 4.26. - Deformações permanentes finais do ARC e da mistura solo ARC para tempos de cura até 28 dias 
Analisando-se a Figura 4.26, observa-se que as deformações permanentes finais do ARC apresentaram valores menores do que os da mistura solo - ARC. Tomando-se os valores de deformação permanente final do ARC em relação aos da mistura solo - ARC para cada tempo de cura, verifica-se que as diferenças foram de $-17 \%,-9 \%$ e $-57 \%$, respectivamente para 0,7 e 28 dias de cura.

A Figura 4.27 apresenta as médias dos resultados do índice de suporte Califórnia do ARC e da mistura solo - ARC.

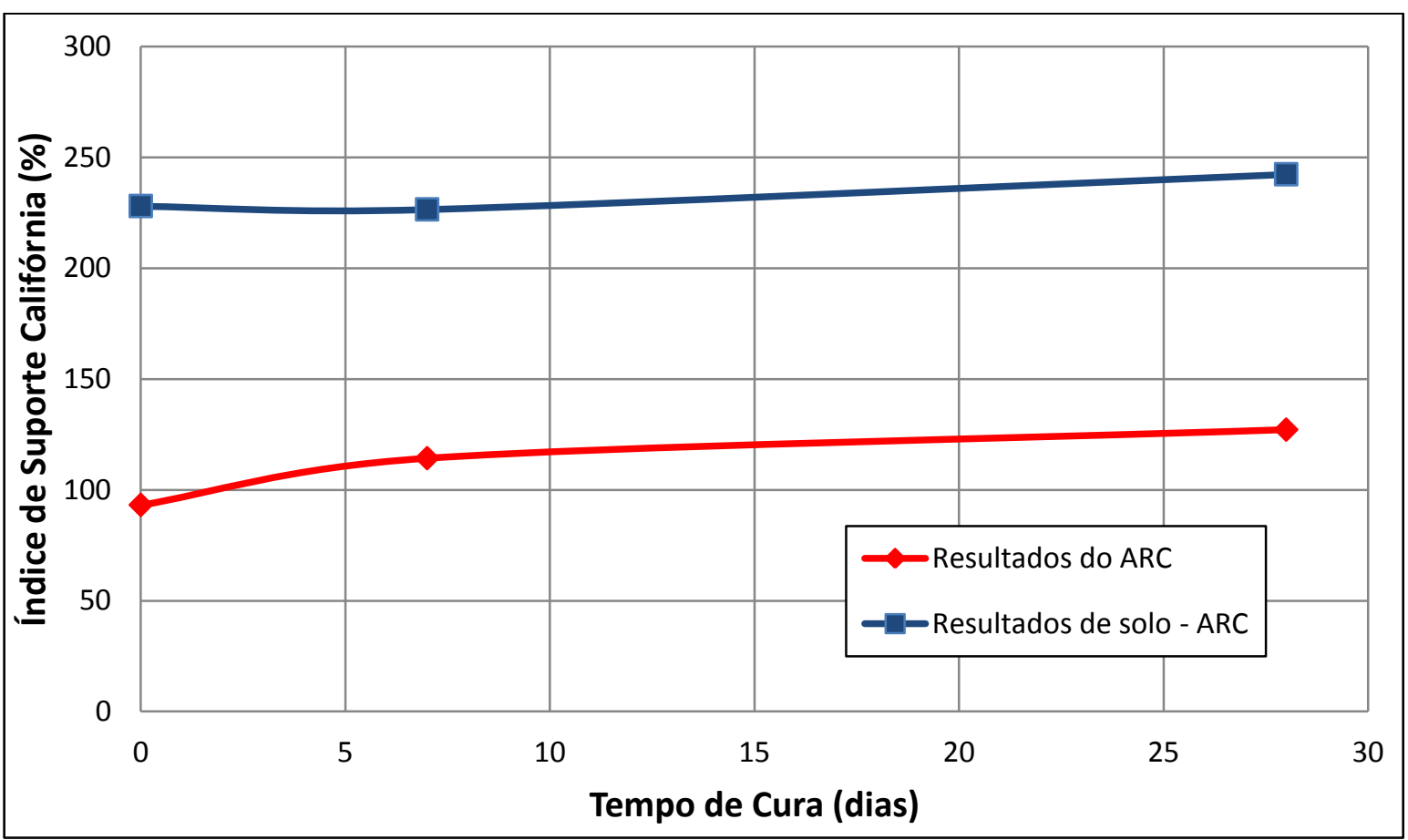

FIGURA 4.27. - Médias dos resultados de CBR do ARC e da mistura solo - ARC obtidos para tempos de cura até 28 dias

Analisando-se a Figura 4.27, observa-se que os valores de CBR da mistura solo - ARC são superiores aos do ARC. Considerando-se que estes valores para ambos os materiais não variam com o aumento do tempo de cura e calculando-se as médias destes resultados para cada um dos materiais, verifica-se que os valores de CBR da mistura solo - ARC são em média 105\% superiores aos do ARC. 
A diferença dos valores de CBR dos materiais estudados pode ser explicada quando se considera que a mistura solo - ARC foi compactada numa energia superior à do ARC, e ainda, que a variação do teor de umidade em relação ao teor de umidade de compactação da mistura solo - ARC foi em média inferior a do ARC, respectivamente, $14 \%$ e $26 \%$, fato o qual é explicado pela baixa permeabilidade oriunda da presença de solo na mistura. 


\section{CONCLUSÕES}

Esta pesquisa teve como objetivo estudar o comportamento mecânico, ao longo do tempo de cura, do agregado reciclado de concreto proveniente da Usina de Reciclagem de São Carlos e da sua mistura com um solo laterítico, a fim de utilizálos na construção de pavimentos.

Vale salientar que as conclusões apresentadas neste capítulo são referentes aos materiais e às condições pesquisadas. Ressalte-se ainda, que o agregado reciclado de concreto foi compactado na energia Proctor intermediária e ensaiado com tempos de cura até 180 dias, enquanto que a sua mistura com solo foi compactada na energia Proctor modificada e ensaiada com tempos de cura até 28 dias. Em seguida são apresentadas as conclusões de todo o estudo.

A cura do agregado reciclado de concreto leva a ganhos de resistência à compressão simples (RCS) e módulo tangente a $50 \%$ da tensão de ruptura $\left(E_{50 \%}\right)$, os quais ocorrem a taxas elevadas nos primeiros dias de cura, reduzindo-se consideravelmente após os 28 dias. Comparando-se os resultados obtidos aos 28 e 180 dias com os resultados sem cura, verificam-se pares de aumentos de resistência e rigidez de $158 \%$ e $61 \%$, e $232 \%$ e $110 \%$, respectivamente para os dois tempos de cura. 
No tocante à mistura solo - ARC verifica-se que a cura promove ganhos de resistência e rigidez, os quais alcançam respectivamente a $92 \%$ e $56 \%$ aos 28 dias de cura.

Acredita-se que o ganho de resistência e rigidez ao longo do tempo de cura se deva à presença de cimento não hidratado no agregado reciclado de concreto, conforme apresentado anteriormente em pesquisas realizadas por Arm (2001), Blanknagel (2005) e Poon e Chan (2006). Este cimento, que é exposto durante a fase de britagem no processo de reciclagem dos resíduos de concreto e argamassa, quando em contato com a água no processo de moldagem dos corpos-de-prova inicia uma reação cimentante, a qual modifica as características mecânicas do agregado reciclado de concreto.

Os valores de RCS e $E_{50 \%}$ do agregado reciclado de concreto observados por Grubba (2009) após a cura foram superiores aos desta pesquisa. Comparando-se os resultados obtidos para RCS e $E_{50 \%}$ aos 90 dias de cura, verifica-se que os resultados de Grubba (2009) foram respectivamente $85 \%$ e $75 \%$ superiores aos desta pesquisa. Atribui-se esta ocorrência ao fato do material utilizado na presente pesquisa ter sido armazenado em local sem cobertura, perdendo assim parte do cimento não hidratado devido à ação das intempéries. Portanto, conclui-se que o armazenamento do ARC em locais que promovam o contato com a água ou que sofra ação das intempéries não é recomendado, haja vista que o potencial efeito cimentante pode ser reduzido.

No tocante aos resultados de resistência à compressão simples do agregado reciclado de concreto após ensaios triaxiais cíclicos, verifica-se que o efeito da 
sobre-compactação ocorrida nos ensaios triaxiais cíclicos conduz ao aumento de resistência à compressão simples em todos os tempos de cura, sendo maior para os menores tempos de cura.

O modelo composto e o da AASHTO são os que apresentaram melhores desempenhos na representação do módulo de resiliência (MR) do agregado reciclado de concreto e o da sua mistura com solo. Tomando-se o modelo composto como referência, verifica-se que o valor do módulo de resiliência do ARC é mais influenciado pela tensão confinante do que pela tensão desvio, sendo que para sua mistura com solo ocorre o inverso.

O módulo de resiliência (MR) do agregado reciclado de concreto e o da sua mistura com solo cresce com o aumento do tempo de cura. Para estruturas de pavimentos com bases construídas com ARC ou solo - ARC, conforme apresentado no Capítulo 4, verifica-se para o modelo composto e para as tensões calculadas no centro desta camada que o módulo de resiliência do primeiro e do segundo material aos 28 dias de cura são de $316 \mathrm{MPa}$ e $1191 \mathrm{MPa}$, respectivamente. Considerandose os valores sem cura, o crescimento foi de $37 \%$ e $94 \%$. Para o ARC curado por 180 dias, alcançou-se uma rigidez de $511 \mathrm{MPa}$, correspondente a um aumento de $121 \%$ se comparado ao valor obtido sem cura.

Considerando-se ainda a estrutura proposta e modelo composto, verifica-se que o MR calculado do ARC desta pesquisa com relação ao da pesquisa de Grubba (2009), foi superior $26 \%$ e $9 \%$, respectivamente para 0 e 90 dias de cura. Portanto, no caso do MR, os valores são muito próximos para as duas pesquisas e não se repete o observado com relação à RCS e $E_{50 \%}$, onde Grubba (2009) obteve valores 
expressivamente superiores. Acredita-se que este fato seja decorrente de Grubba (2009) ter realizado os ensaios triaxiais cíclicos ao final de sua pesquisa, decorrido quase um ano após a execução dos ensaios de compressão simples. Portanto, igualmente ao ocorrido nesta pesquisa, o efeito da cimentação teria sido minimizado, devido a perda de cimento não hidratado durante a armazenagem.

O modelo de Monismith (1975) representa bem a variação da deformação permanente com o número de aplicações de carga do agregado reciclado de concreto e da sua mistura com solo. Verifica-se, para ambos os materiais, que a cura promove a redução da deformação permanente ao longo das aplicações de carga. A deformação permanente do ARC e da sua mistura com solo aos 28 dias de cura, obtida após 100.000 aplicações do par de tensões $\sigma_{c}=68,9 \mathrm{kPa}$ e $\sigma_{d}=186,1$ $\mathrm{kPa}$ no ensaio triaxial cíclico, foi de $0,116 \%$ e $0,190 \%$, respectivamente. Considerando-se os valores sem cura, a redução foi de $48 \%$ e $30 \%$. Para o ARC curado por 180 dias, a deformação permanente foi de 0,096\%, correspondente a uma redução de $57 \%$ se comparado ao valor obtido sem cura.

Para corpos-de-prova ensaiados aos 28 dias, a variação do estado de tensão no ensaio triaxial cíclico não conduziu a variação significativa da deformação permanente.

Quanto aos valores de módulo de resiliência obtidos ao longo das aplicações de carga no ensaio de deformação permanente, verifica-se que estes crescem para tempos de cura menores e mantém-se relativamente constante para tempos de cura maiores. Acredita-se que essa variação esteja ligada ao rearranjo das partículas, oriundo das deformações permanentes dos materiais ao longo das aplicações de 
carregamento no ensaio triaxial cíclico, que ocorre em maiores taxas para tempos de cura menores, deste modo, como a deformação permanente observada para tempos de cura maiores são relativamente pequenas, devido ao efeito de cimentação do agregado reciclado de concreto, o rearranjo das partículas também ocorre, mas a taxas muito pequenas, resultando assim em baixas variações de módulo de resiliência ao longo das aplicações de carga no ensaio triaxial cíclico.

No tocante ao índice de suporte Califórnia do agregado reciclado de concreto e da sua mistura com solo, verifica-se que a cura desses materiais não promove aumento de suporte CBR. No entanto, os valores de CBR encontrados foram em média de $114 \%$ e $234 \%$, respectivamente para o ARC e para a mistura solo - ARC, ambos eles superiores aos valores de $60 \%$, recomendado pela norma NBR 15115 (ABNT, 2004) para o emprego de agregados reciclados de resíduos de construção civil em camadas de base de pavimentos, e também superiores a $80 \%$, recomendado por Nogami e Villibor (1995) para utilização de solo - brita como camada de base de pavimentos.

Considerando-se que a variação do teor de umidade foi baixa, como observado no Apêndice I, e levando-se em conta o cuidado tomado no armazenamento dos corpos-de-prova, acredita-se que a pequena diminuição de umidade seja decorrente em maior parte das reações com cimento e, portanto, as melhorias mecânicas verificadas podem ser atribuídas ao efeito da cimentação.

Com base nos estudos realizados, podemos concluir que o agregado reciclado de concreto é uma alternativa para construção de bases de pavimentos, podendo também substituir o agregado natural da mistura solo arenoso laterítico - 
brita descontínua, muito utilizada nas rodovias do interior de São Paulo, como apresentado por Nogami e Villibor (1995). Finalmente, pode-se observar que o efeito da cimentação com a cura contribui positivamente para o comportamento mecânico dos materiais estudados.

\subsection{RECOMENDAÇÕES PARA TRABALHOS FUTUROS}

A fim de contribuir para o desenvolvimento de novas pesquisas relacionadas ao agregado reciclado de concreto, seguem algumas sugestões para trabalhos futuros:

- Estudar a influência do teor de umidade no comportamento mecânico ao longo do tempo de cura do agregado reciclado de concreto;

- Avaliar a quantidade de cimento não hidratado presente na superfície do agregado reciclado de concreto nas diferentes granulometrias disponíveis nas usinas de reciclagem após a fase de britagem;

- Construir um trecho experimental utilizando agregado reciclado de concreto, a fim de acompanhar seu desempenho ao longo das solicitações de tráfego e das condições ambientais. 


\section{REFERÊNCIAS BIBLIOGRÁFICAS}

AMERICAN ASSOCIATION OF STATE HIGHWAY AND TRANSPORTATION OFFICIALS. AASHTO T 307-99: Standard method of test for determining the resilient modulus of soils and aggregate materials, 1999.

ASSOCIAÇÃO BRASILEIRA DE NORMAS TÉCNICAS. NBR 6508: Grãos de Solo que passam na peneira de 4,8mm - Determinação da massa específica. Rio de Janeiro, 1984.

NBR 6459: Solo - Determinação do limite de Liquidez. Rio de Janeiro, 1984.

NBR 7180: Solo - Determinação do limite de plasticidade. Rio de Janeiro, 1984

. NBR 7181: Solo - Análise granulométrica. Rio de Janeiro, 1984

. NBR 7182: Solo - Ensaio de compactação. Rio de Janeiro, 1984.

. NBR 10004: Resíduos sólidos - Classificação. Rio de Janeiro, 2004.

NBR 15112: Resíduos da construção civil e resíduos volumosos - Áreas de transbordo e triagem - Diretrizes para projeto, implantação e operação. Rio de Janeiro, 2004.

. NBR 15113: Resíduos sólidos da construção civil e resíduos inertes - Aterros Diretrizes para projeto, implantação e operação. Rio de Janeiro, 2004.

. NBR 15114: Resíduos sólidos da construção civil - Áreas de reciclagem Diretrizes para projeto, implantação e operação. Rio de Janeiro, 2004.

. NBR 15115: Agregados reciclados de resíduos sólidos da construção civil Execução de camadas de pavimentação - Procedimentos. Rio de Janeiro, 2004.

NBR 15116: Agregados reciclados de resíduos sólidos da construção civil Utilização em pavimentação e preparo de concreto sem função estrutural Requisitos. Rio de Janeiro, 2004.

ANGULO, S. C.; MIRANDA, L.F.R.; JOHN, V.M. Construction and demolition waste, its variability and recycling in Brazil. In: SUSTAINABLE BUILDINGS 2002, 3., Oslo, 2002. Anais. Oslo: IISBE/GCB, 2002.

ANGULO, S. C. Caracterização de agregados de resíduos de construção e demolição reciclados e a influência de suas características no comportamento mecânico de 
concretos. 2005. 167 p. Tese (Doutorado) - Universidade de São Paulo, São Paulo, 2005.

ARM, M. Self-cementing properties of crushed demolished concrete in unbound layers: results from triaxial tests and field tests. Waste Management and Research, v.21, p.235-239, 2001.

BENNERT, T.; PAPP JR., W. J.; MAHER, A.; GUCUNSKI, N. Utilization of construction and demolition debris under traffic-type loading in base and subbase applications. Transportation Research Record, n.1714, p.33-39, 2000.

BLANKENAGEL, B. J. Characterization of recycled concrete for use as pavement base material. 2005. 66p. Dissertação (Mestrado) - Department of Civil and Environmental Engineering Brigham Young University, Provo, 2005.

BLANKENAGEL, B. J.; GUTHRIE, W. S. Laboratory characterization of recycled concrete for use as pavement base material. Transportation Research Record, n. 1952, p.21-27, 2006.

CARNEIRO, A. P.; BURGOS, P. C.; ALBERTE, E. P. V. Uso do agregado reciclado em camadas de base e sub-base de pavimentos. Projeto Entulho Bom. Salvador: EDUFBA / Caixa Econômica Federal, 2001. p.190-227.

CONSELHO NACIONAL DO MEIO AMBIENTE. Brasília. 2002. Resolução CONAMA $\mathbf{n}^{0}$ 307, de 5 de julho de 2002. Disponível em:

<http://www.mma.gov.br/port/conama/res/res02/res30702.html>. Acesso em: 20 de jan. 2010.

DEPARTAMENTO NACIONAL DE ESTRADAS DE RODAGEM. DNER-ME 049/94: Determinação do Índice de Suporte Califórnia utilizando amostras não trabalhadas. Rio de Janeiro, 1994.

. DNER-ES 303/97: Pavimentação - base estabilizada granulometricamente. Rio de Janeiro, 1997.

DNER-PRO 120/97: Coleta de amostras de agregados. Rio de Janeiro, 1997.

. DNER-ME 201/94: Solo-cimento - compressão axial de corpos de prova cilíndricos. Rio de Janeiro, 1994.

. DNER-ME 035/97: Agregados - Determinação da abrasão "Los Angeles". Rio de Janeiro, 1998.

DNER-ME 083/98: Agregados - Analise granulométrica. Rio de Janeiro, 1998.

DNER - ME 256/94: Solos compactados com equipamento miniatura determinação da perda de massa por imersão. Rio de Janeiro, 1994. 
DNER - ME 258/94: Solos compactados em equipamento miniatura - Mini MCV. Rio de Janeiro, 1994.

. DNER - ME 228/94: Solos - compactação em equipamento miniatura. Rio de Janeiro, 1994.

DNER - ME 131/94: Solos - determinação do módulo de resiliência. Rio de Janeiro, 1994.

DNER-CLA 259/96: Classificação de solos tropicais. Rio de Janeiro, 1996.

EUROPEAN COMMISSION. 2000. Management of construction and demolition waste. Disponível em:<http://ec.europa.eu/environment/waste/studies/cdw/cdw_report.htm.> Acesso em: 20 de jan. 2010.

EPA - ENVIRONMENTAL PROTECTION AGENCY - MUNICIPAL AND INDUSTRIAL SOLID WASTE DIVISION - OFFICE OF SOLID WASTE. United States. 2003. Estimating 2003: Construction and demolition materials amount. Disponível em: < http://www.epa.gov/osw/conserve/rrr/imr/cdm/pubs/cd-meas.pdf> Acesso em: 15 de jul. 2011.

EPA - ENVIRONMENTAL PROTECTION AGENCY - MUNICIPAL AND INDUSTRIAL SOLID WASTE DIVISION - OFFICE OF SOLID WASTE. United States. 1998. Report $\mathbf{n}^{\mathbf{0}}$ EPA530-R-98-010 - Characterization of building-related construction and demolition debris in the United States. Disponível em:

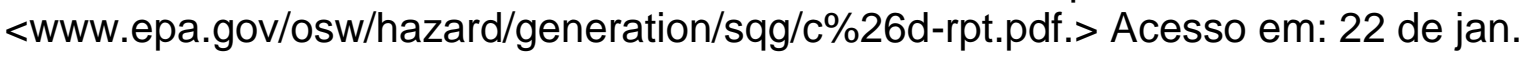
2010.

FERNANDES, C. G. Caracterização mecanística de agregados reciclados de resíduos de construção e demolição dos municípios do Rio de Janeiro e de Belo Horizonte para uso em pavimentação. 2004. 109p. Dissertação (Mestrado) - Coordenação dos Programas de Pós-Graduação de Engenharia, Universidade Federal do Rio de Janeiro (COPPE-UFRJ). Rio de Janeiro, 2004.

FHWA - FEDERAL HIGHWAY ADMINISTRATION U.S. DEPARTMENT OF TRANSPORTATION, United States. 1997. Report n $\mathbf{n}^{\mathbf{0}}$ FHWA-RD-97-148 - User Guidelines for waste and by-product materials in pavement construction. Disponível em: <http://www.rmrc.unh.edu/resources/cd/userguide/begin.htm>. Acesso em: 28 de Jan. 2010.

FHWA - FEDERAL HIGHWAY ADMINISTRATION U.S. DEPARTMENT OF TRANSPORTATION, United States. 2004. Transportation Applications of Recycled Concrete Aggregate. FHWA State of the Practice National Review September 2004. Disponível em: <http://www.rmrc.unh.edu/resources/pandd/rcareport/rcareport.pdf>. Acesso em: 28 de Jan. 2010.

FHWA - FEDERAL HIGHWAY ADMINISTRATION U.S. DEPARTMENT OF TRANSPORTATION, United States. 2005. Report n ${ }^{\circ}$ FHWA-NJ-2005-003 - The 
development of a performance specification for granular base and subbase material. Disponível em: < http://cait.rutgers.edu/files/FHWA-NJ-2005-003.pdf >. Acesso em: 15 de Jul. 2011.

GUIMARÃES, A. C. R. Estudo de deformação permanente em solos e a teoria de Shakedown aplicada a pavimentos flexíveis. 2001. 279p. Dissertação (Mestrado) Universidade Federal do Rio de Janeiro, Rio de Janeiro, 2001.

GRUBBA, D. C. R. P. Estudo do comportamento mecânico de um agregado reciclado de concreto para utilização na construção rodoviária. 2009. 138p. Dissertação (Mestrado) - Escola de Engenharia de São Carlos, Universidade de São Paulo, São Paulo, 2009.

KAKUDA, F. M. A utilização de um equipamento de grandes dimensões na análise do comportamento mecânico de uma seção de pavimento sob carregamento cíclico. 262p. Tese (Doutorado) - Escola de Engenharia de São Carlos, Universidade de São Paulo, São Paulo, 2010.

LAURITZEN, E. K. Economic and environmental benefits of recycling waste from the construction and demolition of buildings. Industry and Environment, Paris, v. 17, n.2, abr. /jun. p. 26-31,1994.

LEKARP, F.; ISACSSON, U.; DAWSON, A. State of the art. I: Resilient response of unbound aggregates. Journal of Transportation Engineering, Vol. 126, n.20094, p.6675, 2000.

LEKARP, F.; ISACSSON, U.; DAWSON, A. State of the art. II: Permanent Strain response of unbound aggregates. Journal of Transportation Engineering, Vol. 126, n.20094, p.70-83, 2000.

LEITE, F. C. Comportamento mecânico de agregado reciclado de resíduo sólido da construção civil em camadas de base e sub-base de pavimentos. $185 \mathrm{p}$. Dissertação (Mestrado) - Universidade de São Paulo, São Paulo, 2007.

MOLENAAR, A. A. A.; VAN NIEKERK, A A. Effects of gradation, composition, and degree of compaction on the mechanical characteristics of recycled unbound materials. Transportation Research Record, n.1787, p.73-82, 2002.

MOREIRA, J. F.; DIAS, J. F., REZENDE, M. E. B. Utilização de resíduos de construção e demolição em base de pavimentos na cidade de Uberlândia - MG. 13ª Reunião de Pavimentação Urbana, Código 48, Maceió - AL, 12p., 2006.

MOTTA, R. S. Estudo laboratorial de agregado reciclado de resíduo sólido da construção civil para aplicação em pavimentação de baixo volume de tráfego. 2005. 134p. Dissertação (Mestrado) - Universidade de São Paulo, São Paulo, 2005.

MEDINA, J. Mecânica dos pavimentos. Rio de Janeiro: UFRJ, 1997. 380p. 
NATAATMADJA A., TAN, Y. L. Resilient response of recycled concrete road aggregates. Journal of Transportation Engineering, set-out, p. 450-453, 2001.

NOGAMI, J. S., VILLIBOR, D. F. Pavimentação de baixo custo com solos lateríticos. São Paulo, Editora Villibor, 1995, 213p.

NUNES, K. R. A. Avaliação de investimentos e de desempenho de centrais de reciclagem para resíduos sólidos de construção e demolição. 2004. 276p. Tese (Doutorado) - Coordenação dos Programas de Pós-Graduação de Engenharia, Universidade Federal do Rio de Janeiro (COPPE-UFRJ). Rio de Janeiro, 2004.

PMSP - PREFEITURA DO MUNICÍPIO DE SÃO PAULO. São Paulo. 2003. PMSP/SP ETS - 001/2003 - Camadas de reforço do subleito, sub-base e base mista de pavimento com agregado reciclado de resíduos sólidos da construção civil. Disponível em: $<$ http://ww2.prefeitura.sp.gov.br//arquivos/secretarias/infraestruturaurbana/normas_te cnicas_de_pavimentacao/pmspets0012003.pdf>. Acesso em: 27 de jan.2010.

PMSP - PREFEITURA DO MUNICÍPIO DE SÃO PAULO. São Paulo, 2008. Uso de entulho reciclado torna-se obrigatório na capital. Disponível em:

$<$ http://www.prefeitura.sp.gov.br/portal/a_cidade/noticias/index.php?p=14065>. Acesso em: 27 Jan de 2010.

POON, C. S. Management and recycling of demolition waste in Hong Kong. Waste Management and Research, v.15, 561-572, 1997.

POON, C. S; QIAO, X. C; CHAN, D. Feasible use of recycled concrete aggregates and crushed clay brick as unbound road sub-base. Construction and Building Materials, ํㅡㄴ 20, p. 578-585, 2006.

RIBEIRO, F.; SERRA, N. G. S.; REZENDE, L. R. R.; GUIMARÃES, R. C. Utilização de entulho da construção civil em pavimentos flexíveis. In: Reunião de

Pavimentação Urbana, 11. Porto Alegre, 2002. Anais. Rio de Janeiro: ABPv, 2002. 1 CD-ROM.

SAEED, A; HAMMONS, M. I.; REED, J. L. Comprehensive Evaluation, Design, and Construction Techniques for Airfield Recycled Concrete Aggregate as Unbound Base. In: Transportation Research Board 86th Annual Meeting, Washington DC, United States, 2007. 16p.

SINDICATO DA INDÚSTRIA DA CONSTRUÇÃO CIVIL DO ESTADO DE SÃO PAULO, SINDUSCON-SP. Gestão Ambiental de Resíduos da Construção Civil: A experiência do SindusCon-SP / Tarcísio de Paula Pinto. São Paulo: SINDUSCON-SP, 2005. $48 \mathrm{p}$.

THULER, R. B. Estudo de solos do estado do Rio de Janeiro para aplicação em rodovias de baixo volume de tráfego. 2005. 125p. Dissertação (Mestrado) - Universidade Federal do Rio de Janeiro, Rio de Janeiro, 2005. 
WILBURN, D. R; GOONAN T. G. U.S. Geological Survey Circular 1176 - Aggregates from Natural and Recycled Sources: Economic Assessments for Construction application/ Materials flow analysis. United States, 1998. Disponível em:

<http://greenwood.cr.usgs.gov/pub/circulars/c1176/c1176.html>. Acesso em: 19 de jan. 2010. 


\section{ANEXO I - CARACTERIZAÇÃO}

TABELA 1 - Características físicas do ARC (Grubba, 2009)

\begin{tabular}{ccc}
\hline & & 22 \\
& Graduação B & 36 \\
Abrasão Los & & 34 \\
\cline { 2 - 3 } Angeles (\%) & 30 \\
& Graduação C & 37 \\
& & 32 \\
\hline Absorção do agregado graúdo & 4,62 \\
(\%) & 4,52 \\
\hline \multicolumn{2}{c}{ Densidade aparente do } & 2,395 \\
\multicolumn{2}{c}{ agregado graúdo } & 2,410 \\
\hline
\end{tabular}

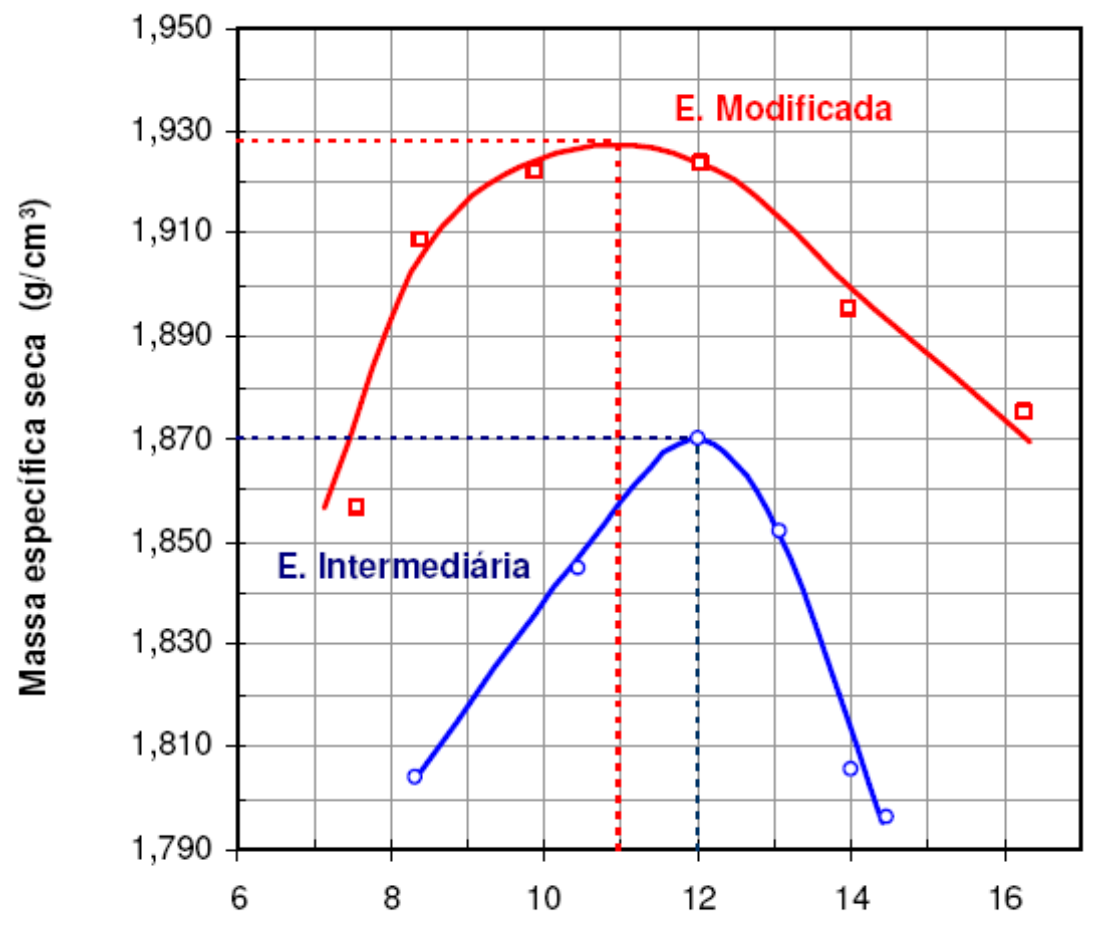

Teor de umidade (\%)

FIGURA 1 - Curvas de compactação do ARC para as energias intermediária e modificada (Grubba, 2009) 


\section{APÊNDICE I - RCS, $E_{50 \%}$ e $\Delta$ w}

TABELA 1 - RCS, $E_{50 \%}$ e variação do teor de umidade do ARC

\begin{tabular}{|c|c|c|c|c|c|c|c|c|}
\hline $\begin{array}{c}\text { Tempo } \\
\text { de cura } \\
\text { (dias) }\end{array}$ & $\begin{array}{l}\text { RCS } \\
\text { (kPa) }\end{array}$ & $\begin{array}{c}\text { RCS } \\
\text { médio } \\
(\mathrm{kPa})\end{array}$ & $\begin{array}{c}E_{50 \%} \\
(\mathrm{Mpa})\end{array}$ & $\begin{array}{c}\mathrm{E}_{50 \%} \\
\text { médio } \\
\text { (Mpa) }\end{array}$ & $\begin{array}{c}\text { W moldag. } \\
(\%)\end{array}$ & $\begin{array}{l}\text { W após } \\
\text { cura (\%) }\end{array}$ & $\begin{array}{l}\Delta W \\
(\%)\end{array}$ & $\begin{array}{c}\Delta \mathrm{W} \\
\text { médio } \\
(\%)\end{array}$ \\
\hline \multirow{3}{*}{0} & 207,73 & \multirow{3}{*}{224,61} & 43,62 & \multirow{3}{*}{48,65} & 12,66 & - & 0,00 & \multirow{3}{*}{0,00} \\
\hline & 206,44 & & 46,12 & & 12,27 & - & 0,00 & \\
\hline & 259,67 & & 56,22 & & 12,53 & - & 0,00 & \\
\hline \multirow{3}{*}{3} & 285,64 & \multirow{3}{*}{292,99} & 51,27 & \multirow{3}{*}{58,22} & 12,76 & 12,69 & 0,07 & \multirow{3}{*}{0,07} \\
\hline & 331,08 & & 70,95 & & 12,26 & 12,19 & 0,07 & \\
\hline & 262,27 & & 52,45 & & 12,23 & 12,16 & 0,07 & \\
\hline \multirow{3}{*}{7} & 345,36 & \multirow{3}{*}{379,98} & 42,91 & \multirow{3}{*}{57,27} & 12,58 & 12,45 & 0,13 & \multirow{3}{*}{0,10} \\
\hline & 403,78 & & 63,76 & & 12,26 & 12,26 & 0,00 & \\
\hline & 390,80 & & 65,13 & & 12,61 & 12,44 & 0,17 & \\
\hline \multirow{4}{*}{28} & 598,54 & \multirow{4}{*}{580,36} & 82,69 & \multirow{4}{*}{86,50} & 12,87 & 12,40 & 0,47 & \multirow{4}{*}{0,37} \\
\hline & 542,71 & & 81,41 & & 12,43 & 12,10 & 0,33 & \\
\hline & 641,38 & & 94,19 & & 12,65 & 12,31 & 0,34 & \\
\hline & 538,81 & & 87,71 & & 12,53 & 12,19 & 0,34 & \\
\hline \multirow{4}{*}{90} & 547,90 & \multirow{4}{*}{552,77} & 93,54 & \multirow{4}{*}{94,63} & 12,50 & 11,31 & 1,20 & \multirow{4}{*}{1,22} \\
\hline & 545,30 & & 78,98 & & 12,38 & 11,35 & 1,02 & \\
\hline & 488,18 & & 86,88 & & 12,45 & 11,22 & 1,23 & \\
\hline & 629,70 & & 119,13 & & 12,83 & 11,39 & 1,44 & \\
\hline \multirow{3}{*}{180} & 740,06 & \multirow{3}{*}{748,28} & 121,42 & \multirow{3}{*}{103,44} & 12,36 & 9,84 & 2,53 & \multirow{3}{*}{2,19} \\
\hline & 733,56 & & 87,03 & & 12,25 & 10,34 & 1,91 & \\
\hline & 771,22 & & 101,86 & & 12,07 & 9,93 & 2,14 & \\
\hline
\end{tabular}


TABELA 2 - RCS e variação do teor de umidade do ARC após ensaios triaxiais cíclicos para determinação do módulo de resiliência

\begin{tabular}{|c|c|c|c|c|c|c|}
\hline $\begin{array}{l}\text { Tempo de } \\
\text { cura (dias) }\end{array}$ & $\begin{array}{l}\mathrm{RCS} \\
(\mathrm{kPa})\end{array}$ & $\begin{array}{c}\text { RCS } \\
\text { médio } \\
(\mathrm{kPa})\end{array}$ & $\begin{array}{c}\text { W } \\
\text { moldag. } \\
(\%)\end{array}$ & $\begin{array}{l}\text { W após } \\
\text { cura (\%) }\end{array}$ & $\Delta W(\%)$ & $\begin{array}{c}\Delta \mathrm{W} \\
\text { médio (\%) }\end{array}$ \\
\hline \multirow{2}{*}{0} & 316,80 & \multirow{2}{*}{316,80} & 12,74 & - & - & \multirow{2}{*}{0,00} \\
\hline & 316,80 & & 12,32 & - & - & \\
\hline 3 & 381,71 & 381,71 & 12,58 & - & - & 0,00 \\
\hline \multirow{2}{*}{7} & 434,94 & \multirow{2}{*}{431,70} & 11,78 & 11,75 & 0,03 & \multirow{2}{*}{0,05} \\
\hline & 428,45 & & 11,46 & 11,39 & 0,07 & \\
\hline 28 & 540,11 & 540,11 & 11,93 & 11,55 & 0,37 & 0,37 \\
\hline \multirow{3}{*}{90} & 707,60 & \multirow{3}{*}{710,19} & 12,26 & 11,23 & 1,02 & \multirow{3}{*}{0,97} \\
\hline & 668,65 & & 12,31 & 11,45 & 0,85 & \\
\hline & 754,34 & & 12,76 & 11,73 & 1,03 & \\
\hline 180 & 795,88 & 795,88 & 11,96 & 9,55 & 2,41 & 2,41 \\
\hline
\end{tabular}

TABELA 3 - RCS e variação do teor de umidade do ARC após ensaios triaxiais cíclicos para determinação da deformação permanente e do módulo de resiliência

\begin{tabular}{|c|c|c|c|c|c|c|}
\hline $\begin{array}{l}\text { Tempo de } \\
\text { cura (dias) }\end{array}$ & $\begin{array}{l}\mathrm{RCS} \\
(\mathrm{kPa})\end{array}$ & $\begin{array}{c}\text { RCS } \\
\text { médio } \\
(\mathrm{kPa})\end{array}$ & $\begin{array}{c}\text { W moldag. } \\
(\%)\end{array}$ & $\begin{array}{l}\text { W após } \\
\text { cura (\%) }\end{array}$ & $\Delta \mathrm{W}(\%)$ & $\begin{array}{c}\Delta W \\
\text { médio (\%) }\end{array}$ \\
\hline \multirow{2}{*}{1} & 471,30 & \multirow{2}{*}{453,77} & 12,08 & - & 0,00 & \multirow{2}{*}{0,00} \\
\hline & 436,24 & & 12,08 & - & 0,00 & \\
\hline \multirow{2}{*}{8} & 395,99 & \multirow{2}{*}{513,49} & 12,18 & 12,08 & 0,10 & \multirow{2}{*}{0,10} \\
\hline & 630,99 & & 12,36 & 12,26 & 0,10 & \\
\hline \multirow{2}{*}{30} & 407,68 & \multirow{2}{*}{575,17} & 12,18 & 11,77 & 0,41 & \multirow{2}{*}{0,39} \\
\hline & 742,65 & & 11,22 & 10,84 & 0,37 & \\
\hline \multirow{3}{*}{182} & 849,12 & \multirow{3}{*}{808,87} & 12,30 & 10,25 & 2,05 & \multirow{3}{*}{2,09} \\
\hline & 797,18 & & 12,14 & 10,06 & 2,08 & \\
\hline & 780,30 & & 11,90 & 9,76 & 2,14 & \\
\hline
\end{tabular}


TABELA 4 - RCS, $E_{50 \%}$ e variação do teor de umidade da mistura solo - ARC

\begin{tabular}{|c|c|c|c|c|c|c|c|c|}
\hline $\begin{array}{c}\text { Tempo de } \\
\text { cura } \\
\text { (dias) }\end{array}$ & $\begin{array}{l}\text { RCS } \\
\text { (kPa) }\end{array}$ & $\begin{array}{c}\text { RCS } \\
\text { médio } \\
(\mathrm{kPa})\end{array}$ & $\begin{array}{c}E_{50 \%} \\
\text { (Mpa) }\end{array}$ & $\begin{array}{c}\mathrm{E}_{50 \%} \text { médio } \\
\text { (Mpa) }\end{array}$ & $\begin{array}{c}\text { W } \\
\text { moldag. } \\
(\%)\end{array}$ & $\begin{array}{l}\text { W após } \\
\text { cura (\%) }\end{array}$ & $\Delta \mathrm{W}(\%)$ & $\begin{array}{c}\Delta \mathrm{W} \\
\text { médio (\%) }\end{array}$ \\
\hline \multirow{2}{*}{0} & 312,90 & \multirow{2}{*}{318,74} & 51,74 & \multirow{2}{*}{45,57} & 7,05 & - & 0,00 & \multirow{2}{*}{0,00} \\
\hline & 324,59 & & 39,40 & & 7,29 & - & 0,00 & \\
\hline \multirow{2}{*}{7} & 324,59 & \multirow{2}{*}{374,57} & 45,14 & \multirow{2}{*}{50,26} & 7,87 & 7,81 & 0,06 & \multirow{2}{*}{0,04} \\
\hline & 424,56 & & 55,38 & & 7,86 & 7,83 & 0,03 & \\
\hline \multirow{3}{*}{28} & 512,85 & \multirow{3}{*}{613,68} & 63,73 & \multirow{3}{*}{71,90} & 7,42 & 7,31 & 0,12 & \multirow{3}{*}{0,22} \\
\hline & 625,80 & & 66,71 & & 7,43 & 7,21 & 0,22 & \\
\hline & 702,40 & & 85,26 & & 7,44 & 7,11 & 0,32 & \\
\hline
\end{tabular}




\section{APÊNDICE II - COMPACTAÇÃO E CBR 5 PONTOS}

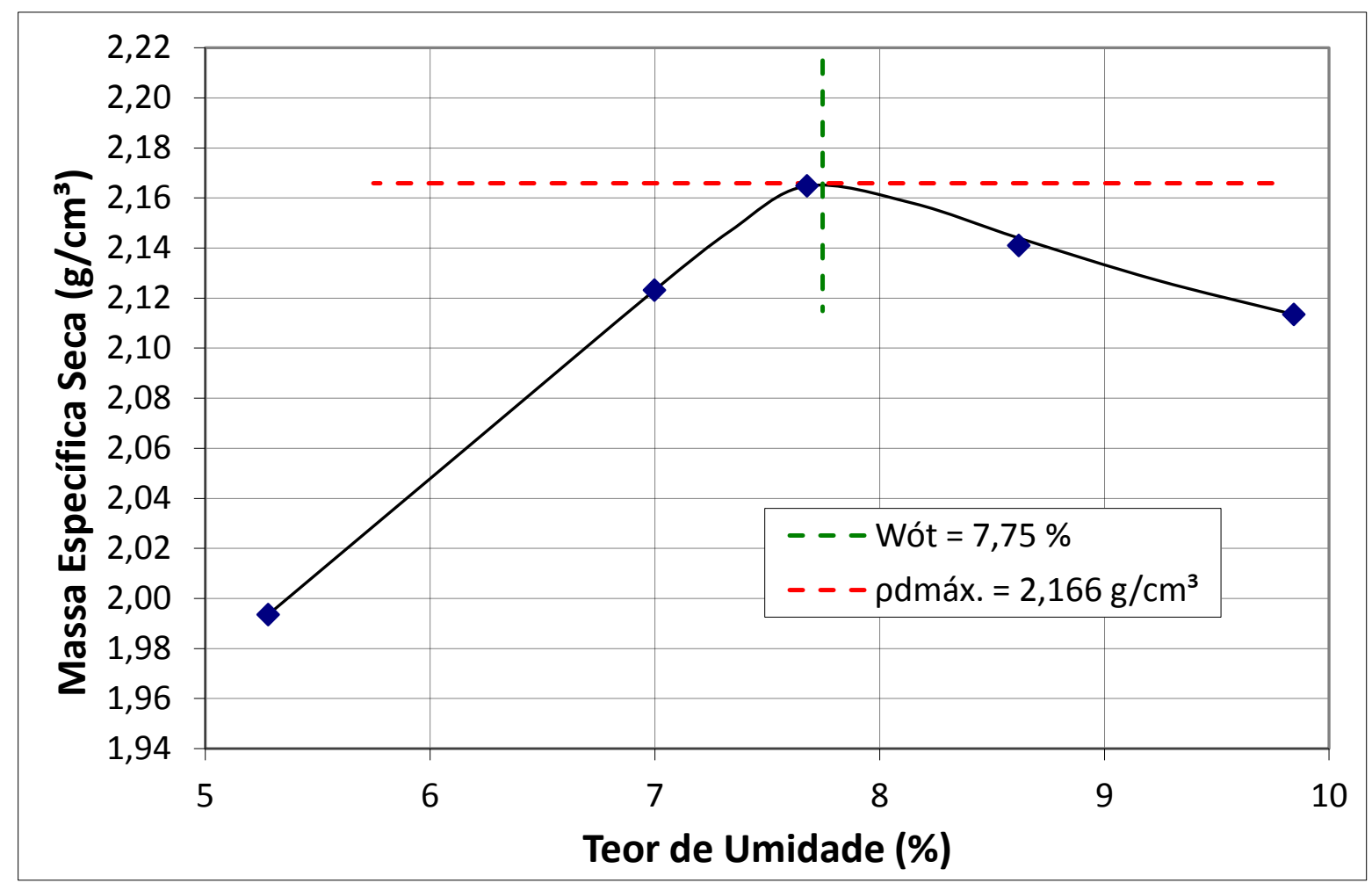

FIGURA 1 - Curva de compactação da mistura solo - ARC 


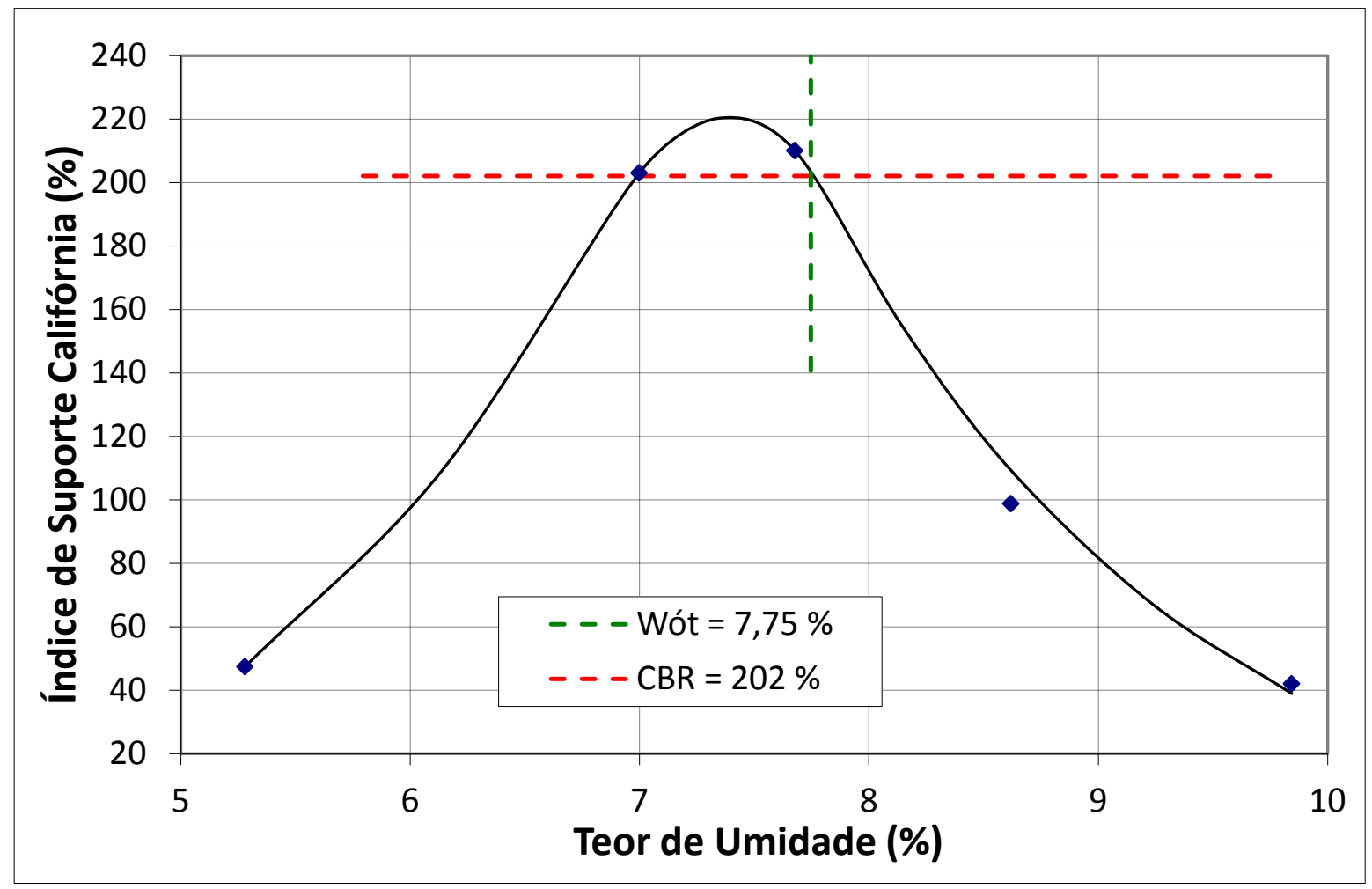

FIGURA 2 - CBR 5 pontos da mistura solo - ARC 